\title{
Navigating Motivation at Work
}

About Leadership, Purpose, Values, and

Basic Psychological Needs

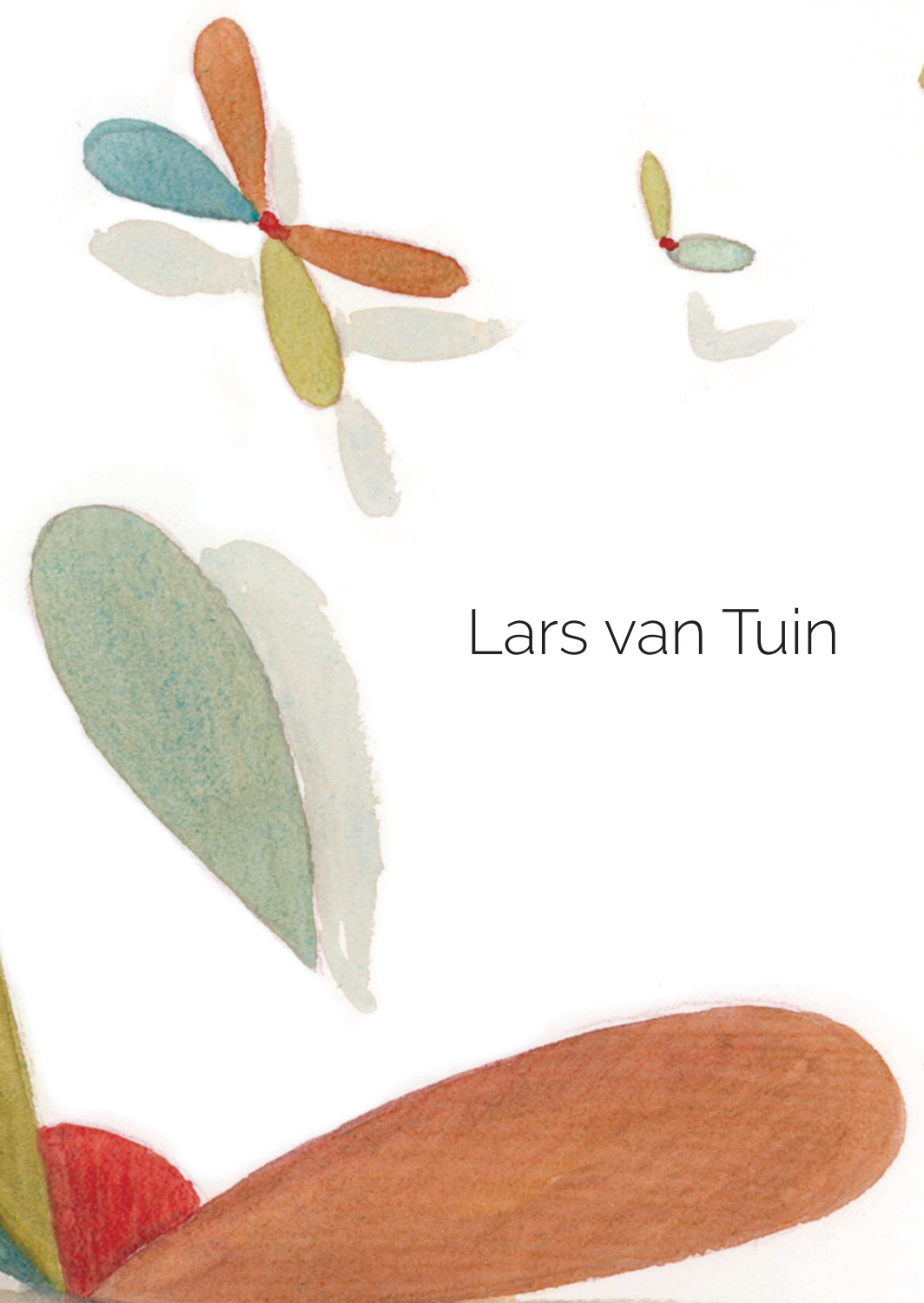




\section{NAVIGATING MOTIVATION AT WORK \\ ABOUT LEADERSHIP, PURPOSE, VALUES, AND \\ BASIC PSYCHOLOGICAL NEEDS}

Lars van Tuin 
ISBN: 978-94-6416-338-4

DOI: https://doi.org/10.33540/270

(c) Lars van Tuin, 2020. All rights reserved.

Cover design and layout: (c) evenlienjagtman.com

Print: Ridderprint | www.ridderprint.nl 


\title{
NAVIGATING MOTIVATION AT WORK ABOUT LEADERSHIP, PURPOSE, VALUES, AND BASIC PSYCHOLOGICAL NEEDS
}

\author{
Varen op werkmotivatie \\ Over leiderschap, ondernemingsdoelstellingen, \\ waarden en psychologische basisbehoeften \\ (met een samenvatting in het Nederlands)
}

Proefschrift

ter verkrijging van de graad van doctor aan de

Universiteit Utrecht

op gezag van de

rector magnificus, prof.dr. H.R.B.M. Kummeling,

ingevolge het besluit van het college voor promoties

in het openbaar te verdedigen op vrijdag 5 maart 2021

des ochtends te 10.30 uur

door

Lars van Tuin

geboren op 24 maart 1963

te Amsterdam 
Promotoren:

Prof. dr. W.B. Schaufeli

Prof. dr. W. van Rhenen 
For my mother 
"Through our scientific and technological genius, we have made of this world a neighborhood and yet we have not had the ethical commitment to make of it a brotherhood

But somehow, and in some way, we have got to do this."

Martin Luther King Washington, D.C., on 31 March 1968. Congressional Record, 9 April 1968. 


\section{CONTENTS}

\section{Chapter 1}

General introduction

Chapter 2

The satisfaction and frustration of basic psychological needs in engaging

leadership

\section{Chapter 3}

A corporate purpose as an antecedent to employee motivation and work

engagement

\section{Chapter 4}

Engaging Leadership: Enhancing work engagement through intrinsic values and need satisfaction

\section{Chapter 5}

Business results and well-being: An engaging leadership intervention study

\section{Chapter 6}

General discussion

References

151

Nederlandse samenvatting

173

Acknowledgements

189

Biography 



\section{CHAPTER 1}

General Introduction 

Work can allow people to self-actualize in their journey through life (Maslow, 1998). With befitting leadership, a broader organizational purpose, and attentive care for values and the basic psychological needs of employees, the workplace can become the birthplace of eudaimonic well-being and enhanced performance (Inceoglu et al., 2018; Maslow, 1998; Ryan \& Deci, 2017; Ryan et al., 2008). That is the central premise carrying this thesis. An ideal workplace provides a space where human beings flourish, grow, learn, and self-develop professionally as well as personally, and contribute to meaningful outcomes beyond their immediate self-interest in an atmosphere of psychological safety (Edmondson \& Lei, 2014), exciting challenges (Doshi \& McGregor, 2015), and joy (Sisodia \& Gelb, 2019).

We will consider the potential benefits of leadership, purpose, and values through the lens of human motivation as defined by self-determination theory and study their associations with work engagement. For leadership, we draw on the concept of engaging leadership (Schaufeli, 2015). With purpose, we examine the impact of a corporate purpose fitting the description of a broader purpose aiming to benefit all stakeholders (Freeman et al., 2004) as opposed to a corporate objective that aims to satisfy shareholders' interests exclusively (Friedman, 2007). Values are studied through employee perceptions of the organization's values. We distinguish an intrinsic orientation focusing on personal growth, contribution, and care, from an extrinsic orientation stressing values such as power, status, and financial success.

We argue that employee motivation is a core process that connects leadership, purpose, and values with the desired outcomes of well-being and engagement. Motivation lies at the heart of human behavior; It explains why we do what we do (Deci \& Flaste, 1996), how we find meaning and significance in our lives and work (Martela \& Pessi, 2018), and why we may experience eudaimonic well-being (Ryan et al., 2008). Through the studies offered in this thesis we aim to build on the basic principles of the UN sustainable development goals for humanity: "To ensure healthy lives and promote well-being for all at all ages" (United Nations [UN], 2019, Goal 3, p. 26); "To promote full and productive employment and decent work for all" (UN, 2019, Goal 8 , p. 38); And "support workers to be more entrepreneurial, creative and innovative" (GRI, 2019, Target 8.3, p. 95). All human beings deserve to fulfil their potential in dignity and equality (UN, 2015).

In contrast, current thinking on leadership displays a preoccupation with economic performance and organizational efficiency over meaning-making (Podolny et al., 2004), employee well-being (Inceoglu et al., 2018), and motivation (Deci et al., 2017). Moreover, the role of purpose is often overlooked and taken for granted (Kempster et al., 2011), 
and studies into the role of values in leadership research remain scarce (Yukl, 2012). We maintain that today's state of crisis of employee engagement (Mann \& Harter, 2016) and the prevalence of burnout and psychosocial stress among employees (Douwes \& Hooftman, 2020; Schaufeli et al.,, 2009) are related to the preoccupation of leadership with economic performance (cf. Alimo-Metcalfe, 2013), the limited attention to purpose and values, and the lack of interest in the essential role of human motivation.

The limited academic interest for purpose, values, and human motivation and the preoccupation with economic performance in leadership studies is problematic. First, because for business organizations to thrive in todays' global political and economic climate with its rapid changes and burgeoning technological advancement, it is paramount that employees are committed, self-motivated, agile, creative, and proactive (Brosseau et al., 2019; Deloitte, 2016; Peters et al.,, 2018). Today's business organizations are knowledge-intensive and operate in a world that portrays as Volatile, Uncertain, Complex, and Ambiguous (VUCA, see also Bennett \& Lemoine, 2014 for an accessible overview). Organizations depend on the flexibility, social skills, and competencies of workers, their innovative capacities, creativity, enduring motivation, and resilience (Peters et al., 2018). The recent outbreak of the Coronavirus dramatically illustrates the volatility through how the outlook on life, work, and living changed almost overnight on a global scale with consequences for human well-being that can hardly be overseen. The equation of leadership with economic performance neglects these complexities and draws on a level of prediction and control that, in fact, does not exist (Lazonick, 2016).

The second reason why the limited interest in purpose, values, and motivation within leadership studies is problematic, is that work itself has become central for individuals longing to lead a life of meaning and value (Ciulla, 2000). This adds to the complexity of leadership (Kaye \& Giulinoni, 2012). Over the past decades, work has increasingly become a vehicle for self-realization, personal growth, life satisfaction, and happiness (Ciulla, 2000; Sisodia \& Gelb, 2019; Wong, 2012) and has become the center stage for the realization of the Western ideal of self-determination and authenticity (Taylor, 1991). Consequently, the expectations and aspirations people have from work, their organizations, and managers have increased, presenting a complexity far beyond the simple mechanical equivalence of leadership and performance.

A third reason why this equation of leadership and performance is problematic is that the negative consequences of traditional management theory (Argyris, 1964) and neoliberal theory and practice (Friedman, 2007) have become manifest during the last 40 years of shareholder value primacy (Berger, 2019; Salter, 2019). For societies, 
organizations, and individuals alike, the inadequacies of orthodox economic theory and failing public policies have contributed to today's crisis of capitalism, fast-growing inequalities, climate change, and social unrest (Jacobs \& Mazzucato, 2016).

However, the pendulum may swing. Recent approaches in leadership and management herald that organizations with leaders who promote a higher purpose, live their values, and heed the needs of their employees are more successful and pave the way for a more sustainable future (Gartenberg et al., 2016; Henderson \& Steen, 2015; Polman, 2016). The Business Roundtable (BRT, 2019) representing the largest U.S. corporations, recently subscribed to that vision. It tellingly added that purpose and values should unify management, employees, and communities alike and drive corporate ethical behavior. The principal task for companies, then, becomes to provide a framework to benefit others and prioritize sustainable long-term rewards over short-term interests for which leadership, purpose, and values are indispensable (Fink, 2019).

The challenge taken up with this thesis is to examine the potential advantageous effects of leadership, purpose, and values from the perspective of human motivation. This perspective is gaining relevance, granted the actuality of the debate on the broader role of business organizations, emerging "shareholder wealth fatigue" (Harrison et al., 2019, p. 2), the current state of employee engagement, and the high levels of burnout. A growing body of studies explains the relationship between leadership and work outcomes-such as engagement, well-being, and performance-referencing human motivation as described by self-determination theory. This theory posits that human motivation is nourished through the satisfaction of three basic psychological needs (Deci \& Ryan, 2000): the need for autonomy (i.e., volitional functioning), competence (i.e., being effective), and relatedness (i.e., being truly connected with others). The fulfillment of these needs leads to a range of positive outcomes in human growth, optimal functioning, and flourishing (Ryan \& Deci, 2017).

Specifically, we argue that leadership-purpose-values are antecedents to work engagement and that human motivation, through basic psychological needs, explains the relationship (Van den Broeck et al., 2008; Meyer \& Gagne, 2008; Solansky, 2014; Vansteenkiste \& Ryan, 2013). It directs the attention to the process of leadership instead of the presumed direct relationship between leadership and economic performance or engagement. Leadership behaviors do not explain the bulk of variance in employee engagement. Leaders do not boost productivity, performance, motivation, or engagement, nor can they. It is the labor and energy of employees that bring things forward. The task of leadership is to create the social, psychological, and material conditions under which people flourish (Ciulla, 2018) and can be productive (Maslow, 
1998). The leadership context should support employees to motivate themselves and direct their energy towards the work at hand (Deci \& Flaste, 1996). It should offer a work context rich with learning, self-development, and opportunities for growth, ample room for initiative and involvement, and meaningful personal relationships and purpose (Rigby \& Ryan, 2018).

Maslow (1965) stated that "(...) proper management of the work lives of human beings, of the way in which they earn their living, can improve them and improve the world and in this sense be a utopian or revolutionary technique" (p. 1). At the start of the millennium, Payne (2000) bemoaned that it would take a change of volcanic force to create such a work context. Now, twenty years later, the idealism may find new ground through studies, research, and widely applied and well-documented experiments with different ways of and visions on leading, working and organizing (cf. Laloux, 2014; Sisodia \& Gelb, 2019). With this thesis, we hope to contribute to the continuing development of insights and knowledge to shape work environments where people may self-actualize and lead a life of meaning and dignity. Below we will introduce self-determination theory and the concepts of engaging leadership, purpose, and values in more detail.

\section{Self-determination theory}

Self-determination theory (SDT) is a macro-theory on the psychology of human motivation that seeks to understand the dynamics in social contexts and conditions that facilitate or hinder human well-being, personal growth, and flourishing (Ryan \& Deci, 2017). It has been developed over the past 40 years by Edward Deci and Richard Ryan. In the past three decades, numerous researchers from across the globe have contributed to the further development and increasing popularity of the theory over various disciplines, ranging from healthcare, education, sports coaching, parenting, developmental psychology, and work organizations (Ryan \& Deci, 2017).

SDT presupposes that human beings are active organisms that are naturally equipped for personal growth and development in relation to their environment and integrate life experiences into a coherent sense of self (Deci \& Ryan, 2000). SDT scholars call this the organismic perspective (Deci \& Ryan, 2000). In terms of the working life, the environment or social context includes the organization within which people work, their colleagues, bosses, peers, subordinates, clients, and suppliers, and the influence this environment has on the individual. When this work context is positive, nourishing, and supportive of the individual, it stimulates personal growth and development and promotes well-being, and supports performance (Gagné \& Deci, 2005). Conversely, a work context that is overly dismissive, controlling, and commanding will impair human thriving (Gagné et al., 2014). Various studies have explored the beneficial effects of a 
supportive work environment (Reeve, 1998) or leadership style (Su \& Reeve, 2010) and charted the different consequences in terms of work outcomes, employee well-being, motivation levels, and engagement (Van den Broeck et al., 2016).

\section{Basic Psychological Needs}

Studying human motivation from the organismic perspective emphasizes the fundamental dialectic dynamic between the person and his or her social environment. The dynamic interplay and sense-making process between a person and their social context may foster or thwart happiness, meaning, well-being, motivation, or engagement (Deci et al., 1994). For the study of work motivation, therefore, one should focus on the pervasive interdependent dynamic, which explains specific outcomes through, what SDT researchers call, nutrients that, just as in biology, are indispensable to support the growth and essential health of the organism (Ryan \& Deci, 2017). SDT distinguishes three such nutrients in the form of three basic psychological needs: Autonomy, Competence, and Relatedness. The essence of basic needs is similar to physical needs in that the fulfillment of a basic need supports the observable well-being and general health of the individual (Deci \& Ryan, 2000). In contrast, the deprivation of a need leads to measurable decrements (Ryan \& Deci, 2017).

The need for autonomy refers to the need to self-author one's actions, and that one's behaviors are congruent with one's authentic interests and sense of volition (Deci \& Ryan, 2000). Autonomy supportive managers involve workers in decision-making processes, explain the importance or purpose of tasks, and create space for employees to co-design their work, optimize their work processes, and self-direct (Niemiec \& Spence, 2016). Autonomy supportive managers also wholeheartedly engage employees in matters that are important to them, give them a say, and listen well when employees voice concerns (May et al., 1998). It is important to note that self-direction is-by definition-contextual because behaviors and actions happen in a particular social environment and are, therefore, interdependent rather than isolated expressions of complete independence. Thus, autonomy is not the same as independence and does not exist without context (Ryan \& Deci, 2017). The task of an autonomy-supportive leader is to shape a context that nourishes autonomy. An autonomy-supportive leader will always set a relevant context for what needs to happen, for example, by providing a clear rationale, and being open to having a conversation about why that goal or task is vital (cf. (Fremeaux \& Pavageau, 2020). The need for autonomy was the first basic need specified within SDT and is often explained with reference to personal causation as conceptualized by DeCharms (1968). 
Competence is the basic need to be effective in one's environment and feel capable of operating within one's life and work effectively with a sense of self-efficacy (Bandura, 1977) and mastery (Pink, 2009). The need for competence in SDT draws on the work of Robert White (1959), who positioned his idea of competence in response to the then still dominant drive theories of Freud and Hull (Hull, 1943). White (1959) presented competence through the perspective of learning and growth through curiosity, playful exploration, and feedback. Work environments that support the need for competence are places where people can acquire and learn to master new skills that stimulate selfdevelopment, that allow space for playful exploration, and where positive feedback is plentiful.

Relatedness is the basic need of being in close and meaningful social and caring connection with others, be it family, friends, community, or work (Ryan \& Deci, 2017). The need for belonging and feeling connected with others is considered a basic human need necessary for flourishing, the deprivation of which has a variety of adverse effects on health and well-being (Baumeister \& Leary, 1995). Other studies found associations between the quality of satisfying personal relationships with healthy aging (Waldinger \& Schulz, 2010) and longevity (Fredrickson, 2013). The need for relatedness is not antithetical to autonomy. Instead, a sense of volition and willingness to enter and maintain personal relationships will facilitate a higher quality of connections. It may induce greater psychological well-being (Ryan \& Deci, 2017).

Employees who find their basic needs satisfied entertain more meaningful relationships (Deci \& Ryan, 2008), have a higher organizational commitment (Niemiec \& Spence, 2016), and show higher resilience (Vansteenkiste \& Ryan, 2013). They also demonstrate creativity (Grant \& Berry, 2011) and enhanced work engagement (Meyer \& Gagné, 2008). Additionally, they display a higher capacity to self-motivate and self-organize (Spence \& Deci, 2013), and tend to exhibit enhanced performance (Van den Broeck et al., 2016).

\section{The Motivation Continuum: A Typology of Motivation}

In work organizations, the support of the basic needs for autonomy, competence, and relatedness of employees leads to healthy and sustainable motivation (Gagné \& Deci, 2005). SDT offers a typology of motivation that distinguishes autonomous motivation, where employees engage in activities with a high level of willingness, volition, and choice (Deci et al., 2017) from more extrinsic types of motivation, where behaviors are managed through external controls such as material and social incentives (Gagné et al., 2014). 
The typology of motivation is conceived as a continuum and was instrumental for the studies in this thesis. It emphasizes that leadership-purpose-values, through basic psychological need fulfillment, support autonomous motivation (Deci at al., 2017) and work engagement (Nikolova et al., 2019). Leadership behaviors, a corporate purpose, and organizational values are all examples of extrinsic motives and constitute-a part of-the social context of work. The fulfillment of basic psychological needs helps employees internalize these extrinsic incentives and transform them into their own (Ryan \& Deci, 2017). When extrinsic incentives are internalized, employees experience their behavior as self-determined or autonomously regulated (Deci \& Ryan, 2000). This experience is associated with higher levels of well-being, creativity, and work engagement and is referred to as autonomous motivation. Conversely, when the work environment thwarts the natural tendency for psychological growth and development through extrinsic pressures and controls, employees tend to experience a type of motivation described as controlling (Deci \& Ryan, 2000).

Autonomous Motivation. Employees can motivate themselves when they identify with a corporate purpose or align their values with those of the organization. When one would ask the employee, "why do you do this work?" he or she would answer "because it is important to me" or "because the work aligns with my personal values" (Gagné et al., 2014). In the same manner, employees can respond to a corporate purpose. They may say, "because I find it important to contribute to this company's purpose." Employees with high levels of autonomous motivation tend to take on more initiative and responsibilities willingly (Slemp et al., 2018). They direct more energy towards the work at hand and display higher perseverance in task completion (De Muynck et al., 2017). The leader may actively support the integration process through engaging employees in the vision creation process and granting employees a say in translating the vision into concrete goals, strategies, and actions. As a result, employees may identify with the leader's vision and make it into their own (Gagné \& Deci, 2005; Niemiec \& Spence, 2016), which satisfies the need for autonomy.

Furthermore, organizing the integration process in an atmosphere of psychological safety (Edmondson \& Lei, 2014) through fostering meaningful interpersonal relations between employees and between employees and their supervisor (Amabile \& Kramer, 2012), helps satisfy the need for relatedness (Deci \& Ryan, 2000). Finally, the need for competence can be fulfilled through opportunities for employees to meaningfully contribute to the department's goals, optimally deploy their talents and develop their skills. (Gagné \& Deci, 2005). The corresponding leadership behavior frequently provides direct reports with positive feedback and actively supports employees' growth and development through interesting challenges and exciting assignments (Gagné \& Deci, 2005). 
Controlled Motivation and Amotivation. Types of motivation that do not satisfy employees' basic needs are controlled motivation and amotivation. Controlled motivation is a type of motivation in which the incentive for action remains extrinsic to the individual and cannot be internalized or only partly internalized (Van den Broeck et al., 2013). A supervising manager who pushes for results, stresses deadlines, prioritizes the realization of KPIs (Key Performance Indicators), and focuses on compliance with process controls and progress reporting shapes a work context in which employees may feel controlled. Consequently, employees will comply with the pressures and controls to avoid negative consequences or obtain favorable outcomes (Baard et al.,. 2004). Amotivation is the type of regulation when employees feel their efforts make no difference, their contribution is meaningless, and their work pointless. Amotivation typically occurs when controlling management behavior is pervasive and strongly associates with adverse work outcomes and low work engagement (Gagné et al., 2014).

Extrinsic and controlling goals also tend to lead to more unethical behaviors. People become distracted from intrinsic reasons for doing their work and instead direct their efforts to comply with the external pressure, even if this evokes unethical behaviors (Ryan \& Deci, 2017). For instance, Kanze et al. (2020) found that companies encouraging fast and aggressive growth fall victim to significantly more unethical behaviors than firms that allow for a more sober and deliberate path. The authors also found that managers would cut corners to comply with external pressures. Earlier research by Ordonez et al. (2009) identified that the management habit of ambitious goal setting brings additional adverse side effects, such as too narrow goal orientations and distorted risk preferences at the cost of organizational values and culture. Work environments with a focus on economic performance, fast and aggressive growth generally produce high levels of controlled motivation, and subsequent low needs satisfaction (Olafsen et al., 2016). These work environments do not only require intense, controlling management attention but are also associated with adverse behaviors, negative outcomes, inferior performance, and a suboptimal organizational culture.

\section{Engaging Leadership}

Leadership is a widely debated and vastly researched topic (Hogan \& Kaiser, 2005). The number of published studies on leadership has grown exponentially over the past decades. There are many models, schools of thought, and leadership traditions (See Alimo-Metcalfe, 2013, and Berger, 2014, for overviews). Leadership studies tend to be leader-centered and performance-focused (Inceoglu et al., 2018). Leaders' capacities and ethical reach tend to be overestimated; we like to see leaders as heroic and charismatic and hold implicit high moral expectations of them (Brown, 2018). 
The everyday reality of leadership and management contrasts with this idealized view: "Most leaders are neither charismatic nor transformational leaders. They are ordinary men and women in business, government, nonprofits, and communities who sometimes make volitional, moral, and cognitive mistakes" (Ciulla, 2018, p. 464). Ciulla continues, "Leaders do not always have to transform people for them to flourish: Their greater responsibility is to create the social and material conditions under which people can and do flourish" (p. 465). Self-determination theory offers a similar take: Leadership is not about motivating and inspiring the individual or bombarding employees with visions of innovation, change, and disruption. The task of leadership is to create the conditions under which people can motivate themselves and direct their motivational energy towards exciting challenges and the work at hand (Deci \& Flaste, 1996).

Engaging leadership (Schaufeli, 2015) draws on the basic psychological needs as defined in self-determination theory (Deci \& Ryan, 2000), for which reason we decided to use this concept. As such, engaging leadership is the first leadership concept that explicitly bases itself on a theory of human motivation and takes a central interest in well-being over performance (Schaufeli, 2015). Individual motivation and enhancement of personal well-being through the fulfillment of basic psychological needs are fundamental notions of engaging leadership. Engaging leadership aims to capture leadership behaviors that are considered autonomy-supportive (Slemp et al., 2018) and associate with the satisfaction of employees' basic psychological needs. Three aspects of leadership are distinguished: Strengthening, Connecting, and Empowering (Schaufeli, 2015).

Strengthening associates with the need for competence. Through strengthening, leaders support employees to self-develop and grow and optimally deploy their talents within the work environment. They facilitate the joy of being good at something (Pink, 2009). Engaging leaders acknowledge the importance of giving frequent feedback, particularly positive feedback, through which the need for competence is satisfied (Deci \& Ryan, 2000)

Connecting aims to satisfy employees' basic need for relatedness and promotes interpersonal relations, teamwork, and team spirit. It facilitates collaboration between team members and across functions. Engaging supervisor behavior promotes the psychological safety for employees to speak up, voice concerns, and show themselves without any fear of negative consequences (May et al., 2010). Engaging leaders create an atmosphere of belongingness which supports employees in their development on both emotional and cognitive levels (Baumeister \& Leary, 1995) 
Empowering associates with autonomy satisfaction. It emphasizes the need to create space for employees to experience freedom and choice in how to engage in their work and with the organization. Through empowering, leaders offer autonomy support and acknowledge the individual contributions of team members (Reeve, 1998). Engaging leaders actively involve employees in strategic decision-making and promote selfregulation and autonomy, without losing sight of the relevance of a context and structure that allows employees to feel safe and free (Edmondson \& Lei, 2014)

In short, engaging leadership facilitates optimal motivation and engagement through socio-contextual support fulfilling employees' basic psychological needs (Ryan \& Deci, 2017). Socio-contextual support refers to the dynamic exchange between the sensemaking-individual and her social environment from which interaction social realities are generated. To manage this dialectic positively and engagingly, leaders must be self-aware about the role they play in this dynamic. Leadership perspectives, most notably authentic leadership (Gardner et al., 2011) posit that leader self-awareness is a necessary stepping stone to recognizing employees' needs and overseeing the impact of one's thoughts and actions. This impact is considerable. Leaders often fail to realize the power of- what Meindl (1995) describes as-the "romance of leadership": the intensity with which employees watch their leaders and speculate on every step a leader takes and every word a leader speaks.

The leadership employees crave most may be very commonplace: a leadership that understands what it "takes to create the social and material conditions under which people can and do flourish" (Ciulla, 2018, p. 465) and motivate themselves (Deci \& Flaste, 1996) without the drama of charisma, disruption, or transformation. Everyday leadership by ordinary men and women who, with the best of their intentions, aim to make the workplace a nourishing space wherein employees and managers alike may thrive. In the studies comprised in this thesis, we aim to identify engaging leadership as an antecedent to employee motivation and subsequent engagement.

\section{Purpose}

Popular business publications and consultancy reports mention the positive effects of a broader purpose on employee motivation and engagement. Still, empirical research into the psychological effects of a corporate purpose on motivation and engagement is lacking (Parmar et al., 2017). However, more and more studies highlight the benefits of a broader corporate purpose beyond the returns for shareholders. As Malnight (2019) states: 
You must ask why does your company exist? What is its impact on society? Why should people want to work for you? In today's world, the answers to these questions cannot just be money. Companies must recognize they have a bigger role to play, and that they can transform the world around them (p. 2).

Recent business studies provide empirical support for the beneficial impact of purpose on business results. Thakor and Quinn (2013) found that companies pursuing a higher goal have the better case compared to companies primarily seeking profit maximization, and Gartenberg et al. (2016) found that a broader purpose predicts financial performance. Other authors corroborated the business sense of a broader corporate purpose and stressed its current underutilization to drive business (e.g., Keller, 2015).

Stockholder primacy dominates the narrative. Concerns of other stakeholders such as employees, society, or the environment are mostly evaluated against their effects on shareholder value or profit (Berger, 2019). Negative social and environmental impact are externalized to the public domain and not taken up by stockholders or brought within corporate governance (Sjåfjell \& Taylor, 2019). In the academic domain, most leadership studies color within the lines of the stockholder doctrine as well (Kempster et al., 2011) and accentuate the effects of leadership on economic performance and organizational efficiency over those of purpose on motivation (Podolny et al., 2004; Sisodia \& Gelb, 2019). Even the benefits of work engagement are fitted to economic and financial performance (Schneider et al., 2018). Against this background, it is not surprising that the effects of a broader purpose on motivation and engagement as well-being receive little attention in leadership studies and organizational psychology. Nevertheless, following the general definition of a broader corporate objective, we should find positive effects on motivation and engagement.

The definition of a broader, stakeholder-oriented corporate purpose that we will use in this thesis (Chapter 3 ) is derived from business studies and business ethics. We define purpose as the meaning and contribution of a firm beyond its financial strategy and performance (Henderson \& Steen, 2015). It should provide a fundamental framework to benefit others and reap sustained long-term rewards over short-term interests (Fink, 2019). In Chapter 3, we state that through a broader purpose the organization's leadership aims to involve all stakeholders and put people first (Sisodia \& Gelb, 2019). Also, the aim is to benefit customers (Ellsworth, 2002) integrate the needs of society (Metcalf \& Benn, 2012), foster employee well-being and engagement (Bajer, 2016), and include and embrace ethics (Freeman, 1994). 
Following self-determination theory and the motivation continuum explained earlier, we expect an appealing corporate purpose-serving a broader interest in the pursuit of a greater good-will support employees to identify with that purpose and therefore facilitate the integration of that corporate purpose with their sense of self (Ryan, 1995). This integration process is essential to nourish autonomous motivation, inspire employee behaviors, and nurture engagement (Ryan \& Deci, 2017). Table 1 presents some examples of known and complimented corporations that exemplify living a corporate purpose, such as Patagonia, Morning Star, and Southwest Airlines. The table also presents other organizations' purposes, some more traditional, like Philips, BSH, Kellog, and ING. All purposes presented express corporate objectives that sit well with the given definition of a broader purpose. However, most publicly traded companies are known for their commitment to shareholders and value extraction and not for their profound commitment to their purpose and value creation (Mazzucato, 2018). Nor does the organization's broader purpose guide their every decision or action (HaskiLeventhal, 2020). The public trust in organizations and their leaders for being true to a broader purpose, speaking the truth and behaving ethically is low (George, 2003; Polman, 2016). Nevertheless, we expect that a broader purpose, as we will examine it, will associate positively with motivation and engagement. If this holds, it supports the arguments for the transition from a shareholder perspective's primacy to a stakeholder perspective (Quinn, 2019), supporting broader sustainability goals, including employee well-being (Mackey \& Sisodia, 2014).

\section{Leading From Values}

Values constitute the core of organizational culture (Padaki, 2000), and define "the way we do things around here" (Kofman, 2006, p. 15). Values can positively influence organizational functioning, such as decision-making, accountability, and commitment when they are internally legitimized (Urbany, 2005) and internalized. The internalization of values at the individual level is important for values (Serrat, 2017). First, because internalization positively predicts the enactment of values (Fotaki et al., 2019; Padaki, 2000). Managers who are aware of their employees' value preferences, who acknowledge these values, and engage in an open dialogue on value preferences are found more successful in implementing a value-based change strategy (Mankoff, 1974). Additionally, employees in departments with clearly defined and communicated organizational values feel more involved in the organization and decision-making and display more participatory behaviors (Fitzgerald \& Desjardins, 2004).

Second, and conversely, when value statements are perceived as management hypocrisy internalization is obstructed and met with cynicism, which happens when these statements serve the goal of external symbolism rather than internal integrity (Urbany, 
2005). This cynicism is not unfounded since most publicly traded organizations have value statements that sound identical and sometimes share more than just semantic similarity (Anderson \& Jamison, 2014). A considerable number of renowned companies have copied parts of other companies' value statements (Roth, 2013). Since the crisis in corporate ethics and governance in 2001, with the scandals that surfaced with companies such as Enron, Worldcom, Tyco, and Ahold, corporate value statements generally include a commitment to integrity (86\%), customers (64\%), diversity (57\%) and entrepreneurship (52\%) as the organizations' principal values (see Table 2). It remains unclear how these values contribute to the organization's performance, if at all (Tessema et al., 2019). Moreover, most organizations do not actively involve internal stakeholders, including employees, in the value statement formulation process, although they are the most impacted (Jaakson, 2010). Value statements are a "must-have" (Serrat, 2017) rather than an instrument to promote sustainability or truly embrace ethics (Freeman et al., 2004).

\section{Table 1}

Some Examples of Corporate Purposes and Mission Statements

$\begin{array}{ll}\text { Patagonia } & \text { "Build the best product, cause no unnecessary harm, use business to } \\ \text { inspire and implement solutions to the environmental crisis." } & \text { "(...) to produce tomato products which consistently achieve the } \\ \text { Morning Star } & \text { quality and service expectations of our customers in a cost-effective, } \\ & \text { environmentally responsible manner." } \\ \text { "To inspire and nurture the human spirit - one person, one cup and one } & \text { neighborhood at a time." } \\ \text { Starbucks } & \text { "To bring inspiration and innovation to every athlete* in the world. ("If } \\ \text { Nike } & \text { you have a body, you are an athlete.)" } \\ \text { "Tosla } & \text { "Improving peoples' lives through meaningful innovation." } \\ \text { Philips } & \text { "Spread ideas." } \\ \text { TED } & \text { "Nourishing families so they can flourish and thrive." } \\ \text { Kellog Company } & \text { "Empowering people to stay a step ahead in life and in business." } \\ \text { ING } & \text { "(...) to empower every person and every organization on the planet to } \\ \text { Microsoft } & \text { achieve more." }\end{array}$

Note. The presented examples are downloaded from the respective companies' websites on June 17, 2020. 


\section{Table 2}

Value Dimensions of Value Statements of 249 NYSE-listed companies

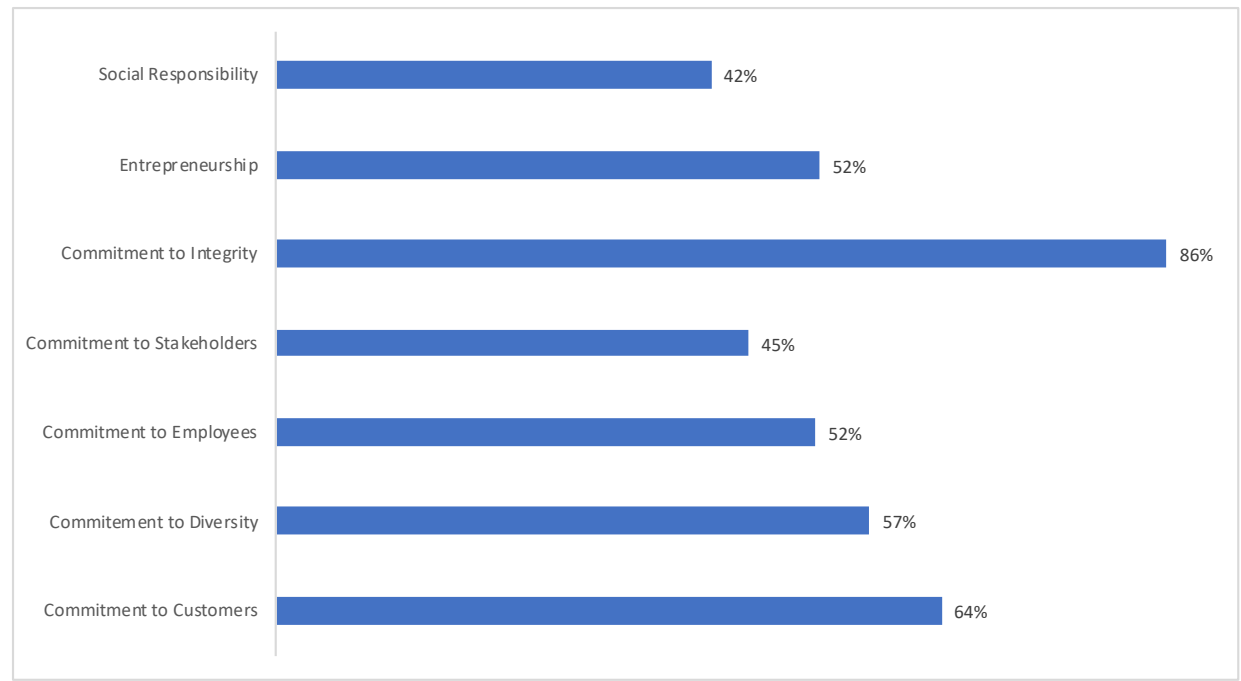

Note. Adapted with permission from Tessema et al. (2019)

Third, values representing intrinsic orientations, such as contributing to a greater good or acting in service of others' well-being, are better internalized than extrinsic aspirations of power, status, and money (Fotaki et al., 2019; Kasser \& Ryan, 1996). Organizational values that support such intrinsic orientations are positively associated with work engagement (Schreurs et al., 2014). In self-determination theory, intrinsic values cluster around the aspirations or end-goals of self-acceptance, affiliation, and community-feeling (Kasser \& Ryan, 1993). Self-acceptance refers to the desire for personal development, growth, and self-direction; Affiliation means to capture the importance of meaningful and intimate personal relationships with family, friends, and colleagues; And Community-Feeling summarizes the desire to contribute to make the world a better place (Kasser \& Ryan, 1993). SDT proposes that such intrinsic values are inherently valuable as they are closely associated with the individual's basic needs satisfaction (Deci \& Ryan, 2000).

In contrast, extrinsic values focus on achieving materialistic values such as financial success, power, and status (Deci \& Ryan, 2000). Financial success refers to the aspiration to achieve wealth and material success. (Kasser \& Ryan, 1993); Power refers to attaining a higher hierarchical position and an appealing image (Vansteenkiste et al., 2007); And Status refers to obtaining social recognition (Kasser \& Ryan, 1996). Extrinsic values are contingent upon other's approval and lead people away from those activities that are inherently need satisfying. When extrinsic aspirations outweigh intrinsic orientations, 
individuals report lower levels of personal and physical well-being, such as higher emotional exhaustion, short-lived satisfaction after goal-attainment, increased turnover intentions (Vansteenkiste et al., 2007), and adverse work motivation (Kasser, 2016).

In Chapter 4, we will argue that engaging leaders should pay close attention to employees' intrinsic preferences and how they perceive the organization's values. Leadership affects how employees perceive their organization's values (van Knippenberg, 2018). Intrinsic values can be internalized and lead to positive outcomes, but in contrast with what most value statements claim, extrinsic values prevail in many organizations. The resulting tension for employees is a given: "Anyone who has worked for any length of time in a business organization has been subjected to (or even involved in making) choices that conflict with what he or she 'knows to be right" (Brown, 1976, p. 22).

In Table 3, we present four examples of value statements of well-known and very different organizations. The purpose is to illustrate what actual value statements look like, not to support or assess them in any way. It neither informs whether these organizations enact their values nor how their employees perceive them. The values study presented in Chapter 4 illustrates how leadership affects employees' value perceptions and subsequent motivation and engagement. The study in this chapter underscores the essence of leadership behaviors for value perceptions over the bare value statements themselves. Just as with purpose, values are as strong and influential as that employees and leaders embrace and live them (Bekke, 2006; Fotaki et al., 2019).

\section{Work Engagement}

Work engagement is a central concern to organizations. Employees who are engaged with their work tend to experience work as fun, lose track of time when working, and perform better (Bakker \& Demerouti, 2013). Such engaged workers show high levels of energy (Schaufeli et al., 2002) and self-efficacy (Bandura, 1977). Additionally, they display enhanced well-being (Peters et al., 2018) and report a healthier work-life balance (Kossek et al., 2014). The rising importance of work to provide in the search for meaning (Ciulla, 2000) and the competition between organizations to source talented and motivated employees (Delaney \& Royal, 2017) have added to the centrality of work engagement for organizations. Still, a considerable number of consultancy reports mention the relatively poor state of work engagement. For example, Mann and Harter (2016) speak of a worldwide employee work engagement crisis, and Gallup (2017) reports that less than $20 \%$ of employees are engaged with their work. Additionally, today's work environments often do not fit the need of younger generations, who are known to bring different value preferences to the workplace (Bersin, 2015; Eversole et al., 2012). 
Table 3

Four Examples of Corporate Value Statements

\begin{tabular}{lll}
\hline Company & Introduction & Value 1 \\
\hline Wholefoods & "These values are the backbone & We satisfy and delight our \\
of our company culture and & customers-Our customers are \\
how we aspire to do business & the lifeblood of our business and \\
& every day - with you, our & our most important stakeholder. \\
& supplier partners, our customers, & We strive to meet or exceed their \\
communities and each other." & $\begin{array}{l}\text { expectations on every shopping } \\
\text { experience. }\end{array}$
\end{tabular}

Deloitte "At the heart of everything we do is a set of Shared Values. These values serve as the basis for the decisions we make and the actions we take, enabling us to deliver impact how and where it matters most for Deloitte clients, our people, and society."

Southwest Airlines

"Above all, Employees will be provided the same concern, respect, and caring attitude within the organization that they are expected to share externally with every Southwest Customer."

Netflix

\section{Lead the way-With our} unmatched scale, scope, skill, and service excellence, Deloitte is not only leading the profession, but reinventing it for the future.

Warrior Spirit-Strive to be the best. Display a sense of urgency. Never give up.
Judgment-You make wise decisions despite ambiguity. You identify root causes, and get beyond treating symptoms. You think strategically, and can articulate what you are, and are not, trying to do.

organization."

Note. The values above are selected from the companies' websites as accessed on June 17 , 2020 
Value 2

We promote team member growth and happiness-

Our success is dependent upon the collective energy, intelligence, and contributions of all of our Team Members.

Serve with integrity-By acting ethically and with integrity, and serving as role models in our communities, Deloitte has earned the trust of clients, regulators, and the public.

Servant's Heart-Follow the Golden Rule. Treat others with respect. Embrace our Southwest Family.
Value 3

We care about our Communities and the environment-We serve and support a local experience, and practice and advance environmental stewardship.

Take care of each otherDeloitte's culture is grounded in the understanding that "we are all in this together." We look out for one another and prioritize respect, fairness, development, and wellbeing.

\section{Fun-LUVing Attitude-}

Be a passionate Team Player. Don't take yourself too seriously. Celebrate successes

Courage-You say what you think, when it's in the best interest of Netflix, even if it is uncomfortable. You are willing to be critical of the status quo. You question actions inconsistent with our values.
Value 4

We Practice Win-Win Partnerships with our suppliers-We view our trade partners as allies in serving our stakeholders. We treat them with respect, fairness and integrity expecting the same in return

Foster inclusion-We are at our best when we foster an inclusive culture and embrace diversity in all forms. We know this attracts top talent, enables innovation, and helps deliver well-rounded client solutions.

\section{Wow Our Customers- Deliver world-class Hospitality. Create memorable connections. Be famous for friendly service}

Integrity-You are known for candor, authenticity, transparency, and being nonpolitical. You only say things about fellow employees that you say to their face. You admit mistakes freely and openly 
A robust body of research has developed over the past two decades identifying various antecedents to engagement, such as leadership (Carasco-Saul et al., 2015), work climate (Bakker, 2011), and organizational support (Saks, 2006). Macey and Schneider (2008) positioned work engagement as a key to competitive advantage and business performance, other scholars even to long-term sustainable performance (e.g., Renee Baptiste, 2008). Because of the width and depth of studies into work engagement on a global scale by countless researchers, the studies presented in this thesis use work engagement as a validated and trusted outcome measure.

\section{The Current Thesis}

The present thesis directs the lens on motivation at work from the angles of leadership, purpose, and values. The overall research question is to what extent motivation, in terms of basic psychological needs, explains the association between leadershippurpose-values and work engagement? In Chapter 2, we examine the concept of engaging leadership. Chapter 3 tests the beneficial impact of a broader corporate purpose. Chapter 4 studies how employees' value perceptions are impacted by engaging leadership and its associations with needs satisfaction and engagement. Chapter 5 tests how a leadership development intervention based on engaging leadership impacts business performance, motivation, and engagement. An overview and integration of these studies is depicted in Figure 1 below.

Chapter 2 studies the concept of engaging leadership and its effects on work motivation and engagement via the satisfaction and frustration of basic psychological needs. We hypothesized that basic psychological needs mediate the relationship between both positive and negative outcomes. Specifically, we expected that engaging leadership would positively affect motivation and engagement through satisfying basic needs, and that need frustration would exhibit a negative association. Earlier studies also examined the mediational role of need satisfaction between transformational leadership (e.g., (Hetland et al., 2015; Kovjanic et al., 2012) or engaging leadership (Rahmadani et al., 2019) and work engagement. The current study (Figure 2) replicates these studies with a work population from another industry and country. Additionally, the impact of needs frustration on work engagement is studied in a leadership context, which has not been done before. The present study also examines the associations and mediating roles of both satisfaction and frustration of basic psychological needs in one overall structural model. 


\section{Figure 1}

Summary of the Overall Model of the Studies

Antecedents
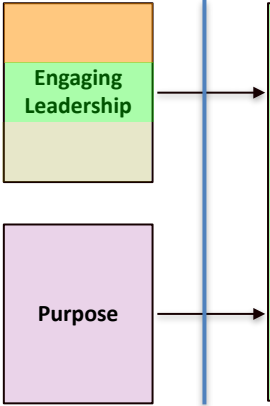

Extrinsic

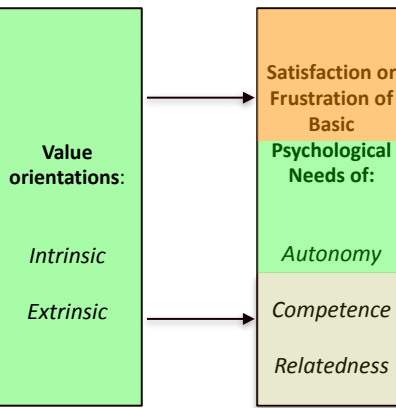

Mediators
Outcomes

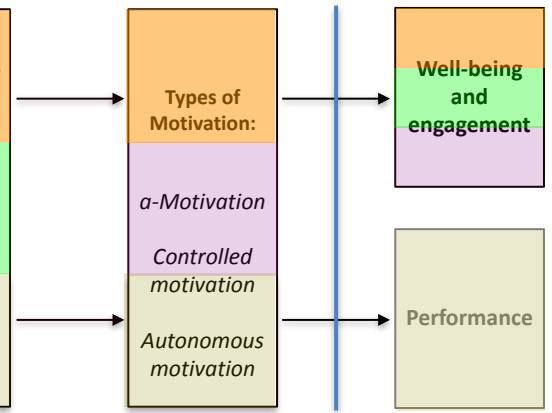

Legend:

Chapter 2

Chapter 3

Chapter 4

Chapter 5

Note. Chapter 2 examines the relationship between engaging leadership and work engagement through the satisfaction and frustration of basic psychological needs. Chapter 3 looks into the effects of purpose on engagement through motivation. Chapter 4 explores the role of engaging leadership and value perceptions and the subsequent effects on need satisfaction and engagement. Also note that value perceptions are explored in various roles: an antecedent, a mediator, and a result. Types of motivation are examined as both an outcome and a mediator.

Chapter 3 tests the relationships between corporate purpose, motivation, and engagement. We selected a real corporate mission and vision that matched the definition of a higher purpose and expected it to affect employee motivation and engagement positively. Furthermore, the purpose was expected to predict work engagement, and we expected autonomous motivation to mediate that relationship (Figure 3).

Chapter 4 addresses the effect of engaging leadership on employees' value perceptions and the subsequent impact on work engagement via need satisfaction. We expected, in line with previous studies (e.g., Van den Broeck et al., 2014; Schreurs et al., 2014), that intrinsic value orientations relate positively to need satisfaction and engagement. In contrast, we expected extrinsic orientations to associate with the same variables negatively. Additionally, we expected engaging leadership to relate positively with intrinsic values and engagement (Figure 4), and we hypothesized that autonomy satisfaction would mediate the path from leadership to engagement. 


\section{Figure 2}

The Research Model on Engaging Leadership

Antecedents
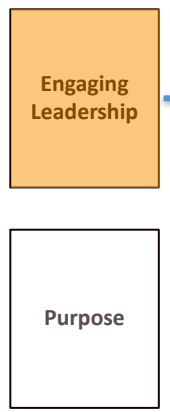

Mediators

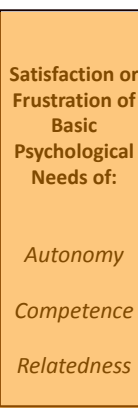

Outcomes

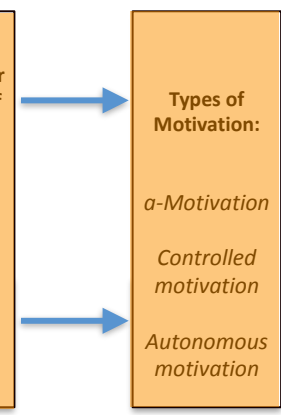

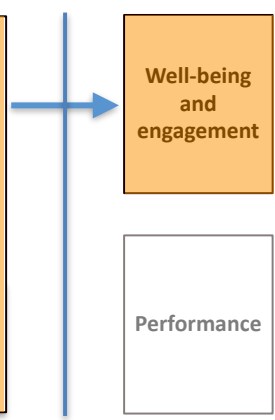

\section{Figure 3}

The Research Model on the Purpose Study

Antecedents
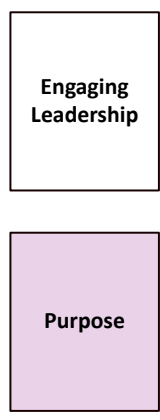

Mediators

\begin{tabular}{|l|}
\hline $\begin{array}{c}\text { Satisfaction or } \\
\text { Frustration of } \\
\text { Basic } \\
\text { Psychological } \\
\text { Needs of: }\end{array}$ \\
Autonomy \\
Competence \\
Relatedness \\
\hline
\end{tabular}

Outcomes

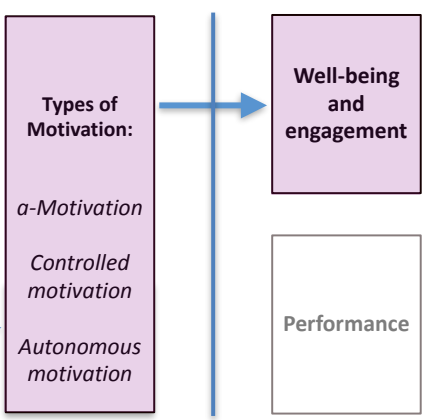




\section{Figure 4}

The Research Model for Value Orientations in Chapter 4

Antecedents

Mediators

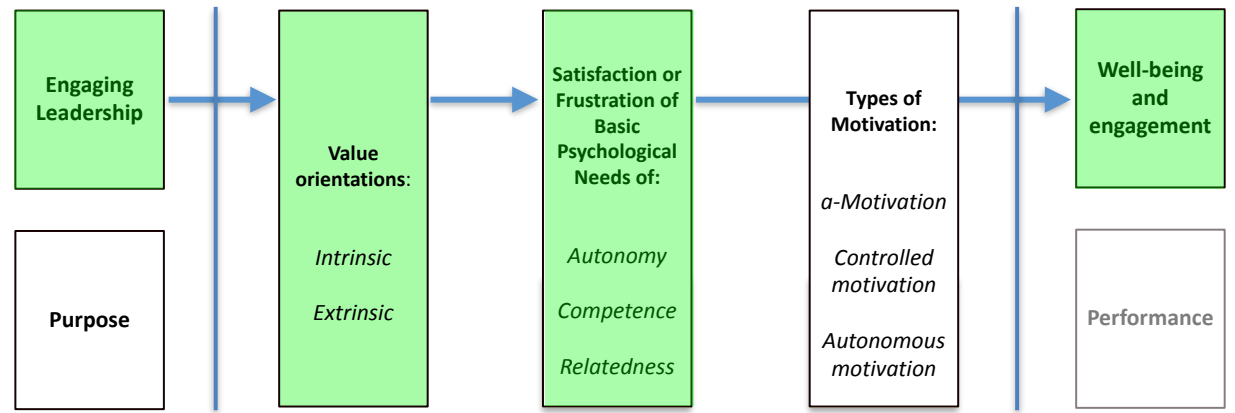

Chapter 5 reports the approach, design, and results of a quasi-experimental intervention study testing the business impact of an engaging leadership development program that focused on psychological well-being through the satisfaction of basic psychological needs (Figure 5). The 8-months intervention program taught the concepts of engaging leadership and basic need satisfaction to midlevel team leaders of a multinational organization. Senior leadership co-created the program with participating team leaders. It aimed to show positive business results on a pre-selected key performance indicator (KPI) and decreased employee absenteeism. Parallel to the business KPIs, the changes in autonomy satisfaction and intrinsic motivation were measured. The chapter discloses the program design, compares the effects to a relevant control group, evaluates the lessons learned, and provides practical suggestions. The main aim of this chapter is to substantiate the potential real-world impact of engaging leadership and basic need satisfaction, as examined in the previous chapters through a practical step-by-step approach. Purpose and values were not considered in the intervention study.

Chapter 6 contains the general discussion and summarizes the studies' results. The theoretical and practical implications and contributions are summarized and discussed. Also, the limitations of the four studies are considered, and recommendations for future research are made. 


\section{Figure 5}

Program Design of the Leadership Intervention Study

Antecedents Mediators

Outcomes

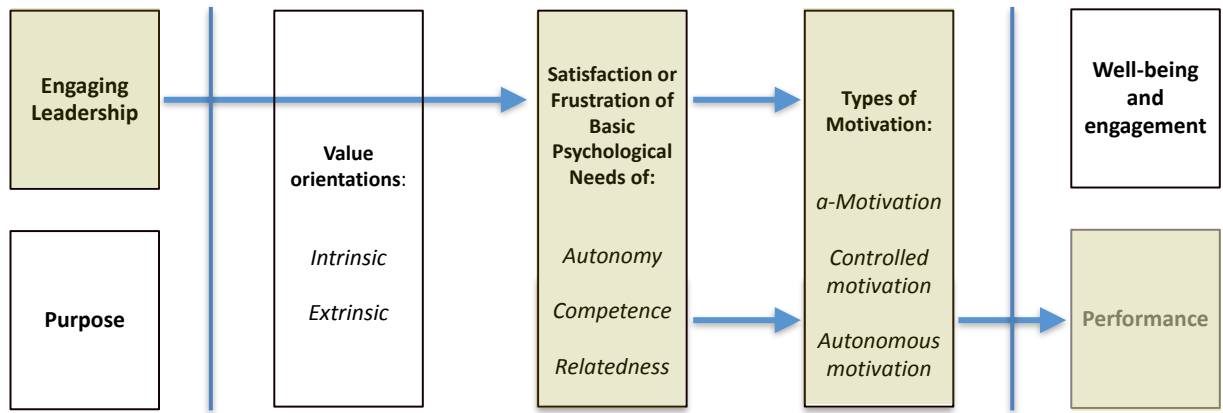






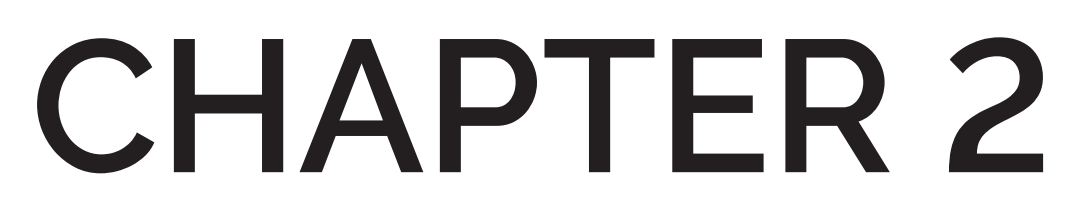

\section{The Satisfaction and Frustration of Basic Psychological Needs in Engaging Leadership}

Appeared as: Van Tuin, L., Schaufeli, W. B., \& Rhenen, W. (2020). The satisfaction and frustration of basic psychological needs in engaging leadership. Journal of Leadership Studies, 14(2), 6-23. http://doi.org/10.1002/jls.21695 

Popular positive leadership concepts such as transformational (Bass, 1985) and authentic (George, 2003) leadership are associated with favorable outcomes, including employee engagement (Babcock-Roberson \& Strickland, 2010) and performance (Gang Wang et al., 2011). As research has continuously aimed to identify effective leadership behaviors, the positive behaviors leaders need to display have expanded (Hoch et al., 2016), and the required depth of leaders' self-awareness and authenticity has increased (Ilies et al., 2005). However, effective leadership behaviors, such as deep listening, asking open-ended questions, giving positive feedback, and shaping psychological safety through elevated levels of self-awareness and authenticity (e.g., Edmondson \& Lei, 2014) do not explain the positive outcomes of leadership approaches. Knowing why a particular leadership approach may prove effective remains a relevant question, as organizations face considerable challenges in today's business environment, which is often characterized as fundamentally volatile, uncertain, complex and ambiguous (VUCA, see also Bennett \& Lemoine, 2014). New generations of employees bring new values to the workplace (A. Rodriguez \& Rodriguez, 2015) and challenge commandand-control hierarchies, while innovative practices such as agile workplaces have rapidly gained ground, also in traditional industries and global corporations (Brosseau et al., 2019).

Judge et al. (2006) called upon researchers to develop more rigorous research designs to provide insight into the process of leadership and potential mediating mechanisms in order to explain the effectiveness of transformational leadership. In the article, the authors considered several studies exploring different mediators to explain the relationship between leadership and various outcomes and noted that the studies had been conducted in a scattered, non-systematic fashion. More recent studies highlight the mediating role of self-efficacy (Salanova et al., 2011), trust (Braun et al., 2013), psychological empowerment (Avolio et al., 2004), leader-member exchange (Yukl et al., 2013), and job characteristics (Piccolo \& Colquitt, 2006), to name a few. While some of the studies mentioned identify direct or indirect relationships between leadership and work outcomes, such as work engagement, none of them are based on a comprehensive theory of motivation (Schaufeli, 2015).

Self-determination theory (SDT, Deci \& Ryan, 2000) is one such theory of motivation. A growing number of studies on the effectiveness of leadership approaches use SDT to explain the relationship between these approaches and positive outcomes through the satisfaction of three basic psychological needs: autonomy, competence and relatedness (e.g., Hetland et al., 2015; Kovjanic et al., 2012). Needs satisfaction is viewed as a promising mechanism (Van den Broeck et al., 2008) or even as the primary explanatory mechanism (Solansky, 2014) underlying leadership effectiveness and leader development. Engaging 
leadership (EL, Schaufeli, 2015), the subject of the present study, is based on SDT and is conceptualized as a process to create work contexts where people can flourish, selfdevelop, meaningfully contribute, and perform well through the satisfaction of basic psychological needs (Ryan \& Deci, 2017) Engaging leadership is expected to positively relate to established outcome measures such as work engagement (Schaufeli et al., 2006) and work motivation (Gagné et al., 2014).

\section{Basic Psychological Needs Theory and Leadership}

SDT is a meta-theory for framing motivational studies through "mini-theories" (Ryan \& Deci, 2017), one of which is basic psychological needs theory (BPNT), which posits that human thriving and well-being universally depend on the satisfaction of three basic psychological needs (autonomy, competence and relatedness; Deci \& Ryan, 2000; Ryan $\&$ Deci, 2017). Autonomy refers to the experience of volition and the sense that one's actions are determined by his or her choices (de Charms, 1968). Competence refers to the experience of a sense of effectiveness or competence in interacting with one's environment and is mostly explained in reference to White (1959). Relatedness refers to the experience of being loved and cared for by others (Baumeister \& Leary, 1995). Work environments that satisfy the three basic psychological needs of employees are said to promote autonomous motivation, performance, and well-being (Deci et al., 2017).

SDT specifies the mechanisms involved in the integration and psychological growth of employees because it points to elements of social environments, such as organizations' leadership practices, that facilitate or undermine human growth processes (Vansteenkiste \& Ryan, 2013). The theoretical rationale behind these mechanisms is SDT's organismic integration theory (OIT), which is a specific SDTmini-theory that conceptualizes human beings as (pro-) active organisms. It assumes that human beings strive to self-organize, self-develop, and grow by integrating their life experiences into an increasingly unified sense of self through a dialectical relationship with their environment (Deci \& Ryan, 1985). The social-contextual support offered by an organization's leadership can positively promote integration through "nutrients" in the form of the fulfillment of the basic psychological needs for autonomy, competence, and relatedness (Ryan, 1995) creating a context within which human beings, as employees and managers, function. Hence, the leadership of an organization shapes the daily social environment wherein employees may find their needs satisfied or thwarted. SDT, through BPNT and OIT, provides a theoretical substantiation for the popularity of emerging leadership approaches and management practices promoting self-leadership, shared leadership, collaborative leadership, self-managing organizations (Lee \& Edmondson, 2017) and other decentralized, less hierarchical forms of organization. 


\section{Autonomous Motivation and Controlled Motivation}

The fulfillment of the three basic psychological needs helps employees take in or internalize values, strategies, goals or behavioral regulations and transform them into their own (Ryan \& Deci, 2017). When the internalization of extrinsic incentives and motives is positive and effective, employees experience their behavior as self-determined or autonomously regulated or motivated (Deci \& Ryan, 2000); This experience is associated with higher levels of well-being, creativity, and work engagement and is referred to as autonomous motivation. Employees with high levels of autonomous motivation also tend to take on more initiative and responsibilities willingly, direct more energy towards the work at hand, and display higher levels of perseverance in task completion (Grant, 2012). For instance, a leader may create a clear, appealing vision for her or his department or team. Additionally, when this leader engages employees in the vision creation process and grants the employees a say in translating the vision into concrete strategies and goals, the leader actively supports the integration process through the satisfaction of the need for autonomy: as a result employees may identify stronger with the vision offered by the leader and make it into their own (Gagné \& Deci, 2005; Niemiec \& Spence, 2016). Organizing the integration process in an atmosphere of psychological safety, through fostering meaningful interpersonal relations between employees and between employees and their supervisor, help satisfy the need for relatedness. The need for competence can be satisfied if an organization actively finds ways for employees to meaningfully contribute to the department's goals, optimally deploy their talents and develop their skills in an environment of positive feedback (Gagné \& Deci, 2005).

Types of motivation that do not satisfy employees' basic needs are controlled motivation and amotivation. Controlled motivation is a type of motivation in which the incentive for action remains extrinsic to the individual and cannot be internalized or can be only partly internalized (Van den Broeck et al., 2013). A supervising manager who pushes for results, stresses deadlines, prioritizes the realization of KPIs (Key Performance Indicators), and focuses on compliance with process controls and progress reporting shapes a work context in which employees may feel controlled. Consequently, employees may comply with the pressures and controls to avoid negative consequences or to obtain positive consequences (Baard et al., 2004)]. It is typical in a setting of controlled motivation for certain behavior to stop when the incentive stops, which forces managers to continue exerting control in order to maintain employee performance (Deci \& Ryan, 2000): Work environments with high levels of controlled motivation and low needs satisfaction require high levels of controlling management attention. Within SDT, researchers speak of amotivation when 
employees feel their efforts make no difference, their contribution is meaningless, and their work is pointless. Amotivation typically occurs when controlling management behavior is pervasive and strongly associates with adverse work outcomes and low work engagement (Gagné et al., 2014).

An organization's leadership may mold a work context that fulfils the basic psychological needs autonomy, competence and relatedness. Through that need fulfillment, the underlying mechanism of internalization and integration of extrinsic motives is nourished and may lead to higher levels of autonomous and intrinsic motivation. Over the years, scholars have consistently emphasized the pivotal role leaders play in creating productive work contexts in which employee motivation is nurtured and nourished through the satisfaction of basic psychological needs (Baard et al., 2004; Deci et al., 2017; Gagné \& Deci, 2005; Ryan \& Deci, 2017; Stone et al., 2009).

\section{Need Frustration}

SDT posits that the mechanism explaining positive psychological outcomes also explains the darker side of people's functioning, which is associated with ill-being and negative effects such as burnout and poor performance through the frustration or thwarting of the three basic needs (Deci \& Ryan, 2000; Vansteenkiste \& Ryan, 2013). Recent research combines frustration with the satisfaction of basic needs to shed light on how positive and negative personal psychological outcomes are produced: need thwarting induces adverse outcomes such as burnout, and needs satisfaction induces positive outcomes such as work engagement (e.g., Bartholomew et al., 2011; Gillet et al., 2015; Huyghebaert et al., 2018).

The lack of satisfaction of a basic need is not the same as need frustration: one's needs may not be satisfied, but dissatisfaction does not necessarily imply the thwarting or frustration of basic needs; Needs frustration and needs satisfaction must be understood as two separate dimensions with a distinct predictive validity in relation to outcomes, although both operate on the same psychological mechanism. Sometimes the underlying psychological mechanism is referred to as a unifying principle (e.g., Meyer \& Gagne, 2008). For example, the satisfaction of basic psychological needs in autonomy-supportive environments is predictive of higher levels of well-being, autonomy, openness, resilience, and vitality (Ryan \& Deci, 2017). In contrast, the frustration of basic needs may lead to the search for need substitutes (Deci \& Ryan, 2000). Need frustration may even induce negative compensatory behaviors (Ryan et al.,, 2006) such as loss of self-control, display of rigid behavioral patterns, and oppositional defiance (For an overview of studies into the separate effects of needs satisfaction and needs thwarting or frustration see Vansteenkiste \& Ryan, 2013). However, the way 
that the satisfaction and frustration of needs behave vis-à-vis each other when they are simultaneously included in one structural model remains unanswered. Are lower frustration levels also associated with higher satisfaction levels, and can increased satisfaction levels also prevent unfavorable outcomes? These questions are essential for leaders in organizations and may provide vital information on what to focus on in leadership. For this reason, the current study included not only needs satisfaction but also needs frustration.

\section{Work Engagement and Leadership}

New generations of employees bring new values to the workplace and challenge the traditional command-and-control leadership model. These employees find it essential to have meaningful work, i.e., to make a contribution through their work to something beyond the work itself, to have the space to self-organize, and to develop and grow professionally and personally through what they do (Lee \& Edmondson, 2017; Shuck \& Herd, 2012). One of the challenges leaders face today is how to maintain high levels of employee engagement: A yearly Gallup report estimates that only $15 \%$ of the full-time working population worldwide is enthusiastic about and engaged with their work, whereas organizations with high employee engagement are more productive and profitable than those with low levels of engagement (Gallup, 2017). Recent research by Schneider et al. (2018) identified a strong connection between the level of employee engagement and a company's financial performance. The concept of work engagement, its antecedents and its effects have been extensively studied and documented in a broad array of studies across the globe (for an overview, see (Schaufeli, 2012) Overall, the literature tends to underscore work engagement as a central concern for leadership: Leaders who actively engage their employees, generate measurable and positive differences and are more aligned with emerging models and practices of the modern workplace (Ardichvili et al., 2016; Shuck \& Herd, 2012).

\section{Engaging Leadership}

Engaging leadership (Schaufeli, 2015) is a recently developed leadership concept based on the theoretical considerations offered by self-determination theory, particularly basic psychological needs theory. Schaufeli's primary aim with developing engaging leadership was to develop a positive model of leadership with a sound theoretical foundation and high predictive validity in fostering work engagement. Transformational leadership (Bass, 1985) was not a suitable candidate because it lacks a firm theoretical foundation (van Knippenberg \& Sitkin, 2013). In the first published study (Schaufeli, 2015) engaging leadership is integrated in the Job Demands-Resources (JD-R) model (Schaufeli \& Bakker, 2004) with work engagement 
as an outcome variable and job demands and job resources as mediators. Many earlier studies found strong confirmation of the direction of the relationship between the JD-R model and work engagement (for a recent review, see Schaufeli \& Taris, 2013). Instead of considering leadership as a mere job resource, as was done in previous JD-R studies, Schaufeli (2015) argued that leadership should be considered in its own right: leaders allocate and manage demands and resources and thus indirectly influence employee well-being and motivation. Indeed, in the 2015 study, job demands and job resources mediated the impact of engaging leadership on burnout and engagement. However, relationships between variables in the JD- $R$ model were specified without any particular psychological explanation (Schaufeli \& Taris, 2013, p. 55). For this reason, basic psychological needs theory served as the underlying, explanatory mechanism.

As such, engaging leadership proposes a conceptualization of leadership that aims to support leaders to shape a work environment that satisfies the three basic psychological needs of employees: autonomy, competence, and relatedness. Also, through fulfilling basic needs, engaging leadership aims to facilitate the internalization of extrinsic motives, such as the organizations' purpose, values, processes, and controls, which may lead to higher levels of autonomous motivation and work engagement.

Building on SDT and the satisfaction of the needs for autonomy, competence, and relatedness, engaging leadership distinguishes three aspects leaders should pay attention to, Empowering. Strengthening and Connecting (Schaufeli, 2015). Empowering aims to satisfy the need for autonomy and is the aspect of leadership that creates space for employees to experience freedom of choice in how to complete their tasks and supports high levels of accountability. Engaging leaders encourage team members to speak out about what is important to them without repercussions. Engaging leaders acknowledge the importance of giving feedback, particularly positive feedback, and recognize the individual contributions of team members (Reeve, 1998). Engaging leaders actively involve employees in strategic decision-making and promote self-regulation and autonomy, without losing sight of the relevance of a context and structure that allows employees to feel safe and free (Edmondson \& Lei, 2014).

Strengthening refers to supporting employees to self-develop and grow and optimally deploy their talents within the work environment. Within this style of leadership, promoting strengths is preferred to correcting weaknesses, and as such, strengthening associates with the basic need for competence. Engaging leaders acknowledge that employees wish to make a difference and want to contribute to the realization of 
something of value beyond their immediate self-interest (Martela \& Pessi, 2018). Also, engaging leaders support employees to grow professionally and develop their skilllevels and recognize the personal and professional importance of being good at something (Gagné \& Deci, 2005).

Connecting is an aspect of engaging leadership that promotes teamwork, team spirit, and collaboration between team members and across functions, and it stresses the importance of meaningful, interpersonal, in-depth relationships. Connecting aims to satisfy employees' basic need for relatedness and refers to supervisor behavior that is supportive and trustworthy and promotes the safety employees need to speak up, voice concerns and show themselves without any fear of negative consequences (May et al., 2010). Engaging leaders recognize the strong positive effects of belongingness on both emotional and cognitive levels (Baumeister \& Leary, 1995)

\section{This Study}

Previous studies modeled basic psychological needs as either a common, composite factor, aggregating the three needs as "need satisfaction" (e.g., Hetland et al., 2015), or as separate needs for autonomy, competence and relatedness (e.g., Kovjanic et al., 2012). Aggregating the three separate needs into one higher-order construct aligns with the idea that all three needs should be satisfied or balanced and "hang together" (Sheldon \& Niemiec, 2006). In addition, it seems practical and economical to aggregate all three needs under one construct. Van den Broeck et al. (2016), however, pointed out that aggregating the needs runs counter to the very conceptualization of the basic needs as separate entities; The authors argued that the three needs are not interchangeable, cannot be reduced to each other, and may differ in their predictive validity. Consequently, in the current study, the needs are modeled both as an aggregate and separately to study the predictive validity of the needs in both setups. The essential question from a leadership perspective is as follows: Do all needs require equal leadership attention?

Bringing the elements together leads to a study design in which the effects of engaging leadership on work motivation (amotivation, controlled motivation, and autonomous motivation) and work engagement are studied in a structural path model via the satisfaction and frustration of basic psychological needs in a parallel mediation design (see Figure 1). 


\section{Figure 1}

The Research Model and Hypotheses.

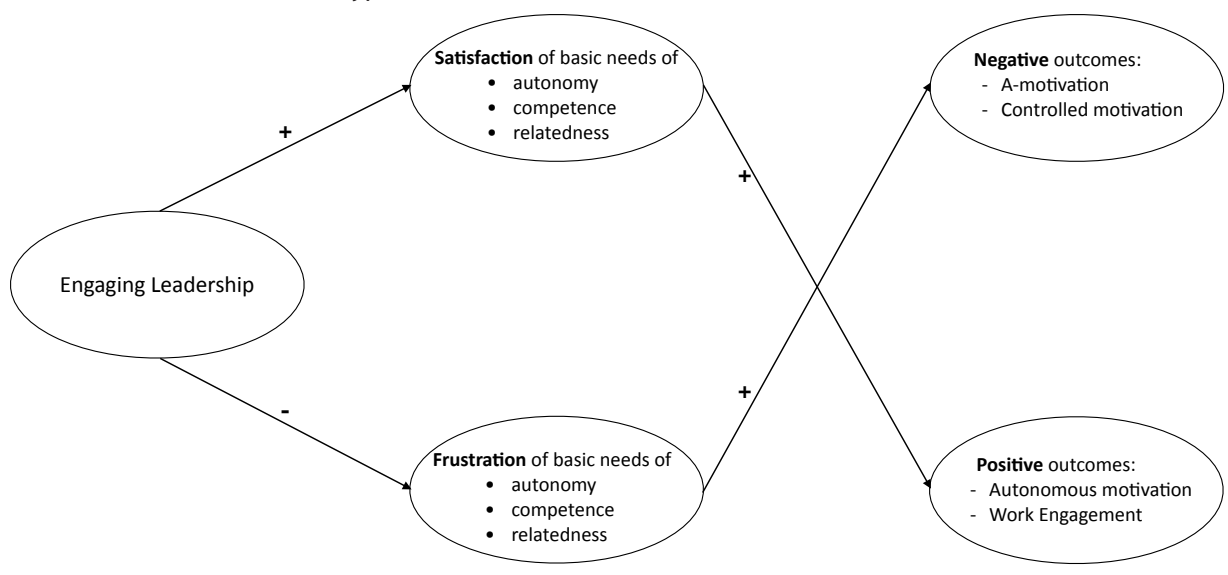

Note. Depicts the parallel mediation model with both satisfaction and frustration of basic needs. For reasons of readability we have chosen to depict the structural model in the above essentialized form. The construct of engaging leadership is directly connected with the outcome measures in the mediation analysis. The constructs for needs satisfaction and frustration are analyzed both as a common factor model, as displayed in the above figure, and as six separate constructs for the satisfaction and frustration of the three individual basic needs. Lastly, the four outcome measures are depicted as two clusters, one for negative and one for positive outcomes.

The present study tests the concept of engaging leadership and its effects on work motivation and engagement via the satisfaction and frustration of basic psychological needs. The roles of need satisfaction and need frustration are simultaneously tested with their respective items, and it is specifically studied how the psychological needs relate, both as a common factor and separately, to work motivation and work engagement. The following hypotheses are posed:

1) The satisfaction of the needs for autonomy, competence, and relatedness mediates the relationship between engaging leadership and positive outcomes (i.e., work engagement and autonomous motivation).

2) The frustration of the needs for autonomy, competence, and relatedness mediates the relationship between engaging leadership and negative outcomes (i.e., amotivation and controlled motivation). 


\section{METHOD}

\section{Participants and Procedure}

Three groups of employees were included. Two groups were from a Dutch technologyand engineering-driven multinational organization, and the third group was from a Dutch subsidiary of a comparable German multinational organization. A total of 499 invitations to an online questionnaire in the English language were distributed via email, with an invitation letter from a representative of senior management. Group sizes and response rates varied. In the first group (from the Dutch organization), 144 invitations were sent and 108 surveys were completed (75\%). In the second group (from the Dutch organization), 279 invitations were sent and 127 surveys (46\%) were completed. In the third group (from the Dutch subsidiary of the German organization), 76 invitations were sent and 69 surveys were completed (92\%). Hence, a total of 304 questionnaires was returned completed (overall response rate $61 \%$ ).

The total sample included 160 male (53\%) and 90 female respondents (30\%); $82.2 \%$ of all respondents disclosed their gender. In the sample, $54 \%$ of respondents were younger than $34,20 \%$ were between $35-49,28 \%$ were older than 49 , and $73.3 \%$ disclosed their age. All demographic questions were optional, while the other items in the survey were not. There were fewer than $1 \%$ missing values on the questionnaire items, and mean replacement of missing values was applied. Outliers were not identified, and skewness and kurtosis were within acceptable limits.

\section{Measures}

Engaging leadership was measured with the 9-Item Engaging leadership Scale developed by Schaufeli (2015). Strengthening, Connecting and Empowering were measured by three items each. An example of strengthening is "My supervisor encourages team members to develop their talents as much as possible." Connecting, which aims to align with the need for relatedness, includes items such as "My supervisor encourages collaboration among team members." Empowering is designed to align with autonomy, and related items include "My supervisor gives team members enough freedom and responsibility to complete their tasks."

Basic psychological needs were measured with the scale developed and validated by Chen et al. (2014), which measures the satisfaction and frustration of the three basic psychological needs. The full scale consists of 24 items, 12 for needs satisfaction and 12 for needs frustration, with four items per basic need. An example of an item for autonomy satisfaction is "I feel a sense of choice and freedom in the things I undertake", a relatedness satisfaction example item is "I feel connected with people who care 
for me, and for whom I care", and a competence satisfaction example item is "I feel confident that I can do things well." An example item for autonomy frustration is "I feel forced to do many things I would not choose to do", an example item for relatedness is "I feel that people who are important to me are cold and distant towards me", and an example item for competence frustration is "I feel disappointed with much of my performance."

Work motivation was measured by the 19-Item Multidimensional Work Motivation Scale (Gagné et al., 2014). The scale measures six dimensions for work motivation along the motivation continuum. Amotivation as well as extrinsic social, extrinsic material, identified and intrinsic regulation are all measured through three items. Introjected regulation is measured with four items. The header for the items is "Why do you or would you put effort into your job?" An example item for amotivation is "I don't know why I'm doing this job; it's pointless work"; Extrinsic social regulation: "To get others' approval (e.g., supervisor, colleagues, family, clients)"; Extrinsic material regulation: "Because others will reward me financially only if I put enough effort into my job (e.g., employer, supervisor)."; Introjected regulation: "Because I have to prove to myself that I can."; Identified regulation: "Because I consider it important to put effort into this job."; And intrinsic regulation: "Because I have fun doing my job."

Work engagement was assessed using the 9-item version of the Utrecht Work Engagement Scale (Schaufeli et al., 2006). It measures vigor, dedication, and absorption. Following Schaufeli et al.'s (2006) recommendations, one common factor for engagement was used. Examples of items are "At my work, I feel like I am bursting with energy" (vigor), "I am enthusiastic about my job" (dedication), and "I feel happy when I am working intensely" (absorption).

\section{RESULTS}

The data were analyzed using partial least squares structural equation modeling (PLSSEM) with SmartPLS version 3. The structural model is complex because it combines the separate needs satisfaction measures and the separate needs frustration measures into one model with the outcome variables, resulting in 11 latent variables, and their respective indicators (44). PLS-SEM is said to be an effective method under such conditions (Hair et al., 2017). 


\section{Measurement Model}

To evaluate the measurement model, following recommendations to establish construct validity in cross-sectional studies (Conway \& Lance, 2010), the internal consistency, convergent validity, and discriminant validity of the measures were assessed. The PLS algorithm of the software was set to the factor weighting scheme, the maximum number of iterations was set to 300 (which is the default setting), and the stop criterion was set at 10E-7. The measurement model converged with 8 iterations. Factor loading values of 70 or higher are preferred. Loadings between .40 and .70 should be examined in relation to theory, and loadings below .40 should be removed in all cases (Hair et al., 2017). The average variance extracted (AVE) should be larger than .50, indicating that the variance explained by the latent variable is larger than the unexplained variance. Composite reliability $(C R)$ and Cronbach's alpha ( $\alpha$ ) should be between .60 and .90 (Hair et al., 2017). Cronbach's alpha is said to underestimate true reliability because it is lower bound. A popular and widely used alternative in conjunction with structural equation modeling is $C R$ (Peterson \& Kim, 2013), although $C R$ tends to overestimate internal consistency reliability. Some scholars suggest reporting both a and $C R$ (e.g., Hair et al., 2017), which is what we do in the present study. The latent variables were also checked for collinearity issues. To establish measurement invariance between the three groups of respondents, the three-step procedure for testing measurement invariance in composite models analyzed with partial least squares was followed (Henseler et al., 2016) which resulted in full measurement invariance between the groups.

Engaging leadership was measured as a one-factor model. In the measurement model evaluation, one item was excluded because it loaded below the .70 threshold ("My supervisor delegates tasks and responsibilities to team members"). The internal consistency of the remaining 8-item scale was $\alpha=.92, C R=.93$.

For basic psychological needs, all six constructs, with four items per construct, were used. All loadings of the indicators with their latent variables were above .70. The reliability and consistency scores for the three constructs that together form need satisfaction were $\alpha=.77-.84, C R=.86-.89$; Need frustration scores were $\alpha=.73-$ $.80, C R=.83-.87$. The discriminant validity of the separate constructs was assessed by examining the cross-loadings and by calculating the heterotrait-monotrait ratios, which were all well below 1 (Henseler et al., 2015).

Work motivation consisted of amotivation, controlled motivation, and autonomous motivation. Amotivation was measured through three items and had an AVE = .72, $a=.81$, and $C R=.89$. Controlled motivation should conceptually be a combination of 
extrinsic social, extrinsic, material and introjected regulation. Introjected regulation had an alpha value $<.60$, the AVE was $<.50$, and only one of the four items loaded $>$.70: "Because it makes me feel proud of myself." One item for introjection loaded better on identified regulation. Controlled motivation, modeled with extrinsic social, extrinsic material, and introjected motivation, resulted in an AVE of .35. Therefore, the introjected construct was dropped from the model completely. Then, controlled motivation was recalculated with social and material regulation only. Although it had a good alpha value (.78), the AVE was still <.35. We then tried to specify controlled motivation by combining the items of social and material regulation following the prescribed procedure for measurement model evaluation with partial least squares (Hair et al., 2017). Eventually, a combination of two items from extrinsic social regulation and one item from the extrinsic material subscale resulted in $\mathrm{AVE}=.58, \alpha=.66$, and $C R=.81$. For autonomous motivation, the three indicators for intrinsic regulation were used, resulting in AVE = .79, while internal consistency and reliability were still good ( $\alpha=.86, C R=.92$ ). Thus, work motivation was summarized in three essential aspects: amotivation, controlled motivation, and autonomous motivation.

In evaluating the scores for work engagement, two items (UWE08 and 09) loaded below the .70 threshold; Hence, they were excluded. The construct was then tested for collinearity. All items with VIF values > 3.0 were excluded, and three items thus remained to measure work engagement-"At my job, I feel strong and vigorous" (vigor); "I feel happy when I am working intensely" (absorption); "I am proud of the work that I do" (dedication)-resulting in AVE = .74, $\alpha=.82$, and $C R=.89$. (see also Schaufeli et al., 2019). Work engagement and autonomous motivation were interpreted as positive outcome measures, and amotivation and controlled motivation were interpreted as negative outcome measures.

Table 1 gives an overview of the means, standard deviations, and intercorrelations between the latent variables after all unsound items are cleared from the measurement model. EL ( $M=3.86, S D=.74)$ is positively correlated $(r=.48, p<.001)$ with needs satisfaction $(M=3.79, S D=.44)$ and negatively correlated $(r=-.46, p<.001)$ with needs frustration $(M=2.26, S D=.54)$. The construct of EL also correlates positively with autonomous motivation $(r=.37, p<.001)$ and work engagement $(r=.44, p<.001)$. The correlation with the negative outcome measure of amotivation is negative $(r=-.37$, $p<.001)$, and the correlation with controlled motivation $(r=-.07, p=.46)$ is not significant. The relations of the six needs to the separate measures are all significant at the $p<.001$ level. The correlations between needs satisfaction and needs frustration and the outcome measures are also all significant at the $p<.001$ level. 
Table 1

Analysis of Means, Standard Deviations and Intercorrelations of Latent Variables

\begin{tabular}{|c|c|c|c|c|c|c|c|c|c|c|c|c|c|c|}
\hline & $M$ & $S D$ & EL & AS & RS & $\mathrm{CS}$ & NS & AF & RF & CF & NF & AM & CM & $\mathrm{AU}$ \\
\hline EL & 3.86 & .74 & 1 & & & & & & & & & & & \\
\hline AS & 3.51 & .65 & .42 & 1 & & & & & & & & & & \\
\hline RS & 3.73 & .59 & .33 & .43 & 1 & & & & & & & & & \\
\hline CS & 4.12 & .49 & .36 & .41 & .31 & 1 & & & & & & & & \\
\hline NS & 3.79 & .44 & .48 & .83 & .77 & .70 & 1 & & & & & & & \\
\hline AF & 2.75 & .79 & -.44 & -.64 & -.34 & -.41 & -.61 & 1 & & & & & & \\
\hline RF & 2.11 & .66 & -.42 & -.38 & -.67 & -.39 & -.63 & .40 & 1 & & & & & \\
\hline CF & 1.91 & .64 & -.20 & -.41 & -.27 & -.66 & -.56 & .40 & .42 & 1 & & & & \\
\hline NF & 2.26 & .54 & -.46 & -.63 & -.55 & -.62 & -.77 & .80 & .77 & .76 & 1 & & & \\
\hline AM & 1.58 & .61 & -.37 & -.48 & -.38 & -.35 & -.53 & .50 & .52 & .40 & .61 & 1 & & \\
\hline $\mathrm{CM}$ & 2.95 & .79 & $-.07^{\circ}$ & $-.19^{\star *}$ & $-.07^{\circ}$ & $-.04^{\circ}$ & $-.14^{*}$ & $.11^{\circ}$ & $.18^{\star *}$ & $.12^{*}$ & $.17^{\star \star}$ & $.01^{\circ}$ & 1 & \\
\hline$A U$ & 3.77 & .71 & .37 & .63 & .39 & .43 & .64 & -.48 & -.36 & -.35 & -.52 & -.51 & $-.19^{\circ}$ & 1 \\
\hline WM & 4.42 & 1.08 & .44 & .49 & .32 & .41 & .53 & -.43 & -.36 & -.35 & -.49 & -.46 & $.01^{\circ}$ & .62 \\
\hline
\end{tabular}

Note. All correlations are significant at the $p<.001$ level, except for: ${ }^{* *}<.01 ;{ }^{*}<.05$; Correlations marked with ${ }^{\circ}$ are nonsignificant and are all related with controlled motivation; EL, Engaging Leadership; AS, Autonomy Satisfaction; RS, Relatedness Satisfaction; CS, Competence Satisfaction; NS, Needs Satisfaction; AF, Autonomy Frustration; RF, Relatedness Frustration; RC, Competence Frustration; NF, Needs Frustration; AM, Amotivation; CM, Controlled Motivation; AU, Autonomous Motivation; WM, Work Engagement.

\section{Structural Model}

The mediation model was tested by connecting EL to the outcome measures via needs satisfaction and needs frustration in a parallel mediation design (see Figure 1). In the model, need satisfaction and need thwarting were each specified as one common factor, with the underlying three basic needs aggregated to form the higherorder constructs of needs satisfaction and needs frustration. The reflective-reflective approach was followed, indicating a reflective relationship between the items and the latent constructs and between the higher-order construct and the latent constructs (Hair et al., 2018). More specifically, EL was connected to each of the four outcome measures via the higher-order constructs for needs satisfaction and needs frustration in one parallel mediation analysis. The bias-corrected and accelerated confidence intervals $(95 \% \mathrm{BCa} \mathrm{Cl}$ ) were generated through bootstrapping with the following settings: 5,000 subsamples, no sign changes, complete bootstrapping, two-tailed, with a $95 \%$ significance level. The degrees of freedom ( $d f$ ) for reporting $t$ values in PLS bootstrap is reported as the number of bootstrap samples $(5,000)$ minus one (Henseler et al., 2009) and apply to all $t$ values mentioned below. 
The outcomes of the analysis, as depicted in Table 2, show a partial mediation via needs satisfaction with autonomous motivation $(t=5.72, p<.001)$ and with work engagement $(t=3.17, p<.001)$ and no significant effects on amotivation and controlled motivation, as predicted in hypothesis 1 . For the path via needs frustration, a partial mediation was found with amotivation ( $t=5.29, p<.001$ ) and controlled motivation $(t=2.95, p<.001)$, as predicted in hypothesis 2 . Additionally, a significant path to work engagement was found ( $t=2.10, p=.004$ ), which was not predicted. Other paths were not significant.

\section{Table 2}

Mediation Analysis of the Common Factor Approach for Needs Satisfaction and Frustration

\begin{tabular}{lcccccccc}
\hline $\begin{array}{l}\text { Engaging } \\
\text { Leadership to }\end{array}$ & $\begin{array}{c}\text { Direct } \\
\text { effects }\end{array}$ & $\begin{array}{c}95 \% \\
\mathrm{BCa} \mathrm{Cl}\end{array}$ & $t$ & $p$ & $\begin{array}{c}\text { Specific } \\
\text { indirect } \\
\text { effects }\end{array}$ & $\begin{array}{c}95 \% \\
\mathrm{BCa} \mathrm{Cl}\end{array}$ & $t$ & $p$ \\
\hline Via Needs Satisfaction & & & & & & & & \\
Amotivation & -.11 & {$[-.25 .03]$} & 1.56 & .12 & -.05 & {$[-.13 .01]$} & 1.52 & .13 \\
Controlled & -.08 & {$[-.25 .13]$} & 0.82 & .41 & -.04 & {$[-.13 .06]$} & 0.80 & .42 \\
Autonomous & .58 & {$[.43 .70]$} & 8.38 & .00 & .28 & {$[.19 .38]$} & 5.72 & .00 \\
Work engagement & .28 & {$[.12 .44]$} & 3.45 & .00 & .14 & {$[.06 .23]$} & 3.17 & .00 \\
& & & & & & & & \\
Via Needs Frustration & & & & & & & & \\
Amotivation & .49 & {$[.34 .62]$} & 6.86 & .00 & -.23 & {$[-.32-.15]$} & 5.29 & .00 \\
Controlled & .27 & {$[.10 .43]$} & 3.33 & .00 & -.13 & {$[-.22-.05]$} & 2.95 & .00 \\
Autonomous & -.04 & {$[-.18 .10]$} & 0.60 & .55 & .02 & {$[-.05 .09]$} & .59 & .56 \\
Work engagement & -.17 & {$[-.32-.01]$} & 2.11 & .04 & .06 & {$[.01 .16]$} & 2.10 & .04 \\
\hline
\end{tabular}

Note. $95 \% \mathrm{BCa} \mathrm{Cl}, 95 \%$ Bias Corrected and accelerated Confidence Interval, [LL, UU].

\section{Satisfaction of the Separate Needs of Autonomy, Competence, and Relatedness}

In the second analysis, the basic psychological needs were modeled separately through the three latent variables for autonomy, competence, and relatedness and were directly connected to the outcome measures. As presented in Table 3, the mediation analysis for the satisfaction of the needs of autonomy, competence and relatedness indicates a full mediation for the path from EL via autonomy satisfaction to autonomous motivation $(t=5.63, p<.001)$ and a partial mediation to work engagement $(t=2.38$, $p=.02$ ). Hence, increases in autonomy satisfaction are associated with increases in positive outcomes, as predicted by hypothesis 1. Additionally, increases in autonomy satisfaction are associated with decreases in unfavorable outcomes, which was not 
expected: amotivation ( $t=2.40, p=.02$ ) and controlled motivation $(t=2.54, p=.01$ ). Competence satisfaction mediated the relationship with autonomous motivation $(t=2.34, p=.03$ ), whereas relatedness satisfaction did not play a role. The analysis showed that the three basic needs behave differently and vary in their significance and strength.

\section{Frustration of the Needs of Autonomy, Competence and Relatedness}

Hypothesis 2 predicted that the frustration of the basic needs for autonomy, competence, and relatedness would mediate the relationship between EL and the negative outcomes of amotivation and controlled motivation. The mediation analysis for needs frustration indicated a dominant role of relatedness frustration, with a full mediation for the paths to amotivation $(t=3.19, p<.001)$ and controlled motivation $(t=2.76, p<.01)$. The other significant mediating effect for the frustration constructs was via autonomy frustration to amotivation $(t=2.79, p<.01)$. The paths via competence frustration were not significant, and as hypothesized, just as all paths to positive outcomes (see Table 4).

\section{Total Variance Explained and Effect sizes}

Then, the total variance explained and the effect sizes of the separate needs in the model were checked (see Table 5). The $R^{2}$ value for autonomous motivation was .48; Work engagement had a total variance explained of $R^{2}=.34$; Amotivation, $R^{2}=.42$; Controlled motivation, $R^{2}=.13$. The low $R^{2}$ value for controlled motivation may be due to the internal consistency and reliability of the measure itself. The effect sizes were calculated following two distinct procedures. The outcomes of the first procedure, $f^{2}=R^{2} / 1-R^{2}$, are depicted in Table 5 , showing the effect of the model on the outcome variables; the table indicates the strongest effect on autonomous motivation $\left(f^{2}=.92\right)$ and amotivation $\left(f^{2}=.72\right)$ and a large effect size on work engagement $\left(f^{2}=.52\right)$.

Lastly, the effect sizes were calculated when one antecedent construct was omitted from the model by alternatingly excluding the specific antecedent constructs from the model one by one. The effect sizes were interpreted following Cohen (1988), with $f^{2}$ values of $0.02,0.15$, and 0.35 indicating small, medium, and large effect sizes, respectively. Thus, there was a medium-large effect size for autonomy satisfaction in relation to autonomous motivation $\left(f^{2}=0.23\right.$ ) and small effect sizes for autonomy satisfaction in relation to amotivation $\left(f^{2}=0.03\right)$ and work engagement $\left(f^{2}=0.02\right)$ and for relatedness frustration in relation to amotivation $\left(f^{2}=.07\right)$. 


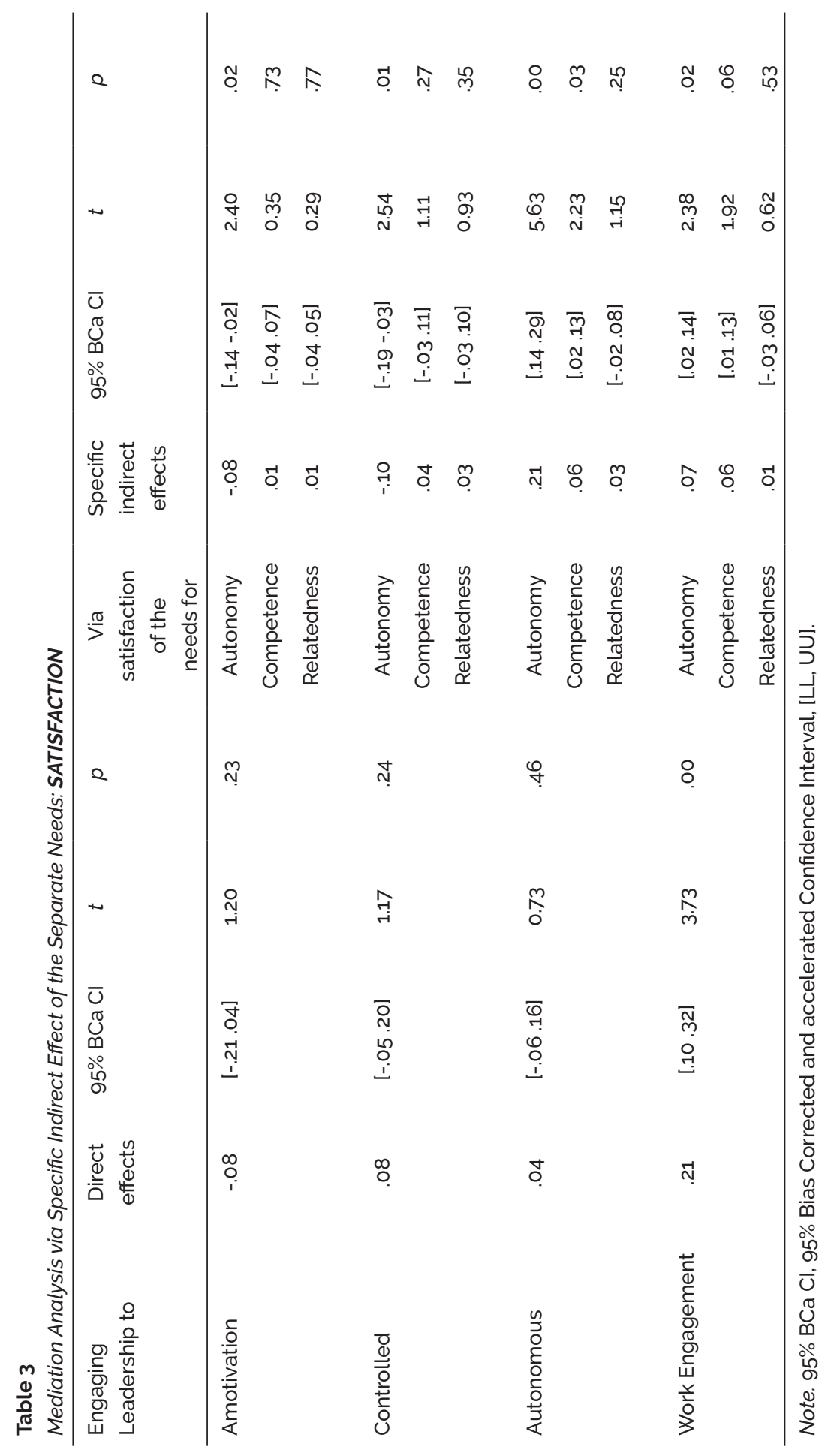




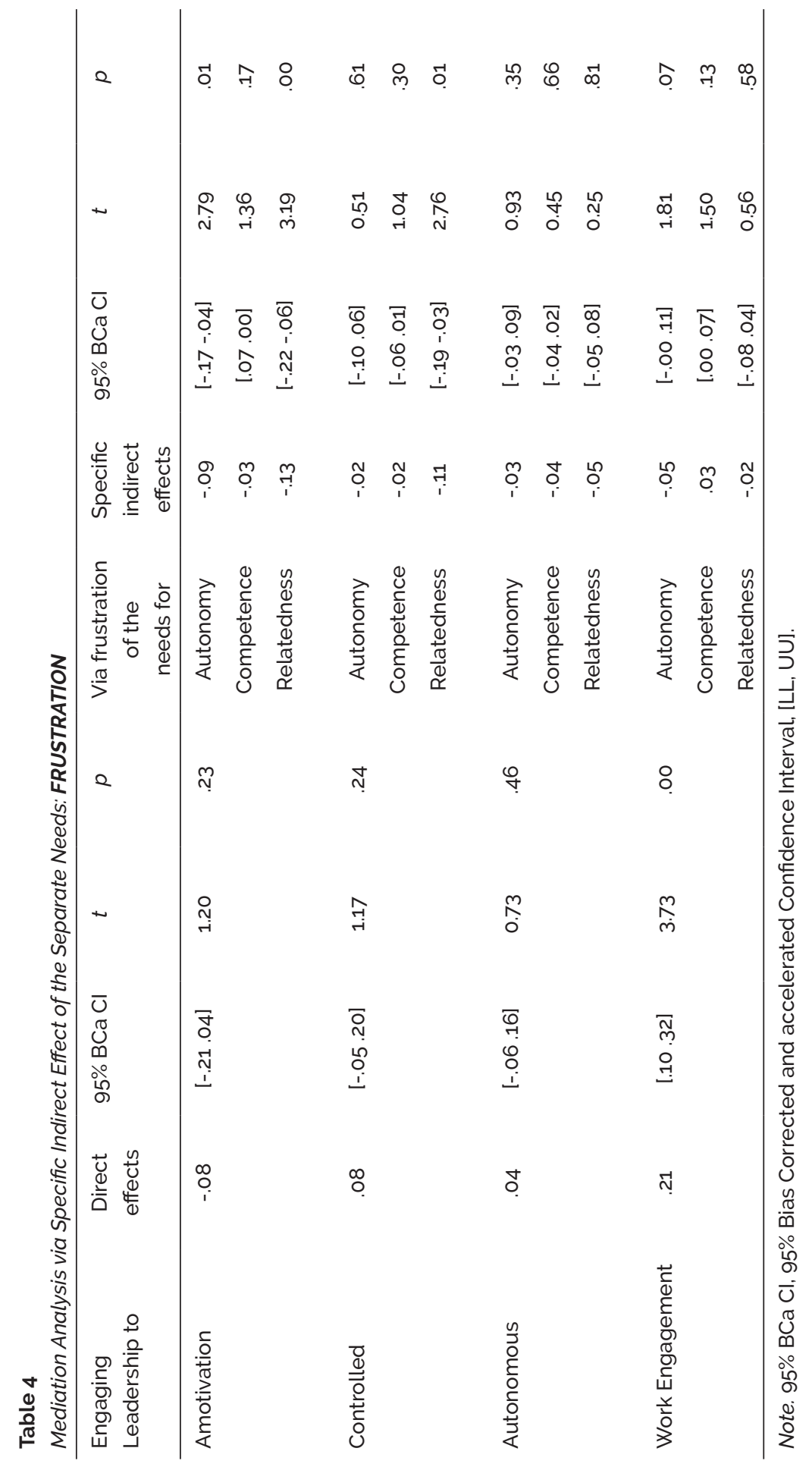


Table 5

Total Variance Explained and Effect Size

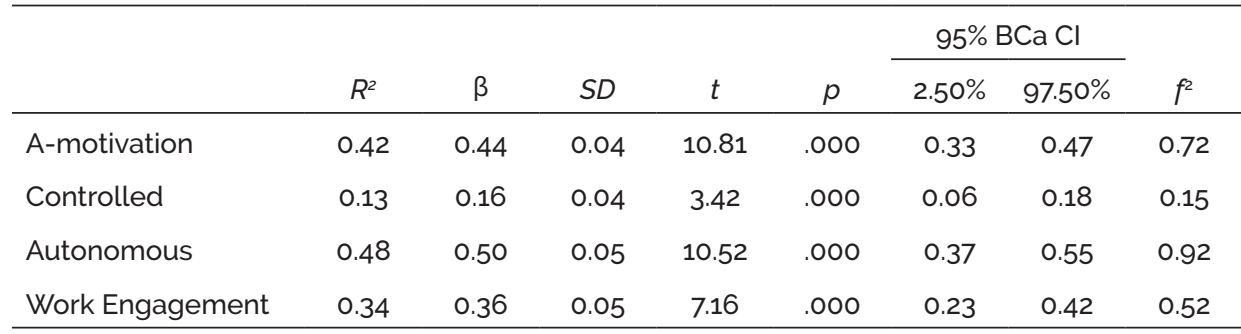

Note. $95 \% \mathrm{BCa} \mathrm{Cl}, 95 \%$ Bias Corrected and accelerated Confidence Interval; $f^{2}=R^{2} / 1-\mathrm{R}^{2}$.

\section{DISCUSSION}

The current study aimed to test the concept of engaging leadership and its effects on work motivation and engagement via the satisfaction and frustration of basic psychological needs. Engaging leadership was strongly and significantly related to both the positive and adverse outcome measures of motivation and engagement. However, when need satisfaction and frustration both were incorporated into the structural model in a parallel mediation design, the direct correlations with the outcome measures were partly overridden by the basic need constructs resulting in partial mediation in support of the hypotheses. The common-factor variable for needs satisfaction partially mediated positive outcomes and that for need frustration mediated negative outcomes between leadership, motivation, and engagement. Additionally, needs frustration partially mediated the relationship with work engagement, which was not expected. Then, the three separate need satisfaction constructs, and the three separate need frustration constructs were combined into one structural path model (see Figure 1). Autonomy satisfaction was found to mediate between engaging leadership and positive outcomes in terms of work engagement (partial mediation) and autonomous motivation (full mediation), but also with less adverse consequences in terms of amotivation and controlled motivation (both full mediation). The latter result was unexpected and implies that leaders who promote autonomy satisfaction may kill two birds with one stone: positive outcomes are likely to increase while negative consequences decrease. Relatedness frustration seemed significant in generating adverse outcomes (i.e., full mediation for both amotivation and controlled motivation). Autonomy frustration partially mediated the path to amotivation. When relatedness frustration levels drop, unfavorable outcomes decrease, but likely will not induce significant change in positive outcome measures. 
SDT proposes that the satisfaction of all three innate basic psychological needs is necessary for human flourishing and sustainable well-being (Deci \& Ryan, 2000) and that these needs should not be thwarted (Ryan \& Deci, 2017). The balance between the three needs is said to contribute to psychological health and well-being, whereas more substantial variability between the satisfaction levels is associated with lower well-being (Sheldon \& Niemiec, 2006); hence, psychological needs are measured in aggregate form rather than as six separate constructs. When needs are modelled as a higher-order construct, one implicitly assumes that all three needs behave similarly. However, the outcomes of the current study underscore the argument of Van den Broeck et al. (2016) not to consider the needs as interchangeable because the effects of the separate needs on the outcome measures indeed differed in strength and significance. Autonomy satisfaction was found to play a specific role because it predicted both positive and adverse outcomes. The analysis of effect sizes further supported the specific role of autonomy satisfaction; When another antecedent construct was excluded from the model, autonomy satisfaction demonstrated the most potent in-sample predictive power.

\section{Implications for Leadership}

A leader who recognizes the essential aspect of autonomy may very well promote a person's freedom and engagement while simultaneously offering a clear work context through, for example, presenting a compelling vision an employee can identify with and support or, more fundamentally, is invited to co-create. Such a leader will recognize autonomy as essential to the initiation and regulation of his or her employees' behavior. Through the leaders' autonomy support, employees may find ways to satisfy their needs for competence and relatedness, and, as Ryan and Deci (2017) posit, in many instances the satisfaction of the needs for relatedness and competence is dependent on the person's capacity to initiate action and self-organize. Moreover, when employees feel autonomous, they are said to be more open in order to effectively cope with positive or negative events and consequently to be more resilient in the face of setbacks and bounce back more quickly after stressful experiences (Vansteenkiste \& Ryan, 2013). Therefore, higher levels of autonomy satisfaction may help employees build stronger inner resources fostering higher well-being. A recent longitudinal study on needs satisfaction and frustration underscores the conclusion of the present study about the specific role of autonomy satisfaction (Cordeiro et al., 2016).

Emerging management approaches, such as agile (Brosseau et al., 2019), sociocracy (Bockelbrink et al., 2019) and holacracy (Robertson, 2015) further illustrate the transition from traditional command-and-control hierarchies to other, more autonomy supportive forms of leadership and organizing work, from work 
processes, to running meetings, to governance. The emerging approaches just described aim to align organizations and more specifically, the way organizations are structured operated and led, with a view on the development needs of human beings (For a select group of theories and views on human development referenced to earlier in this study: Deci \& Ryan, 2000; deCharms, 1968; Ryan \& Deci, 2017). Agile, sociocracy and holacracy as management and leadership practices favor more participatory and inclusive forms of leadership (Ardichvili et al., 2016), and align with the tenets of both engaging leadership and SDT. The outcomes of the current study highlight the essential role of autonomy support and the need for leaders to pay attention to the essential role of personal causation and the internalization of extrinsic motives. Engaging leaders are likely to foster higher levels of motivation and engagement and, through autonomy support, also contribute to lower levels of adverse work outcomes: The knife of engaging leadership via autonomy satisfaction cuts both ways. Lessening need frustration, however beneficial, is not likely to motivate employees: less ill-being does not imply higher well-being. If, however, an engaging leader is able to promote need satisfaction, and particularly autonomy satisfaction, positive outcomes and healthy motivation increase while negative outcomes and unsustainable, unhealthy motivation decrease.

\section{Limitations}

The present study was unique in combining the concept of engaging leadership with both separate and combined need satisfaction constructs into one structural model. The study design allowed us to simultaneously study the behaviors of both the satisfaction and frustration of autonomy, relatedness, and competence in the engaging leadership concept. However, the study was cross-sectional, so any conclusions on causal relationships cannot be drawn. Moreover, the conclusions were based on data from three Dutch departments of industrial engineering organizations, which also limits the generalizability of the findings. Future studies should expand into other areas of business, such as finance, public services, education, and healthcare and should preferably be longitudinal over 3 or more timepoints.

Furthermore, in the structural model analysis, only three items of the work engagement measure were used, because the measurement model evaluation indicated that the three selected items fitted the data best. Two of the three items overlapped with the ultra-short UWES-3 that was validated using large samples of five different countries (Finland, Japan, The Netherlands, Belgium/Flanders, and Spain (Schaufeli et al., 2019). Only our item for absorption ("I feel happy when I am working intensely") differed from the absorption item of the UWES-3 ("I am immersed in my work"). Not surprisingly, the Pearson correlation between the two 3-item engagement scales is high, $r=.87, \mathrm{p}<.001$, 
indicating that they are virtually identical. Moreover, Schaufeli et al. (2019) found that the UWES-3 shared $86-92 \%$ of its variance with the 9-item version of the UWES, depending on the national sample.

The present study did not encompass previous studies on the effectiveness of autonomy-supportive leadership in organizations; A relatively small body of work within SDT focuses on particular aspects of leadership effectiveness (Su \& Reeve, 2010). Additionally, one could examine relationships between engaging leadership, personality profiles and outcomes: E.g., certain combinations of preferences in fivefactor modelling may associate with levels of engaging leadership and with outcomes as has been demonstrated earlier for transformational leadership (cf. Judge \& Bono, 2000)). Future EL studies should also investigate actual leadership interventions and integrate the conclusions of previous studies on work organizations and their relations to and relevance for EL. If they have longitudinal designs and cover different organizations, intervention studies are likely to contribute to the further development of EL as the first SDT-based leadership model.

The research on the role of need frustration, specified both as a common factor and as separate constructs, is relatively new and does not yet include many studies. Especially rare are studies exploring the role of separate needs, whereas studies shed more light on the specific effects of the frustration of basic needs in work environments.

\section{Conclusion}

The recently developed concept of engaging leadership positively associates with work motivation and engagement through needs satisfaction and autonomy satisfaction in particular because autonomy fosters positive outcomes and decreases adverse outcomes. While lower needs frustration levels may lead to less disadvantageous results, lower ill-being does not lead to higher well-being. Additionally, basic needs should be considered separate entities because these needs have distinct dynamics and predictive power in the leadership model. The satisfaction of the composite, higher order construct for either need satisfaction or need frustration may leave out essential information about the strengths and impacts of key drivers of effective leadership; Autonomy satisfaction may prime individuals and intimate the realization of relatedness or competence. 



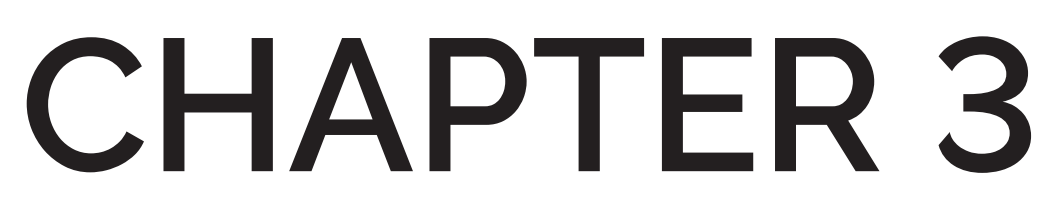

A Corporate Purpose as an Antecedent to Employee Motivation and Work Engagement

Appeared as: van Tuin, L., Schaufeli, W. B., Van den Broeck, A., \& Van Rhenen, W. (2020). A Corporate Purpose as an Antecedent to Employee Motivation and Work Engagement. Frontiers in Psychology, 11. http://doi.org/10.3389/fpsyg.2020.572343 

Purpose-driven organizations can change the world (Barton et al., 2016). The debate on the purpose of organizations seems to develop toward a broader purposedriven leadership (Harrison et al., 2019). In August 2019, the Business Roundtable, representing the largest U.S. companies, issued a press announcement redefining purpose to include all stakeholders: employees, customers, suppliers, communities, and shareholders (Business Roundtable [BRT], 2019). To some, the announcement signaled an end to 50 years sway of shareholder value primacy and profit maximization at all costs (Gelles \& Yaffe-Bellany, 2019). Others speak of "shareholder value fatigue" (Harrison et al., 2019, p. 2), indicating that raw stockholder capitalism wanes and makes place for companies displaying true social responsibility by being good and doing well (Husted, 2016).

Popular business publications and consultancy reports frequently applaud the positive effects of a broader purpose on employee motivation and engagement. In the same breath, many of these publications stress that motivation and engagement are in crisis but indispensable for companies to thrive in a VUCA world (Mann \& Harter, 2016). One would expect to find studies examining the effects of a corporate purpose on motivation and engagement. However, academic leadership studies often overlook the role of purpose and take it for granted (Kempster et al., 2011). And empirical research into the psychological effects of a corporate purpose on motivation and engagement is lacking (Parmar et al., 2017).

Many references in business- (Ebert et al., 2018; Hurst et al., 2016) and academic publications (cf. Shuck \& Rose, 2013) point to the beneficial effects of a personal purpose on meaning in life, well-being, and performance. And it is assumed that identification with a broader corporate purpose will also foster well-being and engagement. However, they do not provide empirical substantiation for that relationship. Some do present an empirical relationship (cf. Sparks \& Schenk, 2001; Steger et al., 2012), but although the authors refer to a higher purpose, they do not measure such a purpose. l.e., Sparks \& Schenk (2001) measure the belief in a higher purpose and define it as "feeling part of a 'cause' that is about more than making money" (p. 860). And Steger et al. (2012) present a scale measuring positive meaning in work, work as a lever for meaning-making, and the perception of contributing to some greater good through work, without defining what that greater good may be. We consider it essential to complement the debate with empirical knowledge about the actual psychological associations of a real corporate purpose that matches a definition of a broader or higher purpose, with motivation, and engagement. 
Based on self-determination theory (Deci \& Ryan, 2000), the present study examined the associations of a corporate purpose with employee motivation and work engagement testing the widespread assumption that a higher purpose leads to enhanced employee motivation and engagement. Additionally, we were interested in what role motivation plays in the dynamic between a purpose as an antecedent with engagement as an outcome. We argue that motivation may explain this relationship, in the same manner that basic psychological needs explain the relationship between, e.g., transformational leadership and work engagement (Kovjanic et al., 2012), or between team-values and work engagement (Schreurs et al., 2014).

This study adds to the knowledge of the potential benefits of a corporate purpose and its relations with motivation and engagement. It contributes to the current understanding of the antecedents of employee well-being and answers to the growing interest in more eudemonic forms of well-being (Ilies et al., 2005; Ryan et al., 2008) and sustainable motivation (Peters et al., 2018). Moreover, the study adds to leadership theory and responds to the lack of research into corporate purpose (cf. Podolny et al., 2004). It provides some support for resolving the underutilization of purpose as an instrument to sustainably motivate employees and drive work engagement (Keller, 2015). And finally, considering purpose as an aspect of good leadership (Shuck \& Rose, 2013), the study adds to the knowledge about the underlying process that may explain the link between leadership and engagement (Inceoglu et al., 2018). From a practical point of view, this study may provide arguments for organizations to reflect on why they do what they do and how this may affect motivation.

\section{Defining Purpose}

For long, various scholars have advocated the transition from the doctrine of shareholder value (Friedman, 2007) to a broader purpose-driven leadership that considers all stakeholders (Freeman et al., 2004). Recent business studies provide empirical support for the beneficial impact of purpose on business results. Companies pursuing a higher purpose have the better case compared to companies primarily seeking profit maximization (Thakor \& Quinn, 2013). Gartenberg et al. (2016) found a broader purpose, combined with clarity and systematic communication around it, predicts financial performance. And Keller (2015) corroborated the business case for a corporate purpose but also concluded that purpose is yet much underutilized.

A broader corporate purpose is generally defined as the meaning and contribution of a firm beyond its financial strategy and performance (Henderson \& Steen, 2015). It should involve all stakeholders and put people first (Sisodia \& Gelb, 2019), aim to 
benefit customers (Ellsworth, 2002), integrate the needs of society (Metcalf \& Benn, 2012), foster employee well-being and engagement (Bajer, 2016), and include and embrace ethics (Freeman, 1994). Beyond the formal wording of a purpose, it should also be actively propagated: a purpose is only as strong as that employees and other stakeholders believe in it (Bekke, 2006). A compelling purpose instills the organization with value and, through actively supporting employees to identify with and find meaning in it, stimulates commitment and inspires action (Ellsworth, 2002).

Larry Fink, CEO of Blackrock, titled his 2019 letter to CEOs "Purpose and Profit" (Fink, 2019) and claimed that a purpose should unify management, employees, and communities alike and drive ethical behavior. As governments fail to do so, Fink (2019) posits that businesses and organizations are called on to set higher, more exacting standards and allow for the public to hold them accountable. Like Ellsworth (2002), Fink presents purpose as the principal raison d'être of a company, providing a fundamental framework to benefit others and reap sustained long-term rewards. He considers it indispensable for leaders to, through purpose, provide direction and responsible stewardship in times of political polarization and economic disruption.

\section{Purpose and Motivation}

A broader corporate purpose may affect motivation and elicit a sense of meaning and well-being in employees (Gartenberg et al., 2016). Self-determination theory (SDT, Deci \& Ryan, 2000) offers a perspective on the underlying mechanism that may explain how environmental aspects, such as a corporate purpose, may lead to higher levels of intrinsic motivation and well-being. At the core of SDT lies the assumption that human beings are active social agents that take in life experiences in social contexts and integrate these with their sense of self, thus making meaning and developing a more unified sense of self-identity (Deci \& Ryan, 2000). An appealing corporate purpose serving a broader interest in the pursuit of a greater good may thus support individuals to identify with that purpose and integrate it with their sense of self, which then nourishes high-quality motivation. And notwithstanding the paucity of studies, motivation and engagement are sought-after qualities in organizations. They are essential to attract and retain talented workers (Delaney \& Royal, 2017) and younger generations (Eversole et al., 2012).

This integration process of a corporate purpose with the self is a very important aspect. It cannot be properly understood without an idea about the beliefs people hold about self-identity in life and work. It is a commonly held belief that a life with a purpose is a life of meaning, happiness, and well-being (Frankl, 2008; Wong, 2012). Work also carries purpose and, over the decades, has increasingly become 
a principal place for self-expression and self-realization (Ciulla, 2000). Work is a stronghold for the Western ideal of authenticity and self-determination (Taylor, 1991). Work may confirm, strengthen, or deny one's sense of self and identity (Fukuyama, 2018; Niemiec \& Spence, 2016).

Consequently, the expectations people have from work and the work environment are high. The current prevalence of purpose and self-realization makes a corporate purpose an essential subject of interest when studying motivation and engagement (Shuck \& Rose, 2013). A corporate purpose may support motivation and foster work engagement when tapping into the prevailing beliefs people hold about work and self-realization through work. In a recent study, Martela and Pessi (2018) argue that a broader purpose imbues a sense of autonomy, self-determination, contribution, and worthiness in the individual, to whom the intrinsic value of the work itself is reinforced by the perceived intrinsic value of that broader purpose.

SDT researchers explain the process of integration of purpose with self-identity as the internalization of extrinsic motives (Ryan, 1995; Ryan \& Deci, 2017) and distinguish different levels of integration and corresponding types of motivation (Gagné \& Deci, 2005). The more an individual can identify with a given purpose, for example, because he or she finds it an essential or inspiring objective to contribute to, the more self-determined the individual may feel. The type of motivation where extrinsic motives, such as a corporate purpose, are effectively internalized with the sense of self, is labeled autonomous motivation. This type of motivation positively associates with work engagement (Meyer \& Gagné, 2008; Niemiec \& Spence, 2016). Employees displaying high levels of autonomous motivation tend to willingly take on tasks and responsibilities as these align with what they find important (Van den Broeck et al., 2013). When employees find joy in their work and when the work itself is engaging and exciting to them, they can direct their motivational energy for the sake of doing the work itself (Ryan \& Deci, 2017). Furthermore, intrinsic motivation is related to enhanced creativity (Amabile, 1985), problem-solving capacities (Song \& Grabowski, 2006), self-regulation (Niemiec \& Spence, 2016), and taking on responsibility and initiative (Grant et al., 2011). A well-defined corporate purpose can support employees in finding meaning and purpose in the work they are doing and, hence, support their autonomous motivation.

In contrast, the type of motivation where the extrinsic motives are not, or only partially internalized, is defined as controlled motivation. This type of motivation implies that the reason an individual performs a task is less for the sake of the activity itself, but rather to obtain a social or material reward or prevent negative consequences (Gagné et al., 2014). More specifically, when being motivated in a controlled way, employees 
feel pressured by others or pressure themselves to do their work. Managers who push for deadlines and delivery on KPIs (Key Performance Indicators), or that demand extensive reporting and micro-manage employees are experienced as controlling. But also, contingent performance evaluations, strict processes, procedures, or monetary rewards can be experienced as controlling (Gagné \& Deci, 2005). High levels of controlling regulations relative to low autonomous motivation are associated with lower well-being, work-related strain and burnout (Van den Broeck et al., 2013), procrastination (Vansteenkiste et al., 2009) and lower work engagement (Howard et al., 2016). In contrast with the expected positive association between a corporate purpose and autonomous motivation, we assume that the relationship with controlled motivation is likely to be negative because antithetical.

When individuals describe the reason for performing a task as meaningless or pointless, this is described as amotivation (Deci \& Ryan, 2000). We also expect amotivation to relate with a higher corporate purpose negatively. A higher purpose is expected to support employees to find meaning and significance in their work, which is directly opposite to the experience of meaninglessness or pointlessness. A consequence of amotivation is that employees experience a lack of control over the situations they are in or feel detached from their work or the actions they undertake (Howard et al., 2016). Known associations of this type of motivation are low engagement, low vitality, emotional exhaustion, higher burnout risk, and turnover intentions (Tremblay et al., 2010).

Hence, it can be expected that purpose positively associates with autonomous motivation, and negatively with amotivation and controlled motivation.

Hypothesis 1: A higher corporate purpose associates positively with (a) autonomous motivation and negatively with (b) controlled motivation and (c) amotivation.

\section{Purpose and Work Engagement}

Work engagement is a central concern to organizations. Work shifted from mechanistic to knowledge-intensive models, and social interaction between employees, their wellbeing, and engagement contribute to the organization's performance (Shuck and Herd, 2012). The rising importance of work to provide in the search for meaning (Ciulla, 2000) and the competition between organizations to source talented and motivated employees (Delaney \& Royal, 2017) add to the complexity. Engaged employees show high levels of energy (Schneider et al., 2018) and self-efficacy (Bandura, 2010). They experience their work as fun and may lose track of time at work (Bakker \& Demerouti, 2008). Additionally, they display enhanced levels of well-being (Peters et al., 2018) and report a healthier work-life balance (Kossek et al., 2014). 
A robust body of research has developed over the past two decades identifying various antecedents to engagement, such as leadership (Carasco-Saul et al., 2015), work climate (Bakker et al., 2007), and organizational support (Saks, 2006). On an aggregated organizational level, Macey and Schneider (2008) showed that job attributes (variety, challenge, and autonomy) and leadership act as the main antecedents of engagement. The authors position work engagement as a potential key to competitive advantage. Others point to the relationship between business performance and work engagement (e.g., Sorensen, 2013), and even long-term sustainable performance (e.g., Renee Baptiste, 2008).

In a conceptual paper Shuck and Rose (2013) argue to complement the dominant focus on performance in work engagement studies (Inceoglu et al., 2018) with the development of favorable conditions to nurture engagement through providing meaning and purpose. Following Shuck and Rose's argument, we hypothesized that purpose would positively associate with work engagement.

Hypothesis 2: Purpose associates positively with work engagement.

Furthermore, Shuck and Rose's argument is in keeping with SDT as a unifying framework underlying and potentially explaining work engagement as a phenomenon (Meyer \& Gagne, 2008; Vansteenkiste \& Ryan, 2013). Following the typology of motivation as described in SDT, and following the argument of Martela and Pessi (2018) that a broader purpose imbues a sense of self-determination in the individual, we expected that autonomous motivation mediates the relationship between purpose and engagement and that amotivation and controlled motivation would not mediate. Previous studies consistently found that needs satisfaction mediates the relationship between the antecedent and outcomes, be it in leadership studies (e.g., Kovjanic et al., 2012), sports (e.g., Gillet et al. 2009), or parenting (Van der Kaap-Deeder et al., 2017). Nevertheless, studies examining the mediating role of controlled and autonomous motivation are rare. However, Grant et al. (2011), in their study into the moderating role of controlled and autonomous motivation in predicting performance, considered it likely to occur.

Hypothesis 3: (a) Autonomous motivation mediates the relationship between purpose and work engagement; (b) Amotivation and (c) controlled motivation mediate negatively between purpose and engagement. 


\section{This Study}

In the present two-step study, we took the corporate purpose of a multinational organization as a point of vantage and tested the associations with employee motivation and work engagement through a cross-sectional self-report survey, following the recommendations for cross-sectional research (Spector, 2019). The selected purpose matched the criteria of a broader or higher purpose and consisted of the organization's mission and vision statement. The mission statement referred to contributing to improving people's lives. The vision statement included contributing to health and sustainability, being a great place to work, inspiring passion for the firm's contribution, and delivering value to customers and shareholders. We asked participants whether the purpose inspired them (Martela \& Pessi, 2018) and whether they felt they were contributing to its realization through their work (Steger et al., 2012). Specifically, we were interested in the potential positive relationship between purpose, motivation, and engagement. Hence, we expected that purpose would relate positively with autonomous motivation and engagement over time. Directionality from purpose to motivation and engagement would confirm the popular belief that a higher purpose predicts higher levels of autonomous motivation and work engagement.

The data were specified in a structural model (Figure 1) to simultaneously examine the associations of a corporate purpose with motivation and engagement. Additionally, we examined the potential mediational effects of motivation on the relationship between purpose and engagement. In Study 2 , the variables purpose, motivation, and engagement were specified in a cross-lagged panel model (Figure 2) to examine the potential directionality over three time-points with a subset of respondents from the cohort of study 1.

Hypothesis 4: Purpose relates to autonomous motivation and engagement over time, rather than the other way around. 


\section{Figure 1}

Research Model for Study 1

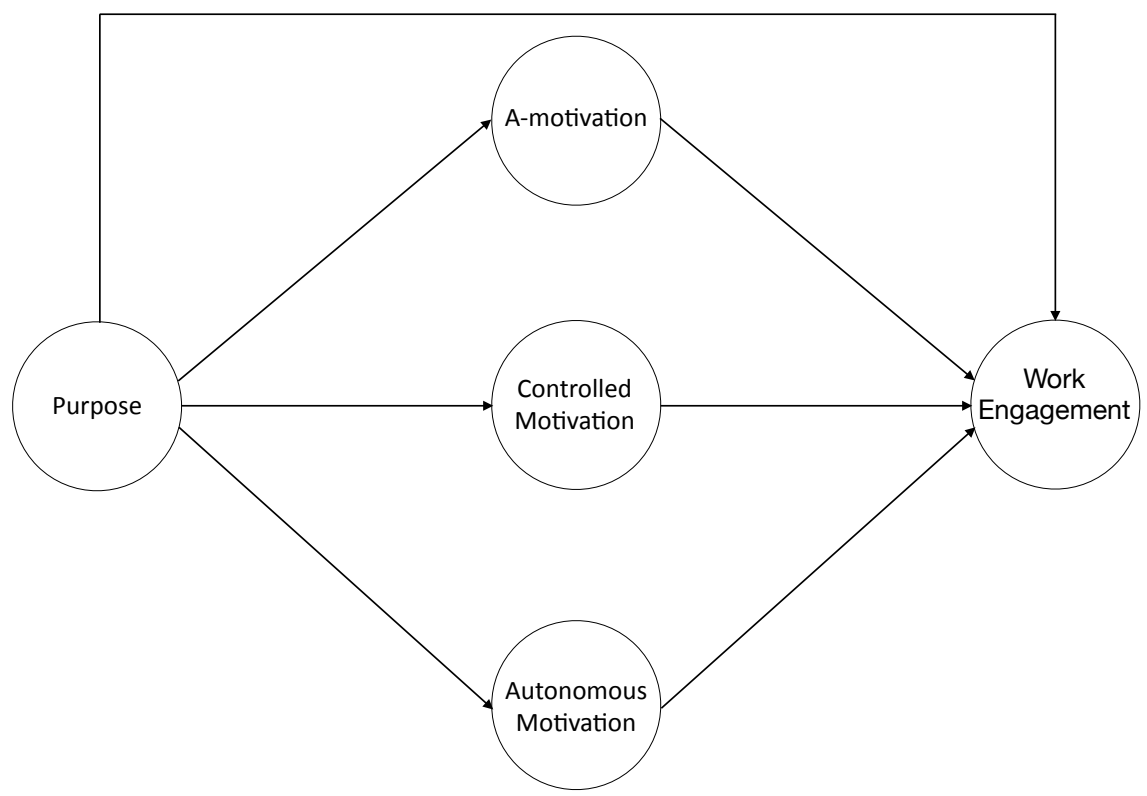

Note. The research model portrays the multiple mediation model of the present study, testing the hypothesis that purpose associates positively with work engagement through autonomous motivation and negatively through controlled motivation and amotivation.

\section{Figure 2}

The Cross-Lagged Panel Model as Used in Study 2

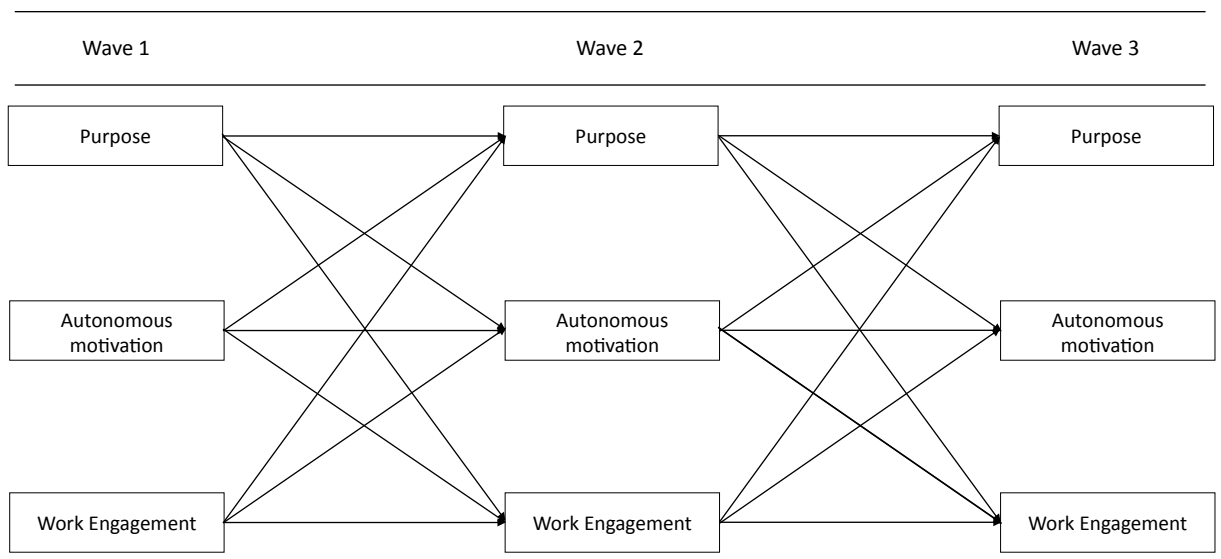

Note. The cross-lagged panel model in study 2 examines the crossed relationships from purpose to autonomous motivation and engagement. 


\section{STUDY 1 \\ METHOD}

\section{Participants and Procedure}

Participants were a convenience sample of back-office workers specialized in order management and information analysis from a Dutch for-profit multinational organization producing, selling, and maintaining professional health systems. The supervising managers were informed about the survey and its purpose and agreed on inviting the employees through email. It was also agreed participation should be voluntary and that there should be no incentives to complete the survey beyond the email invitation itself. Furthermore, the survey was checked for compliance with the survey protocol established by the organization's works council, guaranteeing the confidentiality and anonymity. Then the invitations were sent to 432 prospective respondents to complete an online self-report survey. In total, 277 completed responses were received (64\%). The average age was $42.23(S D=10.42)$, and $43 \%$ was female. Of the respondents, $90 \%$ had a full-time contract, $9 \%$ of which were temporary contracts. The percentage of part-time workers was $10 \%$, of which $8.7 \%$ had a temporary contract. $68 \%$ Of the employees had been in their positions for less than five years, 27\% between 5 -10 years, $4.5 \%$ ten years or longer.

\section{Instruments}

The measures were estimated on a Likert scale from 1 (strongly disagree) to 5 (strongly agree) except for work engagement. Reliabilities are reported through Cronbach's alpha $(\alpha)$, congeneric reliability $\left(\rho_{c}\right)$, and average variance extracted (AVE, Cho, 2016; Hair et al., 2017; Peterson \& Kim, 2013). The items and their factor loadings are presented in Table 1

Purpose was assessed by presenting the organization's mission and vision to the respondents, followed by seven items that were composed of keywords from the deconstructed mission and vision statements. The items were (1) "I am inspired by this mission and vision"; (2) "I feel that I contribute to (...) in my daily work."; (3) "We strive to make the world healthier."; (4) "We strive to make the world more sustainable."; (5) "(... see Footnote 1) is the best place to work."; (6) "We deliver superior value to our customers."; (7) "We deliver superior value for our shareholders". $a=.85, \rho_{C}=.86$, $\mathrm{AVE}=.56$. 
Table 1

Scale Items, Factor Loadings and Reliabilities

\begin{tabular}{|c|c|c|c|c|c|}
\hline Scale & Item & $b$ & $a$ & $\rho_{c}$ & AVE \\
\hline \multirow[t]{7}{*}{ Purpose } & This mission and vision inspires me. & 0.58 & \multirow[t]{7}{*}{0.85} & \multirow[t]{7}{*}{0.86} & \multirow[t]{7}{*}{0.56} \\
\hline & I feel that I contribute to $(. . .)^{\text {a }}$ in my daily work. & 0.74 & & & \\
\hline & We strive to make the world healthier. & 0.77 & & & \\
\hline & We strive to make the world more sustainable. & 0.70 & & & \\
\hline & $(. . .)^{a}$ is the best place to work. & 0.63 & & & \\
\hline & We deliver superior value to our customers. & 0.73 & & & \\
\hline & We deliver superior value for our shareholders. & 0.71 & & & \\
\hline \multirow[t]{3}{*}{ Amotivation } & $\begin{array}{l}\text { I don't, because I really feel that I'm wasting my } \\
\text { time at work. }\end{array}$ & 0.86 & \multirow[t]{3}{*}{0.81} & 0.89 & \multirow[t]{3}{*}{0.73} \\
\hline & $\begin{array}{l}\text { I don't, because I don't think this work is worth } \\
\text { putting efforts into. }\end{array}$ & 0.87 & & & \\
\hline & $\begin{array}{l}\text { I don't know why l'm doing this job, it's pointless } \\
\text { work. }\end{array}$ & 0.83 & & & \\
\hline \multirow[t]{3}{*}{$\begin{array}{l}\text { Controlled } \\
\text { motivation }\end{array}$} & $\begin{array}{l}\text { Because others will reward me financially only } \\
\text { if I put enough effort in my job (e.g., employer, } \\
\text { supervisor, ...). }\end{array}$ & 0.74 & \multirow[t]{3}{*}{0.68} & 0.76 & \multirow[t]{3}{*}{0.54} \\
\hline & $\begin{array}{l}\text { Because others offer me greater job security } \\
\text { if I put enough effort in my job (e.g., employer, } \\
\text { supervisor...). }\end{array}$ & 0.45 & & & \\
\hline & $\begin{array}{l}\text { Because I risk losing my job if I don't put enough } \\
\text { effort in it. }\end{array}$ & 0.92 & & & \\
\hline \multirow{3}{*}{$\begin{array}{l}\text { Autonomous } \\
\text { motivation }\end{array}$} & Because I have fun doing my job. & 0.87 & \multirow[t]{3}{*}{0.85} & \multirow[t]{3}{*}{0.91} & \multirow[t]{3}{*}{0.77} \\
\hline & Because what I do in my work is exciting. & 0.88 & & & \\
\hline & Because the work I do is interesting. & 0.87 & & & \\
\hline \multirow{3}{*}{$\begin{array}{l}\text { Work } \\
\text { engagement }\end{array}$} & At my job, I feel strong and vigorous. & 0.86 & \multirow[t]{3}{*}{0.80} & \multirow[t]{3}{*}{0.88} & \multirow[t]{3}{*}{0.72} \\
\hline & I feel happy when I am working intensely. & 0.81 & & & \\
\hline & I am proud of the work that I do. & 0.87 & & & \\
\hline
\end{tabular}

Note. ${ }^{\text {a }}$ For reasons of anonymity the name of the organization and the mission are withheld. 
For work motivation, we used items from the multidimensional work motivation scale (Gagné et al., 2014) to measure three types of motivation (amotivation, controlled motivation, and autonomous motivation) with three items each. The header for the scale was, "Why do you or would you put efforts in your job?" An example of an item for amotivation is, "I don't, because I really feel that I'm wasting my time at work." Reliabilities were $\alpha=.81, \rho_{\mathrm{C}}=.89$, AVE $=.73$. An example of controlled motivation is "Because others offer me greater job security if I put enough effort in my job", $a=.68$, $\rho_{\mathrm{C}}=.76, \mathrm{AVE}=.54$. And an example of autonomous motivation: "Because the work I do is interesting", $\alpha=.85, \rho_{\mathrm{C}}=.91, \mathrm{AVE}=.77$.

Work engagement was assessed using the 9-item version of the Utrecht Work Engagement Scale, UWES (Schaufeli et al., 2006), which measures vigor, dedication, and absorption. Following Schaufeli et al.'s (2006) recommendations one common factor for engagement was used $\left(\alpha=.80, \rho_{C}=.88 \mathrm{AVE}=.72\right)$ and it was measured on a Likert scale ranging from o (never) to 6 (every day). Examples of items are "At my job I feel strong and vigorous" (Vigor); "I am proud of the work that I do" (Dedication); I feel happy when I am working intensely (Absorption).

\section{RESULTS}

\section{Preliminary Analyses}

First, the data were checked for missing values, which was $<1 \%$. Outlier analysis plotting Cook's distances and centered leverage resulted in eliminating 7 cases from the analysis so that further analyses were conducted with $n=270$. Then, to test whether data were missing completely at random, Little's MCAR test (Little \& Rubin, 2002) was applied, which showed that MCAR was not violated, $x^{2}(51)=61.50, p=.15$. No effects were found for age, gender, tenure, or type of contract. The means, standard deviations, and bivariate correlations are presented in Table 2. Notably, the Pearson correlations of controlled motivation were all insignificant.

\section{Analysis}

The structural research model comprised purpose, amotivation, controlled motivation, autonomous motivation, and work engagement, which were tested simultaneously with their respective items. The estimator for the mean- and variance adjusted likelihood ratio was set to maximum likelihood. To evaluate model fit a range of fitindices was used following (Kline, 2016; Marsh \& Balla, 1994): the chi-square $\left(x^{2}\right)$; the root mean square error of approximation (RSMEA); and the comparative fit index (CFI, Bentler, 1990) in combination with the standardized root mean square residual (SRMR). 
The model had an acceptable fit to the data, $x^{2}(160)=326.14, p<.001$; RMSEA $=.06$, $90 \% \mathrm{Cl}$ [.05, .07]; $\mathrm{CFI}=.93 ; \mathrm{SRMR}=.08$ and explained $56.7 \%$ of the variance in work engagement.

\section{Table 2}

Means (M), Standard Deviations (SD), and Bivariate Correlations (r).

\begin{tabular}{|c|c|c|c|c|c|c|c|c|}
\hline & & $M$ & $S D$ & 1 & 2 & 3 & 4 & 5 \\
\hline 1 & Purpose & 3.61 & 0.59 & 1 & & & & \\
\hline 2 & Amotivation & 1.56 & 0.63 & $-.26^{* * *}$ & 1 & & & \\
\hline 3 & Controlled Motivation & 2.84 & 0.69 & .11 & .08 & 1 & & \\
\hline 4 & Autonomous Motivation & 3.77 & 0.66 & $.31^{\star \star *}$ & $-.46^{* * *}$ & -.05 & 1 & \\
\hline 5 & Work Engagement & 4.74 & 0.96 & $49^{* * *}$ & $-.37^{* * *}$ & -.03 & $.59^{* \star *}$ & 1 \\
\hline
\end{tabular}

Note. $N=270 ;$ significance (two-tailed): ${ }^{* * *} p<.001$

\section{Figure 3}

Standardized Path Coefficients

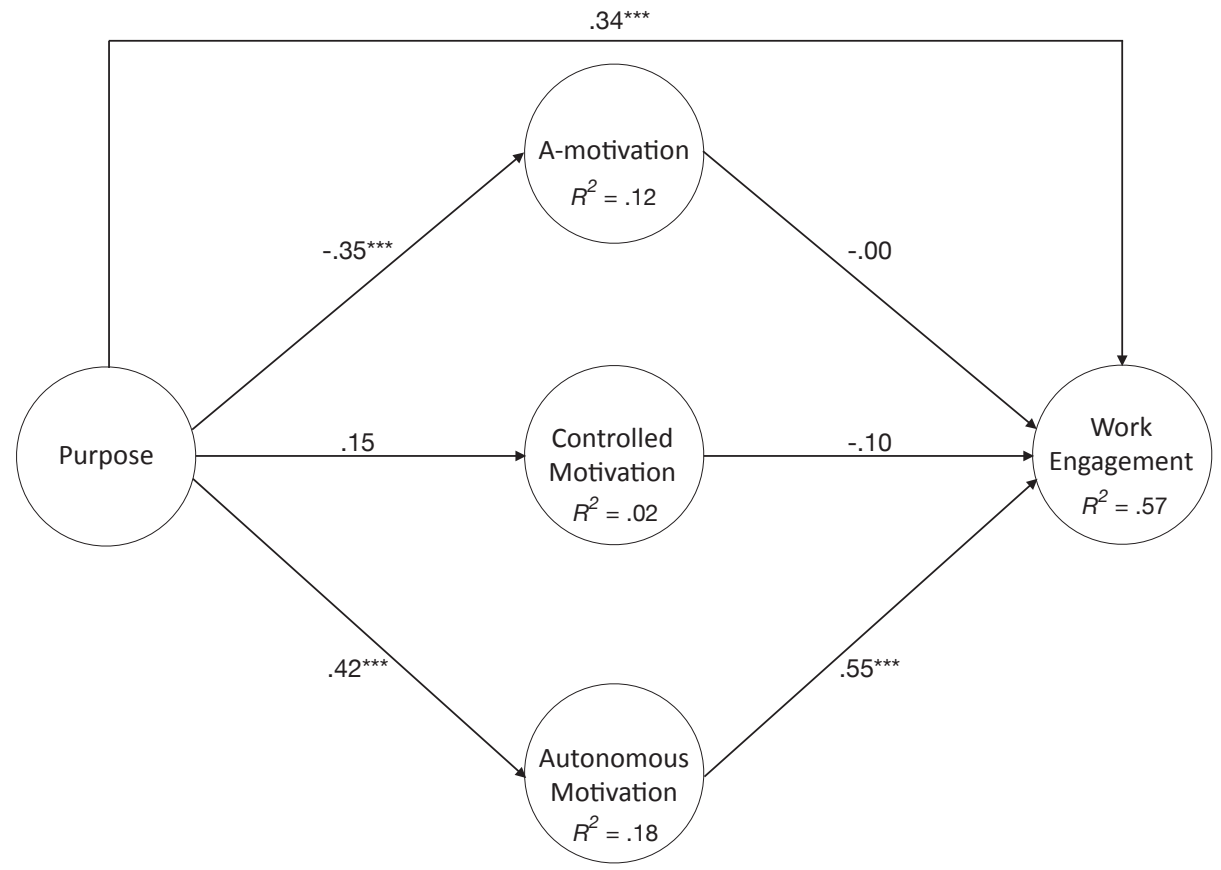

Note. Standardized path coefficients from purpose to work engagement via amotivation, controlled motivation and autonomous motivation. 


\section{Hypothesis Testing}

Hypothesis 1 predicted purpose to associate positively with (a) autonomous motivation and negatively with (b) amotivation and (c) controlled motivation. The results (see Figure 3 ) indicate a positive and significant path from purpose to autonomous motivation ( $\beta=.42, p<.001)$, while the path to amotivation is negative $(\beta=-.35, p<.001)$ and the path to controlled motivation is insignificant $(\beta=.15)$. Hence, hypothesis $1 \mathrm{a}$ and $1 \mathrm{~b}$ are supported by the data, while hypothesis $1 \mathrm{c}$ is not.

Hypothesis 2 posited that purpose positively associates with work engagement. This is also supported by the data $(\beta=.34, p<.001$ ). Hypothesis 3 stated that (a) autonomous motivation mediates the relationship between purpose and work engagement, which was supported by the data. As depicted in Table 2, the relationship between purpose and work engagement was partially mediated by autonomous motivation, $\beta=.23, p<.001,95 \% \mathrm{BCa} \mathrm{Cl}[.14, .33]$, whereas there was no mediational role for (b) amotivation and (c) controlled motivation, which was not expected. To examine the impact of autonomous motivation on the percentage of variance explained in work engagement, another test was carried out specifying only the direct effects of purpose on work engagement. This test resulted in a total variance explained of $18.8 \%$ against $56.7 \%$ of the proposed and tested model, which underscored the fundamental role of autonomous motivation in the model.

\section{Table 3}

The Relationship Between Purpose and Work Engagement as Mediated by Autonomous Motivation

\begin{tabular}{lllll}
\hline & & & & \multicolumn{2}{c}{$95 \% \mathrm{BCa} \mathrm{Cl}$} \\
\cline { 4 - 5 } & $\beta$ & $S D$ & $2.50 \%$ & $97.50 \%$ \\
\hline Total effects & $0.56^{* * *}$ & 0.07 & 0.42 & 0.67 \\
Total indirect effects & $0.22^{* * *}$ & 0.06 & 0.11 & 0.33 \\
Direct effects & $0.34^{* * *}$ & 0.08 & 0.19 & 0.50
\end{tabular}

Specific indirect effects via

Amotivation

$\begin{array}{cccc}0.00 & 0.03 & -0.06 & 0.06 \\ -0.01 & 0.01 & -0.06 & 0.00 \\ 0.23^{* * *} & 0.05 & 0.14 & 0.33\end{array}$

Controlled Motivation 0.33

Autonomous Motivation

Note. 95\% BCa Cl, Bias Corrected and accelerated Confidence Interval; $\beta$, standardized regression coefficient. 


\section{STUDY 2}

The second study aimed to examine directionality between the study variables purpose, autonomous motivation, and work engagement. Amotivation and controlled motivation were not tested because the first study indicated that these two variables did not mediate.

\section{METHOD}

Participants were selected from a subset of the participants in study 1 and contained the order managers of the customer fulfillment center of that same organization. Data were gathered over three waves with an eight months interval. E-mail invitations were sent to 163 prospective respondents by their supervisors to complete an online selfreport survey. Analogous to study 1 participation was voluntary, and no incentives for participation were issued. At the first wave, 119 completed responses were received (73\%) against 120 at wave 2 (74\%), and 81 at wave 3 (50\%). The subsequent analysis of the data was performed with 56 same respondents. Of the respondents at wave 1, 47\% were female, the average age was 39 years $(S D=10.31$ ), and the average tenure was four years or less. Most employees (67\%) had a full-time contract, of which $11 \%$ had a temporary arrangement, and 33\% worked part-time (32 hours per week or less), of which $34 \%$ had a temporary contract. There were no effects of gender, age, tenure, or type of contract.

\section{Measures}

The measures applied were the same as in study 1: purpose, autonomous motivation, and work engagement. Reliabilities at the subsequent time points were expressed in Cronbach's alpha, congeneric reliability and average variance extracted. All values were within acceptable limits. Cronbach's Alpha values varied between .76 for work engagement at wave 1 and .87 for autonomous motivation at wave 3. Values for congeneric reliability varied between .82 for purpose at wave 1 and .92 for autonomous motivation at wave 2. Average variance extracted varied between .49 for purpose at wave 2 and .79 for autonomous motivation at wave 2 . 


\section{RESULTS}

\section{Preliminary Analysis}

Missing data analysis indicated that $0.7 \%$ of data on the used variables were missing. MCAR was tested with the three variables over the three time points and was not violated, $X^{2}(52)=51.83, p=.48$, and dropout due to systematic attrition was therefore presumed not to have occurred (Asendorpf et al., 2014). Nevertheless, it was examined whether respondents would be more likely to drop out of the study related to one or more of the three variables used in the study. Drop out was defined as all respondents that dropped out at wave 2 or 3 . Respondents who completed the survey at wave 1 and 3 , but not at wave two were considered to have stayed on. The effect sizes of the systematic attrition analysis indicated that respondents with lower means for work engagement had a slightly higher chance of dropping out of the study at later waves $(d=.14)$. Following the recommendations in Asendorpf et al. (2014) when MCAR is not violated, it was decided not to correct the data by multiple imputation.

The means, standard deviations, and intercorrelations are depicted in Table 4.

\section{Structural Model}

The variables purpose, autonomous motivation, and work engagement were specified in a cross-lagged panel model (CLPM) design, as depicted in Figure 2 and analyzed with Mplus 8, version 1.5(1). To estimate the model Hamaker et al.'s (2015) method was followed: The procedure was to specify the lagged and crossed effects, to make wave one endogenous, and to allow the residuals at the subsequent waves to be correlated, which resulted in the following model fit information: $X^{2}(8)=9.37, p=.31, \mathrm{RMSEA}=.065$, $90 \% \mathrm{Cl}[.00 .20], \mathrm{CFI}=.985, \mathrm{SRMR}=.047$. 


\section{Table 4}

The Means (M), Standard Deviations (SD,) and Intercorrelations ( $r$ )

\begin{tabular}{|c|c|c|c|c|c|c|c|c|c|c|c|}
\hline & \multirow[b]{2}{*}{$M$} & \multirow[b]{2}{*}{$S D$} & \multicolumn{3}{|c|}{ Purpose } & \multicolumn{3}{|c|}{$\begin{array}{c}\text { Autonomous } \\
\text { Motivation }\end{array}$} & \multicolumn{3}{|c|}{ Work Engagement } \\
\hline & & & $\mathrm{T}^{\mathrm{a}}$ & $\mathrm{T} 2$ & T3 & $\mathrm{T} 1$ & $\mathrm{~T} 2$ & T3 & $\mathrm{T} 1$ & $\mathrm{~T} 2$ & T3 \\
\hline \multicolumn{12}{|c|}{ Purpose } \\
\hline $\mathrm{T} 1^{\mathrm{a}}$ & 3.61 & 0.52 & 1 & & & & & & & & \\
\hline $\mathrm{T} 2$ & 3.50 & 0.53 & $.51^{* * *}$ & 1 & & & & & & & \\
\hline T3 & 3.51 & 0.59 & $.49^{* * *}$ & $40^{* *}$ & 1 & & & & & & \\
\hline
\end{tabular}

\section{Autonomous Motivation}

$\begin{array}{llllllccl}\text { T1 } & 3.76 & 0.59 & .37^{* *} & .39^{* *} & .05 & 1 & & \\ \text { T2 } & 3.69 & 0.74 & .14 & .27^{* *} & .14 & .60^{* *} & 1 & \\ \text { T3 } & 3.54 & 0.71 & .23 & .17 & .25 & .30^{*} & .32^{*} & 1\end{array}$

Work Engagement

\begin{tabular}{llllllllllll} 
T1 & 4.90 & 0.88 & $.32^{*}$ & $.28^{*}$ & .22 & $.54^{* * *}$ & $.30^{*}$ & $.27^{*}$ & 1 & & \\
T2 & 4.79 & 1.04 & .09 & .23 & .16 & $.47^{* *}$ & $.64^{* *}$ & $.28^{*}$ & $.40^{* *}$ & 1 & \\
T3 & 4.60 & 0.93 & .93 & .25 & $.43^{* *}$ & .23 & $.27^{*}$ & $.66^{* *}$ & $.37^{* *}$ & $.45^{* *}$ & 1 \\
\hline
\end{tabular}

Note. ${ }^{a}$ T1 - T3 = Timepoints 1, 2, 3: Significance (two-tailed): ${ }^{*} p<.05,{ }^{\star *} p<.01,{ }^{* \star *} p<.001$

\section{Figure 4}

The Crossed and Lagged Panel Model

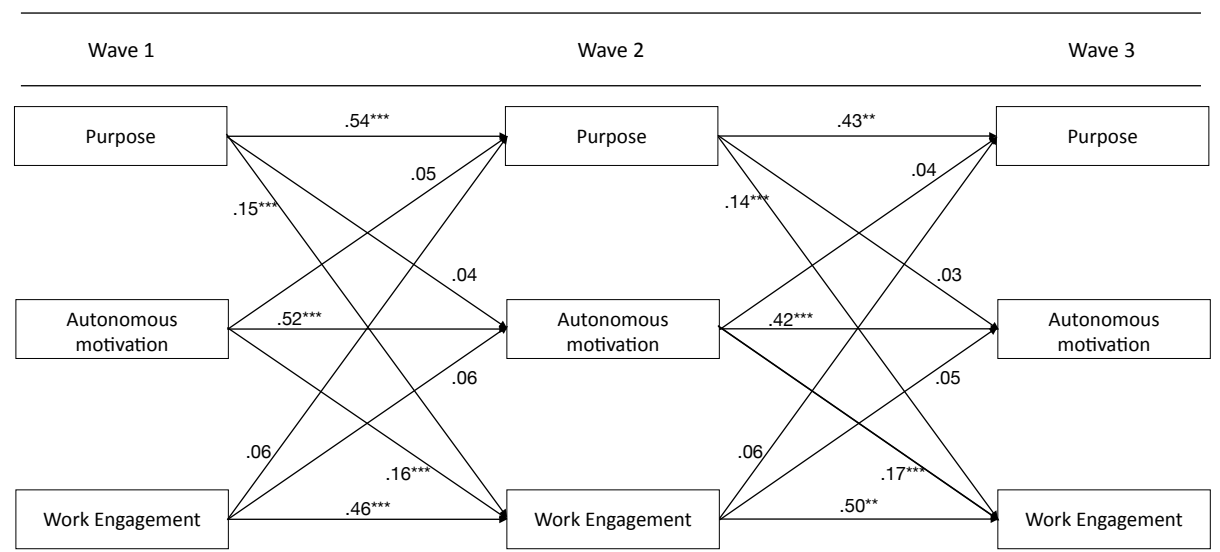

Note. The crossed paths indicate directionality from purpose to engagement and from motivation to engagement. 


\section{Hypothesis Testing}

Hypothesis 4 predicted a specific directionality from purpose to autonomous motivation and engagement and, hence, rule out the alternative direction from motivation or engagement to purpose. The stability of the means across time was checked through constraining the means for purpose at wave 1. A regular cross-lagged panel model returns the means at wave one and the intercepts for the subsequent waves, assuming the means to be constant over time by ignoring them and fitting the model to covariances only (McArdle \& Nesselroade, 2014). The analysis indicated that the means were not constant, for which reason it was decided to estimate the model based on grand centered means (Hamaker et al., 2015). The data partly supported Hypothesis 4: The results (see Figure 4) indicated significant crossed relationships from purpose to engagement, Wave 1-2: $\beta=.15, p<.001$; Wave 2-3: $\beta=.14, p<.001$ and from motivation to engagement, Wave 1-2: $\beta=.16, p<.001$; Wave 2-3: $\beta=.17, p<.001$. For both crossed relationships, only the directions from purpose to engagement and motivation to engagement were significant. Between purpose and motivation no crossed effects were found. These results signal a difference with the results of study 1 , where the association between purpose and autonomous motivation was significant.

\section{DISCUSSION}

Despite being frequently stated in popular media, the beneficial impact of a corporate purpose on employee motivation and engagement hardly receives attention in the current literature. In this study, we examined these relationships across two studies, using a cross-sectional and longitudinal design. In the first study, we found a positive cross-sectional association between purpose and autonomous motivation (Hypothesis 1a) and between purpose and engagement (Hypothesis 2). The structural model explained $56.7 \%$ of the variance in engagement with autonomous motivation as a mediator (Hypothesis 3a). Furthermore, purpose did associate negatively with amotivation (Hypothesis $1 \mathrm{~b}$ ), but, contrary to what we expected, not with controlled motivation (Hypothesis 1c). Nor did amotivation or controlled motivation mediate the relationship between purpose and engagement (Hypotheses 3b-c).

The subsequent longitudinal study indicated a specific directionality in the relationship between purpose and engagement and between motivation and engagement. Purpose predicted subsequent employee engagement rather than the other way around (Hypothesis 4). The results highlight that employees who report being inspired by their organization's higher purpose assert they are positively contributing to its realization. They also state they are striving to make the world a 
better place, and are more engaged than others for whom the corporate purpose is less inspirational. The directionality supports the widespread assumption that a corporate purpose leads to engagement. Thus, a higher corporate purpose can be considered as an antecedent to work engagement, just as, for example, leadership (Carasco-Saul et al., 2015) and work climate (Bakker et al., 2007). Contrary to what we expected, and despite the positive and significant regression coefficients in the cross-sectional study, the longitudinal study did not corroborate the effect from purpose to autonomous motivation.

Organizations need engaged workers (Bakker \& Schaufeli, 2008). Macey and Schneider (2008) maintain that work engagement constitutes a key to competitive advantage. Engagement also issues in the debate on the future of work, which is driven by rapid technological advancements such as artificial intelligence and big data (Arntz et al., 2020) and a growing interest in soft skills (Casillas et al., 2019). Still, work engagement remains a concern considering its current low levels (Gallup, 2017). The future of work debate occurs amidst growing political and economic complexities, fears over increasing inequalities, and unequal distribution of opportunities for learning and growth (cf. ILO, Global Commission on the Purpose of Work, 2019; Jacobs \& Mazzucato, 2016). The formulation of a broader corporate purpose such as intimated in the press release of the Business Round Table of August 2019 (BRT, 2019) and Fink's letter to CEOs (Fink, 2019), might point to increasing awareness within corporations about their pivotal role in society (Husted, 2016). If this awareness translates into behaviors exemplifying the larger corporate purpose as described in the press announcement, then perhaps, after all, business can be a force for good (Polman, 2016).

The present study contributes to our knowledge of the impact of a broader corporate purpose on motivation and engagement. It has relevance considering the cultural beliefs about the centrality of work. A well-defined business objective taps into the deeply embedded cultural ideal of self-determination and authenticity (Taylor, 1991). Self-actualization through work has become an aspect of the modern sense of self-identity (Ciulla, 2000). Contributing to serve a greater good supports eudaimonic well-being and nurtures the experience of authenticity (Ilies et al. 2005; Martela \& Pessi, 2018).

The present study also adds to the leadership domain, as it expands our knowledge about the underlying process between a purpose as an aspect of good leadership and subsequent engagement (Inceoglu et al., 2018). Motivation, particularly autonomous motivation, explained most of the variance in work engagement in 
the cross-sectional study. Quite similar to the explanatory value of basic need satisfaction found in other studies into leadership and work engagement (e.g., Kovjanic et al., 2012; Rahmadani et al., 2019).

We did not find significant directionality in the relationship between purpose and motivation over time, but we maintain that studying the underlying process between leadership and engagement is very relevant. Within SDT, the interplay between motivation and purpose is part of the dialectical dynamic between a person's sense of self and their social context. Perception-of-purpose and self-identity are constructs experienced at the personal level, but by their very nature remain dynamic and are articulated in interaction with one's cultural environment and social context. Taylor $(1991,2007)$ describes this dynamic between the individual's sense of self and one's cultural environment as dialogical or conversational. Other scholars have comparable ways of emphasizing the relational, conversational dynamic to explain the ontology of social and psychological phenomena (e.g., (Maturana \& Varela, 1992; Winch, 1988).

We suggest reaching beyond the corporate purpose itself, emphasizing the conversational essence of purpose and the importance of dialogue between different stakeholders to make a purpose come to life (Bekke, 2006; Gartenberg et al., 2016). A corporate objective may play a role in mobilizing employees for a particular cause, and-as long as it aligns with the persons' sense of self-it may bolster their self-identity and fuel autonomous motivation (Martela \& Pessi, 2018). Hence, a corporate purpose may emerge as an essential element in attracting, selecting, and retaining employees who already have high levels of autonomous motivation and, consequently, find their autonomous motivation further enhanced through that specific purpose (Delaney \& Royal, 2017).

The study also adds to leadership theory and responds to the current lack of research into corporate purpose. Finally, considering purpose as an aspect of good leadership (Shuck \& Rose, 2013), the study contributes to the debate on the narrow preoccupation of organizational leadership with economic performance and its stress on increasing rationalization of business processes and efficiency at the expense of a normative, moral and ethical narrative (Freeman et al., 2018).

\section{Limitations and Suggestions for Future Research}

The present study has some limitations. The results are based on a convenience sample from one multinational for-profit organization in a cross-sectional self-report survey. The subsequent longitudinal study had a small sample size. Another limitation is the absence of comparable studies on the effects of corporate purpose, so there was no reference 
material of other organizations to build on, limiting the potential for generalizations on the obtained study outcomes. To counter the limitations of the cross-sectional data, we followed the suggestions of Spector (2019). The subsequent CLPM analysis was conducted with grand centered means to correct the intermediate changes in the means (Hamaker et al., 2015).

A few suggestions for future research spring forward evaluating the present study and its limitations. First, it would be interesting to learn about the effects of comparable purposes of other organizations. Future research could also widen the scope and study the impact of different types of objectives. For instance, (1) a higher corporate purpose that stresses people, planet, and profit, and (2) a shareholder value-oriented objective with centrality for profit maximization. Parmar et al. (2017) compared the impact of an inspiring stakeholderoriented mission with a shareholder- and profit-oriented goal on the mean scores for autonomy, competence, and relatedness. The authors found higher means for purpose over profit. Wewould expect such a typology to identify comparable associations between purpose, motivation, and engagement. Future studies could expand on the present outcomes and study the effects of a corporate purpose on other well-known variables such as turnover intentions, job satisfaction, and organizational citizenship behaviors.

The effects of a corporate purpose on meaning in life are of specific interest. Human beings yearn for meaning in their lives (Wong, 2012). Work has become a place in life where people look for meaning and self-realization (Ciulla, 2000; Steger et al., 2012), but few people find true meaning through work (Mackey \& Sisodia, 2014). As mentioned earlier in this paper, we found no studies into the specific effects of corporate purpose other than the work of Parmar et al. (2017). In contrast, there are many studies into meaningfulness and work as a source for meaning in life (e.g., Bailey et al., 2017; Di Fabio \& Blustein, 2016; Lysova et al., 2019; Yeoman et al., 2019). Some studies mention "broader" purpose (Martela \& Pessi, 2018) as an antecedent to meaningfulness, but do not specifically refer to a corporate purpose.

Fourth, it would add to the knowledge on the interplay between purpose, motivation, and engagement to add qualitative studies based on interviews or focus groups as well as various longitudinal studies, preferably in an RCT setting. Presumably, engaging employees and leaders in a generative dialogue around purpose and meaning will contribute to motivation and engagement. Lastly, we expect the associations of purpose, motivation, and engagement to differ between generational cohorts, considering the different work preferences and values younger generations bring to the workplace (Eversole et al., 2012; A. Rodriguez \& Rodriquez, 2015; Lee \& Edmondson, 2017). 


\section{Practical Implications}

From a more practical point, the study invites corporate leaders to rethink their organizations' purpose beyond economic performance and revisit the significance of leadership for meaning-making through a broader objective, which used to be worthy of intellectual inquiry (Podolny et al., 2004). Even more so, because the underutilization of purpose as an instrument to sustainably motivate employees and drive work engagement (Keller, 2015) coincides with the crisis in work engagement (Mann \& Harter, 2016) and sustainable motivation. Defining the organization's objectives within a broader stakeholder perspective (Freeman, 2004) adds to employee engagement and brings organizational and performance benefits (Schneider et al., 2018). Additionally, a broader purpose may play a role in attracting and retaining talented workers (Delaney \& Royal, 2017). It may appeal to younger generations, who are known to bring different work value preferences.

Below, we list some practical suggestions for a broader corporate objective mentioned in this study. It is not an exhaustive list, but rather suggestions that foster autonomous motivation, engagement, and performance and which we consider worth reflecting. The first thing to evaluate is the firms' broader corporate purpose beyond its financial strategy and performance. What larger cause does the organization pursue? Who should benefit? Who (or what) does the firm consider its stakeholders? And how are they involved? What does the firm do to propagate its purpose? Secondly, how are employees involved, and in what way does the firm's purpose put people first? How does the purpose foster employee well-being and engagement, and what instruments are applied to stimulate that? Does the firm have processes and procedures to actively discuss its purpose with employees (and other stakeholders)? Additionally, a useful question to consider is whether and how employees feel inspired by the firm's purpose and what may be needed to reinforce this? For example, by discussing to what extent employees feel they contribute to realizing the firm's purpose through their work? Thirdly, how does communication around the purpose and its integration in current work processes support autonomous motivation? What is missing still? And does the purpose appeal to younger generations, considering that younger generations bring different preferences? Fourth, how does the firm specifically aim to benefit customers through its purpose? Fifth, how are the needs of society understood, and how does the firm's purpose integrate those needs? Lastly, how does the purpose include and embrace ethics? How are ethics integrated into governance and current ways of working? 


\section{Conclusion}

The present study confirmed the widespread assumption that a higher corporate purpose leads to engagement. Whether or not autonomous motivation mediates this relationship is less clear. The cross-sectional study revealed a significant association between purpose and motivation, but the longitudinal study did not confirm its directionality. Autonomously motivated employees may find inspiration and further enhancement in an appealing, broader purpose, still, that purpose per se may not prove an antecedent to motivation. The paper answered the growing interest in the potential beneficial effects of a broader purpose, whereas the specific impact on motivation and engagement had not been studied before.

\section{Footnotes}

${ }^{1}$ For reasons of anonymity the specific purpose of the organization is withheld as well as the name of the organization and any reference that may identify the organization. 




\section{CHAPTER 4}

\section{Engaging Leadership: Enhancing Work Engagement Through Intrinsic Values and Need Satisfaction}

Submitted for publication as: van Tuin, L., Schaufeli, W.B., \& Van den Broeck, A. (2020). Engaging Leadership: Enhancing Work Engagement Through Intrinsic Values and Need Satisfaction. Utrecht University: Department of Social, Health and Organizational Psychology. 

Traditionally, literature on leadership theory and leader development emphasizes the attributes and capacities of the leader (cf. Avolio \& Gardner, 2005; Bass, 1985), showing that leaders' specific behaviors have important implications for employees (Derue et al., 2011). Most research examining the impact of leaders, however, focuses on employee performance as an outcome, leaving the role of leaders in fostering the well-being of their employees underexplored (Inceoglu et al., 2018). Still, employee well-being, for example in terms of work-engagement, is important for employees and employers alike. Fostering employee engagement helps organizations to fulfil the UN sustainable development goals for humanity to "ensure healthy lives and promote well-being for all at all ages" (United Nations [UN], 2019 Goal 3, p. 26) , "promote full and productive employment and decent work for all" (UN, 2019 Goal 8, p. 38) and "support workers to be more entrepreneurial, creative and innovative" (GRI, 2019, Target 8.3, p. 95). Moreover, employees displaying high levels of work engagement show high levels of energy, feel enthusiasm, and feel competent (Bakker \& Demerouti, 2008). As a result, employees feel well (Schaufeli, 2012), display high levels of extra-role behavior (Schaufeli \& Salanova, 2009), and enhanced performance (Mueller, 2019), which in turn contributes to financial performance (Schneider et al., 2018) and growth (Sorensen, 2013) at the organizational level.

The current study aims to expand on the studies examining the associations of leadership and work engagement, answering Inceoglu et al.'s recent call (2018) to explore the process through which leaders may affect employee well-being. Drawing on self-determination theory (Deci \& Ryan, 2000), the central premise of the current study is that leadership has a positive impact on work engagement through how employees perceive the values promoted in the organization. Particularly, our study will examine employees' perceptions of intrinsic values and the subsequent satisfaction of the basic psychological needs for autonomy, competence, and relatedness.

One of the tenets of self-determination theory (SDT) is that people-but also social contexts-may stress different values. While some value aspirations contribute positively to a person's well-being, others are detrimental (Ryan et al.,1996). Intrinsic values, such as contribution to the community and self-development, generally contribute to a person's motivation, perseverance, and psychological well-being (Deci \& Ryan, 2000). Extrinsic values and a materialistic orientation, such as striving for financial success, power, and status mostly impact motivation and well-being negatively (Dittmar et al., 2014). The perception of intrinsic, as opposed to extrinsic values within the organisational context have been shown to foster employability (Van den Broeck et al., 2014). Intrinsic values were also found to associate positively with work engagement at team level helping team members to satisfy their basic 
psychological needs for autonomy, competence and relatedness (Schreurs et al., 2014). Despite the importance of values in the work context, the antecedents of these intrinsic value perceptions remain largely unknown. We argue that engaging leadership may foster such intrinsic values.

Theoretically, studying leadership as an antecedent of the perception of organizational values adds to the literature on leadership and values, which is still scarce (Yukl, 2012). Specifically, our study adds to the leadership literature and the emerging literature on engaging leadership in particular: While some studies provided preliminary evidence for the potential of (engaging) leaders to increase employee work engagement (Schaufeli, 2015), studies explaining the pathway through which this occurs remain limited (Inceoglu et al., 2018; Rahmadani, 2019). The current study aims to show how this underlying effect might occur. Moreover, we add to the literature on SDT, by unraveling how perceptions of intrinsic and extrinsic contextual values may develop, which then impact employee well-being positively (Van den Broeck et al., 2014). From a methodological point of view, the adoption of a two-study approach allows us to replicate our results across samples in different business domains and the use of a longitudinal design in the second study allows to test for the directionality between engaging leadership and value orientations. On a practical note, our study provides useful guidance for day-to-day leadership, such as the importance of regularly entering into dialogue with employees on their value perceptions and aspirations to facilitate the integration of individual value preferences with organizational values (cf. Likert, 1967; Rigby \& Ryan, 2018).

\section{Engaging Leadership}

The construct of engaging leadership (Schaufeli, 2015) draws on the basic psychological needs as defined in self-determination theory (Deci \& Ryan, 2000). According to self-determination theory, all people have three basic or essential needs that must be satisfied for people to grow, develop and feel well: the need for autonomy (i.e., volitional functioning), competence (i.e., being effective), and relatedness (i.e., being truly connected with others). The satisfaction of these needs leads to a range of positive outcomes in terms of performance and well-being (Van den Broeck et al., 2016). In focussing on how leaders may support these needs, engaging leadership is the first leadership concept that explicitly is based on a theory of human motivation and serves a central interest in human well-being. Engaging leadership tags along on the yet emerging trend towards human-centered (Global Commission on the Purpose of Work [ILO], 2019) or person-centred leadership approaches (van der Mark, 2019). Individual human motivation, enhancement of personal well-being through basic psychological needs satisfaction, and values are a central concern in engaging leadership. 
With its rooting in self-determination theory, engaging leadership answers a concern about the limited application of social psychological theories to describe and clarify the processes underlying leadership (Bormann \& Rowold, 2018). Van Knippenberg and Sitkin (2013) raised this concern about transformational leadership, but it also extends to other constructs such as authentic- (Avolio \& Gardner, 2005) or ethical leadership (Brown \& Treviño, 2006). The lack of a theoretical rationale leads to item-overlap and redundancy (Derue et al., 2011). Many leadership theories tend to distinguish the same or comparable leadership behaviors but put different labels on them (Yukl et al., 2016). Furthermore, other constructs, such as, for example, authenticin addition to transformational leadership, do not add additional variance to the latter (Hoch et al., 2016). Hence, it does not increment the explanatory value. Borman and Rowold (2018) suggest leadership constructs, such as transformational, authentic, or ethical leadership, can be described more parsimoniously with self-determination theory as the underlying mechanism. Engaging leadership explicitly bases itself on self-determination theory (Schaufeli, 2015). Nevertheless, item overlap with other measures (e.g., Empowering leadership, Amundsen \& Martinsen, 2015) is still likely to occur (Shaffer et al., 2016).

The construct of engaging leadership distinguishes three leadership behaviors: Empowering, Strengthening, and Connecting (Schaufeli, 2015) that aim to align with basic psychological needs theory. Empowering associates with autonomy satisfaction and emphasizes the need to create space for employees to experience freedom and choice in how to engage in their work and with the organization. Through empowering and autonomy support, leaders recognize the individual contributions of team members which induces positive work behaviors (Slemp et al., 2018) Engaging leaders actively involve employees in strategic decision-making and promote self-regulation and autonomy, without losing sight of the relevance of a context and structure that allows employees to feel safe and free (Edmondson \& Lei, 2014).

Strengthening associates with the need for competence. Through strengthening leaders support employees to self-develop and grow and optimally deploy their talents within the work environment (Deci et al. 2017). Building on strengths is preferred to correcting weaknesses (Rath \& Conchie, 2008). Strengthening also recognizes the importance of making a difference and the wish to contribute to something beyond one's immediate self-interest (Martela \& Pessi, 2018). Through strengthening engaging leaders support employees to develop their skill-levels, to grow professionally and facilitate the joy of being good at something (Gagné \& Deci, 2005; Pink, 2009). Engaging leaders acknowledge the importance of giving frequent feedback, particularly positive feedback, through which the need for competence is satisfied (Deci \& Ryan, 2000). 
Connecting aims to satisfy employees' basic need for relatedness and promotes interpersonal relations, teamwork, team spirit, and facilitates collaboration between team members and across functions. By connecting their team members engaging leaders acknowledge the importance of meaningful, interpersonal, intimate relationships (Huyghebaert et al., 2018). Connecting supervisor behavior typically promotes the psychological safety employees need to speak up, voice concerns, and show themselves without any fear of negative consequences (May et al.,2010). Engaging leaders create an atmosphere of belongingness which supports employees in their development on both emotional and cognitive levels (Baumeister \& Leary, 1995).

Together, these three aspects of engaging leadership are expected to relate to optimal employee motivation and work engagement. A previous study on engaging leadership indicated an indirect effect on burnout and engagement via job demands and -resources, as well as a direct impact on employability, performance, and commitment (Schaufeli, 2015). Later studies showed a positive association of engaging leadership with work engagement through the satisfaction of the basic psychological needs (Rahmadani et al., 2019) as well as positive effects on employee learning and innovative job behavior (Rahmadani et al., 2020), team job crafting (Mäkikangas et al., 2017), autonomy satisfaction and social support (Nikolova et al., 2019). Additionally, a recent leadership intervention study showed that training managers in engaging leadership behaviors led to improved business results, lower absenteeism, and wellbeing (van Tuin et al., 2020).

In the current study we expect that engaging leadership relates positively with work engagement through the fulfillment of basic needs. In addition, the current study aims to expand on previous results by further examining the process through which engaging leadership increases employee work engagement. Building on SDT, we argue that leadership will influence how employees perceive the values of the organization and that these value perceptions, in their turn, affect need satisfaction and subsequent work engagement.

\section{Value Perceptions: Intrinsic over Extrinsic}

Values are guiding principles in our lives (Sagiv \& Schwartz, 2000). The values of an organization and how these are perceived by employees have vast implications. For instance, research on value systems found support for the claim that values representing human growth needs such as self-direction, are positively associated with well-being (Sagiv \& Schwartz, 2000). In self-determination theory such values are described as intrinsic and cluster around the importance of self-acceptance, affiliation, 
and community-feeling (Kasser \& Ryan, 1993). Self-acceptance refers to the desire for personal development, growth, and self-direction; Affiliation means to capture the importance of meaningful and intimate personal relationships with family, friends, and colleagues; and Community-Feeling summarizes the desire to contribute to make the world a better place (Kasser \& Ryan, 1993). SDT proposes that such intrinsic values are inherently valuable as they are closely associated with the individual's basic need satisfaction (Deci \& Ryan, 2000).

In line with SDT, at the individual level, the benefits of intrinsic values comprise greater life-satisfaction (Sheldon \& Krieger, 2014) and less depressive symptoms (Ling et al., 2016). Similar beneficial effects prevail when people see intrinsic rather than extrinsic values being promoted in their environment (Rigby \& Ryan, 2018). Intrinsic values at the team level were found to positively associate with the level of work engagement of the individual team members via the satisfaction of basic psychological needs (Schreurs et al., 2014). Also, perceived organizational support of intrinsic values facilitated employees to experience the organization as supportive and committed to their further development, and induced lateral and upward employability, stimulating retention and commitment (Van den Broeck et al., 2014). Even at the country level, the perceived importance attached to intrinsic and extrinsic values seems to have an impact: in countries where intrinsic values abound, youngsters are happier, healthier, and more satisfied with life (Van den Broeck et al., 2019). Beyond the impact of value orientations on well-being, Vansteenkiste et al. (2007) found that basic need satisfaction mediated the relation between value orientations and job outcomes. Hence, it is to be expected that the perception of value orientations of the organization will also impact employees' well-being through the satisfaction of basic psychological needs.

In contrast, extrinsic values focus on the achievement of financial success, power, and status (Deci \& Ryan, 2000). Financial Success refers to the aspiration to achieve wealth and material success. (Kasser \& Ryan, 1993); Power refers to attaining a higher hierarchical position and an appealing image (Vansteenkiste et al., 2007); Status refers to obtaining social recognition (Kasser \& Ryan, 1996). Extrinsic values are contingent upon the approval of others and lead people away from those activities that are inherently need satisfying. When extrinsic aspirations outweigh intrinsic orientations, individuals report lower levels of personal and physical well-being, such as higher emotional exhaustion, short-lived satisfaction after goal-attainment, increased turnover intentions (Vansteenkiste et al., 2007), and adverse work motivation (Kasser, 2016).

In line with the propositions of SDT and the empirical literature reviewed above, we propose the following hypothesis: 
Hypothesis 1: (a) Perceived intrinsic value orientations are positively associated with needs satisfaction and work engagement, whereas (b) extrinsic value orientations are negatively related with needs satisfaction and work engagement.

We argue that employees' perception of the values of the organization is likely to be affected by how leadership is being perceived (van Knippenberg, 2018). Burns (1978) maintains that good leaders forge relationships based on mutual needs, aspirations and values; Good leaders help employees find meaning and meaningfulness in their work (Martela \& Pessi, 2018) and, through work itself, employees may contribute to a broader purpose (Ilies et al., 2005; Martela, 2017; Ryan et al., 2008). Furthermore, good leaders support employees' desires for self-development and growth (Amabile \& Kramer, 2012) and those leaders create the necessary psychological safety to speak out freely without repercussions (May et al., 2010). Good leadership also acknowledges that people are more generous and ethically inclined than economic theory has taught for decades (Bowles, 2016).

Studies into value perceptions in other life domains also confirmed that environmental factors, such as support through parent's goal orientations (Duriez et al., 2007), or goal framing in educational settings (Vansteenkiste et al., 2008) influence value perceptions (Van den Broeck et al., 2019). Furthermore, in value orientations research, psychological needs are found to explain the effects of values on outcomes (e.g., Niemiec \& Spence, 2016; Vansteenkiste et al., 2007; Schreurs et al., 2014). Hence, in the present study it is presumed that

Hypothesis 2: Engaging leadership is (a) positively related with intrinsic value orientations and (b) negatively associated with extrinsic orientations.

Given the aforementioned hypotheses, we expect also the following:

Hypothesis 3: The relationship between engaging leadership and work engagement is Mediated by intrinsic value orientations and need satisfaction.

These three hypotheses are tested in two studies. Study $1(N=436)$ was designed as a cross-sectional self-report study. Beyond testing the hypotheses, the aim of this first study also was to specify a robust, parsimonious structural model identifying a path from leadership via value orientations and needs satisfaction to work engagement (see Figure 1). For the second study ( $N=69$ ), we adopted a longitudinal design using measurements over three time-points (see Figure 4 ) testing the crossed-lagged relations of engaging leadership with value orientations, need satisfaction and engagement and examining directionality (see Figure 5). 
Figure 1

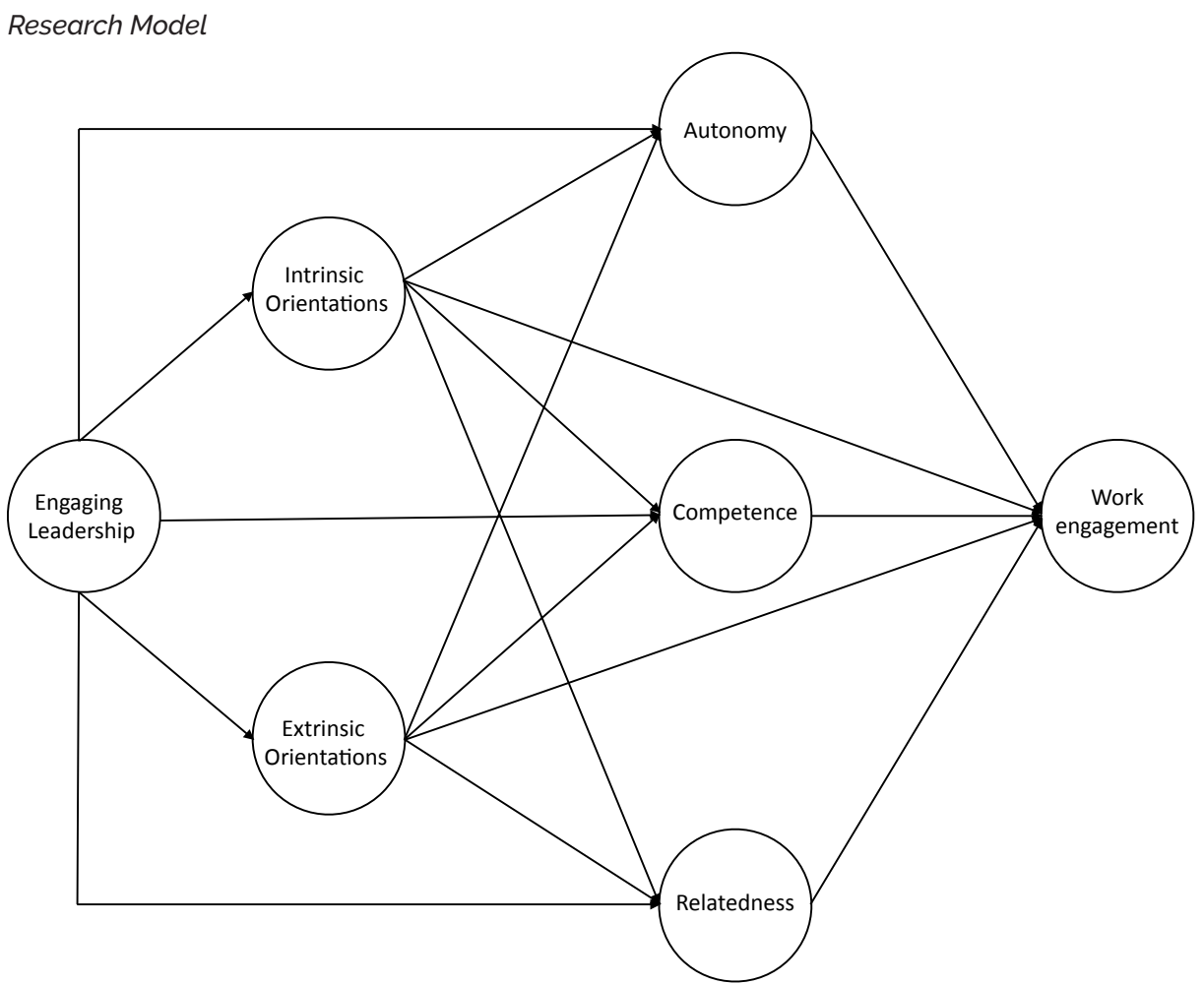

Note. The direct relationship between engaging leadership and work engagement is not portrayed.

\section{STUDY 1 METHOD}

\section{Participants and Procedure}

Data were gathered from employees of two separate back-office departments (i.e., supply chain management and enterprise information management) of an international manufacturing organization in health systems in Europe. Participants were notified through their direct supervisors they would receive an invitation from their department heads to fill out an online questionnaire on how they experienced leadership and its effect on motivation. Invitations were sent to 159 and 277 employees of the two departments, respectively, (436 in total) of which 123 and 127 surveys were completed, respectively, resulting in an overall response rate of $57 \%$. A complete measurement 
invariance test was conducted to examine if the data of the two back-office departments could be pooled following the procedure by Van de Schoot et al. (2012). The $p$ values for the compared models (configural, metric, scalar) were all $>.05$, indicating that the two populations did not significantly differ on the survey items and confirming that the data could be pooled. In total, $60 \%$ of the respondents were male and $40 \%$ were female. The average age was 41.93 years $(S D=10.46) ; 61 \%$ of all respondents worked four years or less in their current jobs and $17 \%$ worked over 10 years in their current jobs. Most employees ( $81 \%)$ were employed full- time, of which $4 \%$ had a temporary contract, and $19 \%$ worked part-time ( $<32 \mathrm{hr}$ per week) of which employees $7 \%$ had a temporary contract.

\section{Instruments}

Engaging leadership was measured with the 9-Item Engaging Leadership scale as developed by Schaufeli (2015). It includes the aspects of Strengthening (e.g., "At work, my supervisor encourages team members to develop their talents as much as possible."), Connecting (e.g., "At work, my supervisor promotes team spirit.") and Empowering (e.g., "At work, my supervisor gives team members enough freedom and responsibility to complete their tasks."), which were measured as one common factor. Responses were measured on a 5-point Likert scale, ranging from 1 (completely disagree) to 5 (completely agree). Reliability for the applied measures was estimated with composite reliability or congeneric reliability $\left(\rho_{C}\right.$, Cho, 2016), which typically is computed in combination with structural equation modeling (Peterson \& Kim, 2013). Additionally, average variance extracted (AVE) was reported indicating the amount of variance explained by the latent variable relative to measurement error. The reliabilities for engaging leadership were $\rho_{\mathrm{C}}=.93, \mathrm{AVE}=.64$.

Perception of value orientations was measured in terms of intrinsic values and extrinsic values and consisted of four items each, following the structure and wording of value orientations as described by Van den Broeck et al. (2014). Specifically, the introduction to the items was: "Organizations signal various values. To what extent do you agree with the following statements? In the organization where I work it is important ..." The items for intrinsic orientations $\left(\rho_{\mathrm{C}}=.87, \mathrm{AVE}=.63\right.$ ) covered the themes of care, contribution, challenge and growth (e.g., "that colleagues care about each other and support each other?") and for extrinsic orientations $\left(\rho_{c}=.89, A V E=.74\right)$ the themes were image, power, financial success and influence (e.g., "to have a prestigious position.").

Basic psychological needs satisfaction was measured with the scale as developed and validated by Sheldon and Hilpert (2012). The scale comprises 9 needs satisfaction items and measures the needs of autonomy, competence, and relatedness with three items each. An example of an item for autonomy satisfaction $\left(\rho_{C}=.82, A V E=.61\right)$ is: "My 
choices express my true self.". For competence satisfaction ( $\rho_{c}=.84, \mathrm{AVE}=.63$ ) this was: "I do well, even at the hard things."; And example for relatedness satisfaction ( $\rho_{c}=.82$, $\mathrm{AVE}=.61$ ) is: "I feel close and connected with other people who are important to me."

Work engagement was assessed using the 9-item version of the Utrecht Work Engagement Scale (Schaufeli et al., 2006). It measures vigor, dedication, and absorption. Examples of items are "At my work, I feel bursting with energy" (vigor), "I am enthusiastic about my job" (dedication), "I feel happy when I am working intensely" (absorption). Following Schaufeli et al.'s (2006) recommendations one common factor for engagement was used $\left(\rho_{C}=.89\right.$, AVE $\left.=.74\right)$.

\section{RESULTS STUDY 1}

\section{Preliminary Analysis \\ Missing Data and Outliers}

In preparing the dataset for analysis the data was first checked for missing values and outliers following the recommendations by Aguinis et al. (2019). Little's MCAR test (Little \& Rubin, 2002) indicated that MCAR was not violated, $x^{2}(353)=347.85$, $p=.57$. Some outliers were identified, three of which had potential leverage, and were removed from subsequent analyses.

Then, the means, standard deviations, and intercorrelations between the variables were examined (see Table 1). The correlations of engaging leadership with intrinsic value orientations were positive, as were the bivariate correlations with the separate needs, and work engagement. Interestingly, the correlations with extrinsic orientations were mostly weak, although extrinsic orientation correlated significantly with relatedness satisfaction.

\section{Structural Model Evaluation}

The model (Figure 1) comprised engaging leadership, the perceived intrinsic and extrinsic measures, the separate constructs for autonomy, competence, and relatedness, and work engagement and its parameters were estimated through structural equation modelling. The latent variables in the structural model were simultaneously tested with their respective items in a parallel multiple mediation design. The estimator for the mean- and variance adjusted likelihood ratio was set to the MLMV test statistic following MaydueOlivares (2017). To evaluate the model parameters and fit with the data we used a range of fit indices (Kline, 2016). The test of the hypothesized model, considering its complexity, had an acceptable fit: $\mathrm{x}^{2}(333)=407.16, p<.001, \mathrm{x}^{2} / d f=1.22, \mathrm{RMSEA}=.03,90 \% \mathrm{Cl}[.018, .040]$, $\mathrm{CFI}=.94, \mathrm{SRMR}=.07$ and explained $57.4 \%$ of the variance in work engagement. 
Table 1

Means, Standard Deviations, and Intercorrelations

\begin{tabular}{lccccccccc}
\hline & $M$ & $S D$ & EL & INO & EXO & AS & RS & CS & WE \\
\hline EL & 3.89 & 0.74 & 1 & & & & & & \\
INO & 3.77 & 0.74 & $.41^{* \star *}$ & 1 & & & & & \\
EXO & 2.97 & 0.81 & -0.10 & $-.28^{* * *}$ & 1 & & & & \\
AS & 3.66 & 0.67 & $.41^{* * *}$ & $.39^{* * *}$ & -.05 & 1 & & & \\
RS & 3.62 & 0.57 & $.20^{* *}$ & $.24^{* \star *}$ & $-.14^{* *}$ & $.29^{* \star *}$ & 1 & & \\
CS & 3.93 & 0.54 & $.19^{* *}$ & .10 & .02 & $.35^{* \star *}$ & $.23^{* * *}$ & 1 & \\
WE & 4.82 & 0.97 & $.38^{* * *}$ & $.38^{* * *}$ & -.04 & $.56^{* * *}$ & $.20^{* *}$ & $.32^{* * *}$ & 1 \\
\hline
\end{tabular}

Note. $N=247 . p$-values (two-tailed): ${ }^{*}<.05,{ }^{* *}<.01,{ }^{* * *}<.001 ;$ EL, Engaging Leadership; INO, Intrinsic Value Orientations; EXO, Extrinsic Value Orientations; AS, Autonomy Satisfaction; RS, Relatedness Satisfaction; CS, Competence Satisfaction; WE, Work Engagement.

\section{Hypothesis Testing}

Hypothesis 1 stated that (a) perceived intrinsic value orientations are positively associated with needs satisfaction and work engagement, whereas (b) extrinsic value orientations are negatively related with needs satisfaction and work engagement. As shown in Figure 2 intrinsic value orientations related positively with autonomy $(\beta=.39, p<.001)$ and relatedness $(\beta=.33, p<.001)$, whereas the standardize regression coefficients to competence and work engagement were nonsignificant. The path coefficients from extrinsic orientations to the separate need satisfaction constructs were all nonsignificant. Hence, Hypothesis $1 a$ was partly supported by the data but $1 \mathrm{~b}$ was not supported.

Hypothesis 2 predicted that; (a) Engaging leadership is positively related with intrinsic value orientations and (b) negatively associated with extrinsic orientations. The standardized regression coefficient from engaging leadership to intrinsic value orientations (Figure 2 ) was positive and significant $(\beta=.47, p<.001$ ), while the path to extrinsic values was nonsignificant $(\beta=-.11)$. Hypothesis za was supported and Hypothesis $2 \mathrm{~b}$ was only partly supported.

Hypothesis 3 predicted that the relationship between engaging leadership and work engagement is mediated by intrinsic value orientations and need satisfaction. To test this hypothesis, we started from the parallel multiple mediation analysis, which included the two value orientations and the separate basic psychological needs (Figure 2), which specification had reasonable model fit. Then, a few consecutive steps were followed to trim the model to establish a parsimonious, indirect and direct, path from 
engaging leadership to work engagement. It was decided to eliminate free parameters on the basis of theory (Kline, 2016) which resulted in firstly eliminating extrinsic orientations, because value orientations theory predicted that employees prefer intrinsic orientations over extrinsic values (Kasser, 2002). The next, more rigorous, step was to eliminate the paths to and from the constructs of relatedness and competence. The rationale for this step was provided by the theoretical consideration that autonomy satisfaction may precede experienced competence and relatedness (Ryan \& Deci, 2017). This resulted in the following fit information: $x^{2}(129)=150.42, p=.10, x^{2} / d f=1.17$, RMSEA $=.026,90 \% \mathrm{Cl}$ [.000, .042], CFI $=.98, \mathrm{SRMR}=.04$. The lower bound at zero of the RMSEA confidence interval indicates a close fit (Kline, 2016). To illustrate the outcome Figure 3 was drawn, depicting the resulting multiple mediation model (see also Table 2 ), the standardized path coefficients, and the total variance explained $\left(R^{2}=55.4 \%\right)$.

\section{Figure 2}

Measurement Model with Standardized Path Coefficients and Significance

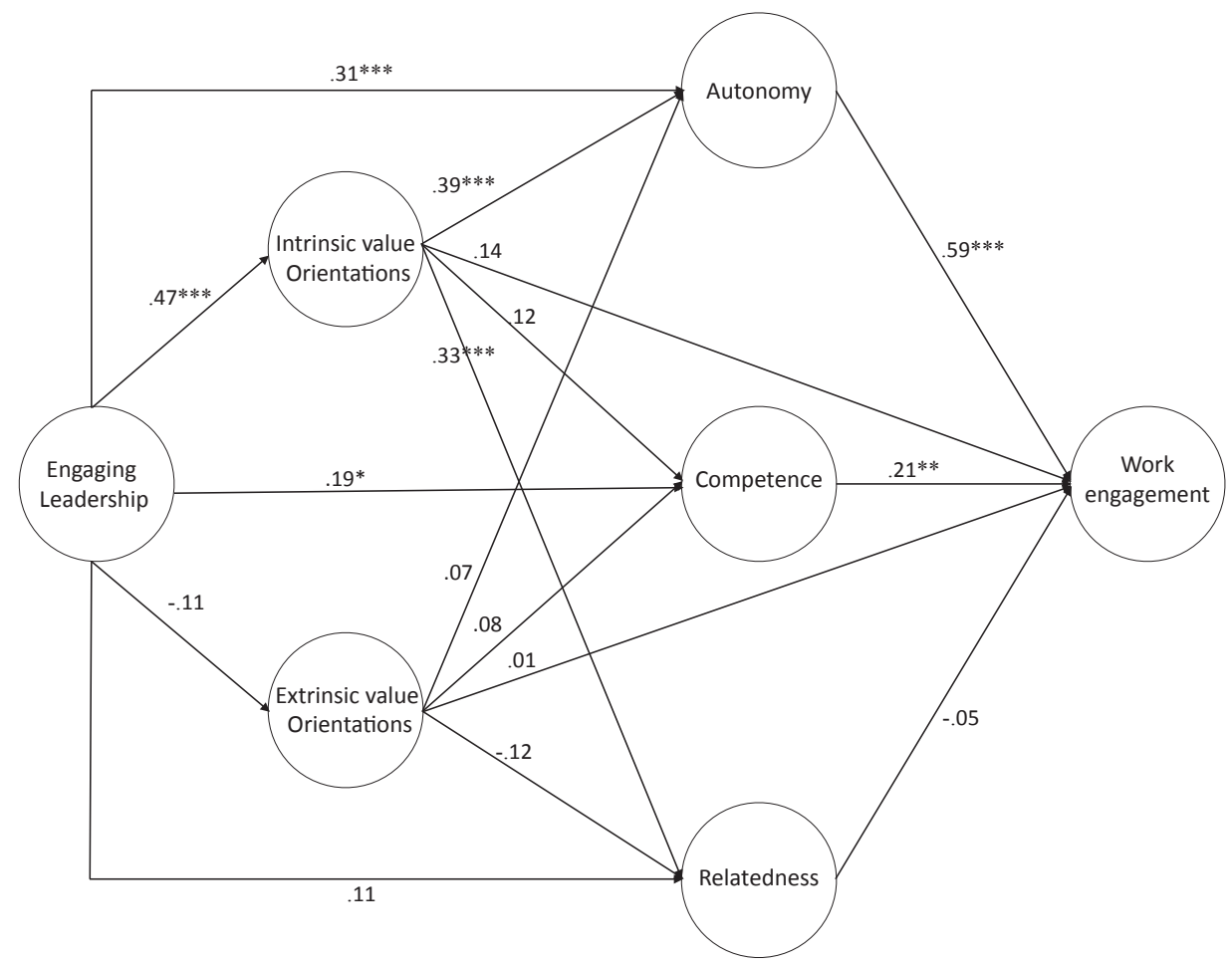

Note. Estimation of the data resulted in the depicted standardized path coefficients. The direct relationship between work engagement and engaging leadership was not significant $(\beta=.06)$ and is not portrayed. Significances are indicated with ${ }^{*}<.05,{ }^{* *}<.01,{ }^{* * *}<.001$. 


\section{Figure 3}

Trimmed and Resulting Model

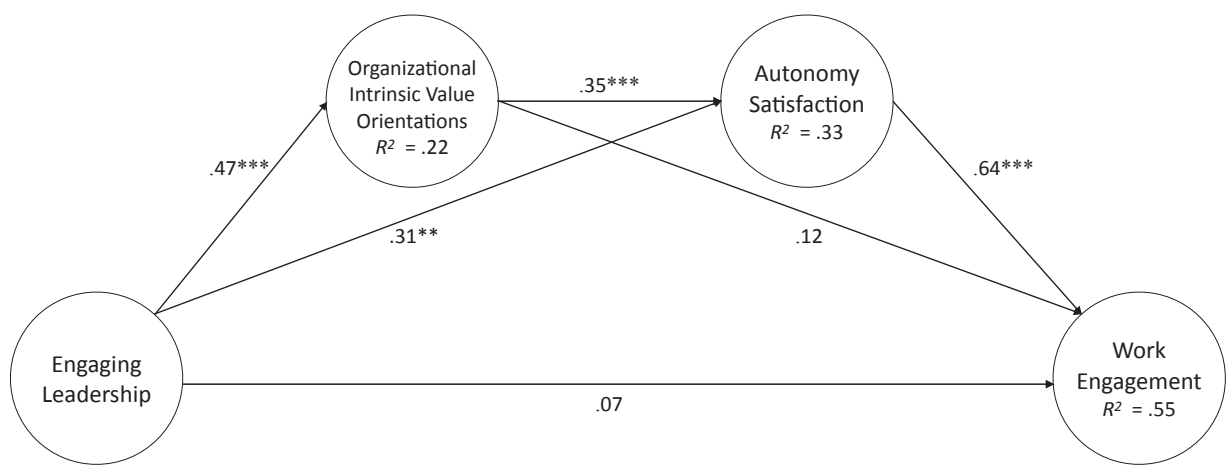

Note. The trimmed model portrays a multiple mediation from engaging leadership to work engagement via perceived intrinsic values and autonomy satisfaction. Both the perceived intrinsic values of the organization and experienced autonomy satisfaction contribute to the variance in work engagement.

\section{Table 2}

Multiple Mediation Analysis for Engaging Leadership to Work Engagement

\begin{tabular}{lccccc}
\hline & & & & \multicolumn{2}{c}{$95 \% \mathrm{Bca} \mathrm{Cl}$} \\
\cline { 5 - 6 } & $\beta$ & S.E. & $p$ & $2.50 \%$ & $97.50 \%$ \\
\hline Total effects & 0.43 & 0.07 & 0.00 & 0.29 & 0.57 \\
Total Indirect effects & 0.36 & 0.07 & 0.00 & 0.23 & 0.53 \\
Direct effect & 0.07 & 0.09 & 0.43 & -0.09 & 0.26 \\
& & & & & \\
Specific indirect effects & & & & & \\
via INO & 0.05 & 0.05 & 0.23 & -0.03 & 0.15 \\
via AS & 0.20 & 0.08 & 0.02 & 0.06 & 0.38 \\
VIA INO, AS & 0.11 & 0.05 & 0.02 & 0.04 & 0.23 \\
\hline
\end{tabular}

Note. 95\% BCa Cl, 95\% Bias Corrected and accelerated Confidence Interval; INO, Perceived Intrinsic Value Orientations of the Organization; AS, Autonomy Satisfaction; $\beta$, Standardized Path Coefficients.

The relationship between engaging leadership and work engagement is mediated by intrinsic value orientations in support of Hypothesis 3 , but from the three basic needs, only autonomy satisfaction mediated the relationship between leadership and engagement. 


\section{STUDY 2}

The aims of study 2 were twofold: to corroborate the model that resulted from the cross-sectional analysis in study 1 (Figure 3) and to test potential directionality from engaging leadership to intrinsic value orientations. It would strengthen the association between leadership and values if the resulting model from study 1 would hold over three time-points, with an independent group of respondents from another organization. The research model, as depicted in Figure 4, was designed to replicate the resulting model of study 1 . Testing the directionality from engaging leadership to intrinsic value orientations aimed to rule out the alternative hypothesis that value perceptions would influence how engaging leadership is perceived, and was tested in a crossed- and lagged panel model (CLPM) design as depicted in Figure 5.

\section{Figure 4}

Research Model Replicating the Outcomes of Study 1

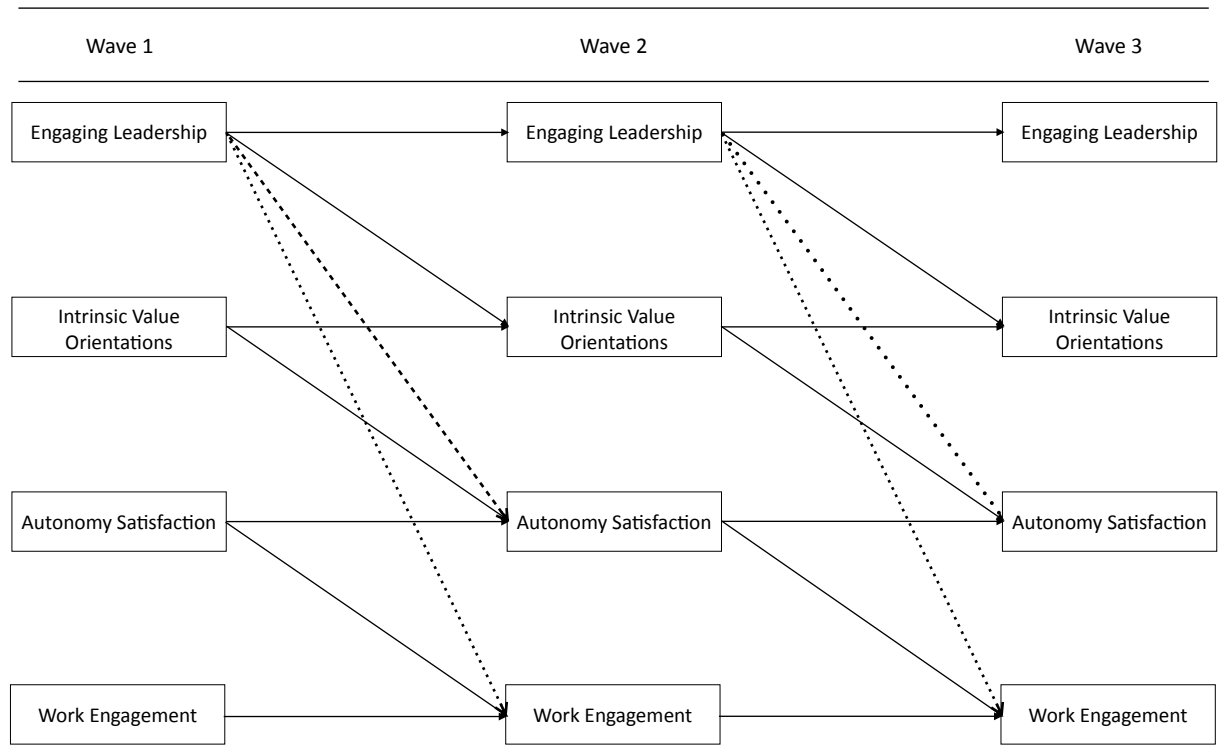

Figure1. Key to the arrows indicating the models tested for comparison of fit with the data

Model 1

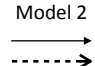

Model 3

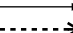$$
\cdots \cdots \rightarrow
$$

Note. Replicating the resulting model from study 1 three models were compared. The straight arrows in the picture represent model 1 . For model 2 the dotted arrow to autonomy satisfaction was added. For model 3 this was the dotted line to work engagement. These three models represent the paths as depicted in figure 3 . 


\section{Figure 5}

The Crossed and Lagged Panel Model to Test Directionality from Engaging Leadership to Intrinsic Value Orientations

Wave 1

Note. Cross-Lagged Panel Model testing directionality from engaging leadership to perceived intrinsic value orientations over three timepoints.

\section{METHOD}

\section{Participants and Procedure}

The participants in study 2 were engineers from the technical function of a European manufacturer in automotive industry. The education level of the engineers was high; $77.8 \%$ had a bachelors-, Masters-degree, or Ph.D. A total of 69 respondents, of which $89 \%$ were male, completed the survey at all three waves. Participants were invited to participate by the department head through email and a short personal introduction by group leads. The average age of respondents was 44 at Wave $1, S D=10.61$. At wave 1, 72 invitations were distributed and at wave 3 in total 75 employees were invited, because the department employed three more engineers. The response rate at wave 1 was $96 \%$, and $92 \%$ at wave 3 , which high completion rates were due to the dedication and engagement of the department head and his associates, who had the outspoken ambition to increase work engagement over time. The department initiated periodic surveys to track progress over time. As a result, three one-year-interval surveys were administered which were accessed and completed online. The survey comprised all measures at each wave.

\section{Instruments}

Engaging leadership, perceived intrinsic value orientations, and work engagement were measured with the same scales as in Study 1. Autonomy satisfaction was measured with four items from the basic need satisfaction scale by Chen et al. (2014). An example of two of the items is "I feel a sense of choice and freedom in the things I 
undertake", and "I feel my choices express who I really am". Reliability for the applied measures was estimated with congeneric reliability (Cho, 2016); Additionally average variance extracted was reported. For all the applied measures over each of the three waves congeneric reliability was $\rho_{c} \geq .79$ and average variance extracted was AVE $\geq .51$.

\section{RESULTS}

\section{Preliminary Analysis}

The model had 19 variables across three waves, 57 in total and overall $2.57 \%$ of the data was incomplete. Little's MCAR test indicated that the data were missing completely at random, $X^{2}(279)=256.58, p=.83$. Two outliers were detected with scores above the norm value of $4 / n$, but it was decided to keep them because leverage was limited.

The data were estimated with longitudinal structural equation modelling (LSEM). The model was specified as a crossed and lagged panel model (CLPM). To support model selection, we used the Akaike information criterion (AIC) and the Bayesian information criterion (Vrieze, 2012). Additionally, the chi-square with the degrees of freedom and significance are reported, together with the normed chi-square, the RMSEA and its 90\% confidence intervals, CFI and SRMR (Kline, 2016).

\section{Analysis}

A known issue with crossed and lagged panel modeling is it does not distinguish between- and within-person variances, which may lead to spurious results if it turns out there were enduring trait-like individual differences over the subsequent waves (McArdle \& Nesselroade, 2014). The random intercept cross-lagged panel model (Hamaker et al., 2015) mitigates this issue by separating the within-person differences from the between-person variances through testing the model with random intercepts. Hence, the first step in the analysis of the three waves was to test whether the withinperson variances were significant. The analysis indicated, however, that the withinperson variances were insignificant $(p>05)$, implying the model could be estimated with the standard CLPM procedure.

Then the three models as depicted in Figure 4 were estimated seperately. First, the crossed and lagged effects were specified, wave 1 was made endogenous, and the residuals at the subsequent waves were allowed to covary. The outcomes indicated that model 1 in Figure 4 fitted the data best: The delta in AIC and BIC between model $1-2$ was $\triangle \mathrm{AIC}=5.30, \Delta \mathrm{BIC}=12 ;$ Model $1-3$ was $\triangle \mathrm{AIC}=6.75, \Delta \mathrm{BIC}=17.92 ;$ Model $2-3$ $\triangle \mathrm{AIC}=-1.45, \Delta \mathrm{BIC}=-5.92 ;$ The fit indices for model 1 indicated $X^{2}(33)=26.24, p=.64, X^{2} /$ 
$d f=.80, \mathrm{RMSEA}=.00,90 \% \mathrm{Cl}[.00, .06], \mathrm{CFI}=1.00, \mathrm{SRMR}=.06$. To illustrate the outcomes of the model comparison Figure 6 was drawn, plotting the outcomes of the present test of the model that resulted from study 1 , where the bolded connectors represent the outcomes of study 1 and suggest a preferred direction of the leadership model. However, to evaluate the directionality between engaging leadership and intrinsic value orientations a crossed and lagged analysis should be conducted, testing both $\left(X_{1} \rightarrow Y_{2}\right)$ and $\left(Y_{1} \rightarrow X_{2}\right)$ over the three waves.

\section{Figure 6}

Plotting Study 2 on the Outcomes of Study 1

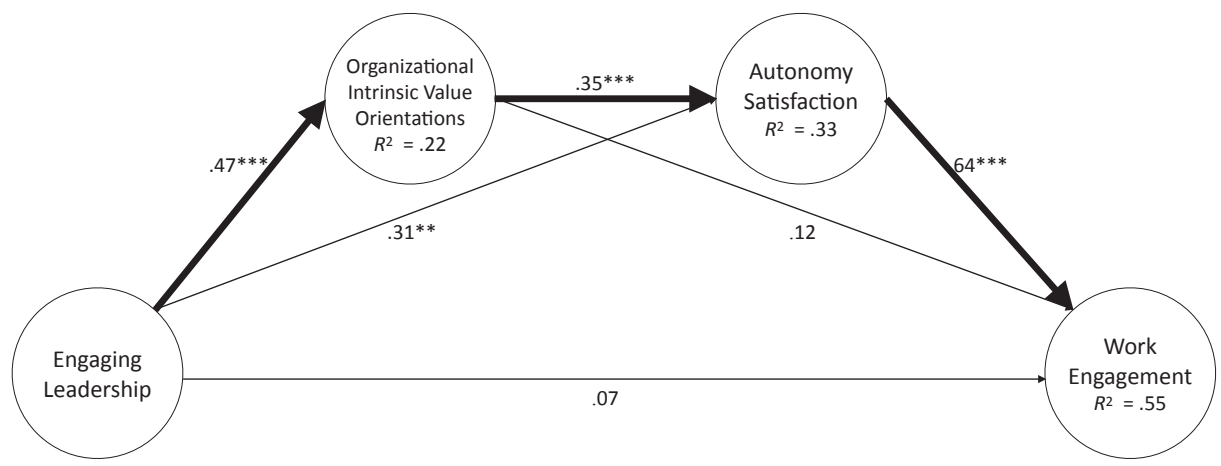

Note. The bolded connectors between the constructs depict model 1 (Figure 4). When plotted on the outcomes of the first study a specific directionality in the model is suggested. The standardized path coefficients depicted and variance explained are those found in study 1.

\section{Testing Directionality}

To estimate directionality the cross-lagged paths from engaging leadership (EL) and intrinsic value orientations (INO) were added to the model as depicted in Figure 5. It was decided to test the stability of the means across time through constraining the means for intrinsic orientations at wave 1. A regular cross-lagged model gives the means at wave 1 and the intercepts for the subsequent waves, assuming the means to be constant over time by ignoring them and fitting the model to covariances only (McArdle \& Nesselroade, 2014). The analysis revealed, however, that the means for intrinsic value orientations were lower at the first wave than at the subsequent waves, which was expected and in line with the outspoken ambition of the department. Next, in order to include the constraints on the means in the CLPM (again following Hamaker et al., 2015), grand mean centred variables were created to estimate the means of the observed variables instead of just the means at wave 1 and intercepts at wave 2 and 3 . The grand mean centred variables were allowed to be correlated at the first 
wave and the residuals were allowed to be correlated at the subsequent waves. The outcomes are shown in Figure 7. Evaluating the significant path coefficients from engaging leadership to intrinsic value orientations $(\beta=.20, p<.05$ and $\beta=.22, p<.05$ ) and the nonsignificant paths from intrinsic value orientations to engaging leadership ( $\beta=-.09$ and $\beta=-.06$ ) confirmed the directionality from engaging leadership to intrinsic value orientations.

\section{Figure 7}

Cross-Lagged Panel Model for Engaging Leadership and Intrinsic Value Orientations

Wave 1

Note. The cross-lagged effects between the grand mean centred variables indicate a directionality from engaging leadership to intrinsic value orientations $\left(\beta=.20^{*}, .22^{*}\right)$ and not vice versa.

\section{DISCUSSION}

The present study examined the associations of engaging leadership with employees' perceptions of the organization as promoting intrinsic or extrinsic values and the subsequent associations with work engagement via need satisfaction. Across two studies using a cross sectional and a longitudinal design, our results show that engaging leadership associates with work engagement via perceived intrinsic organizational values and satisfaction of the need for autonomy (Hypotheses 2a, 3), while engaging leadership did not associate with extrinsic value perceptions (Hypotheses 2b). Furthermore, the CLPM analysis indicated specific directionality from leadership to perceived intrinsic values identifying engaging leadership as an antecedent to employees' intrinsic value perceptions, rather than the other way around. Furthermore, intrinsic value orientations associated positively with needs satisfaction and engagement (Hypothesis 1a). Contrary to what we expected, extrinsic value orientations did not associate negatively with the separate need satisfaction measures (Hypothesis 1b). 
The contribution to knowledge development on positive leadership and the relatively new concept of engaging leadership is threefold. First, we found that engaging leadership can be considered as an antecedent to intrinsic value perceptions, which is relevant because it adds the dynamic of values to this leadership concept and adds to the positive effects that paying attention to values may generate through autonomy satisfaction.

Second, and answering to Inceoglu et al.'s (2018) call, the present study sheds some light on the underlying process that may explain the relationship between engaging leadership and resulting work engagement. We found that need satisfaction, as described in self-determination theory, offers relevant explanatory power in explaining the effects of engaging leadership. The structural model that we tested (from engaging leadership to work engagement via intrinsic value perceptions and autonomy satisfaction) explained $55.4 \%$ of the variance in engagement-when all three basic needs were modeled, even $57.4 \%$. Nevertheless, the only identified mediational effect was for satisfaction of the need for autonomy. Although this does not deny the relevance of competence and relatedness, it highlights the specific autonomy satisfaction may play in the system of needs (Van den Broeck et al., 2016; Ryan \& Deci, 2017). These results expand previous studies' findings that basic psychological needs mediate the relations between transformational leadership (Bass, 1985) and work engagement (e.g., Kovjanic et al., 2012; Hetland et al., 2015) and between engaging leadership (Schaufeli, 2015) and work engagement (Rahmadani et al., 2019).

The third contribution of this study is the relationship between leadership and intrinsic values, of which Yukl (2012) reported that it had been scarcely studied. Considering the directionality of the association between leadership and values, and the subsequent effects on need satisfaction and engagement, we argue that values and value perceptions are essential ingredients for good leadership and are worthy of more attention in leadership studies.

In general, the results of this study suggest that engaging leaders contribute to employees' need satisfaction and work engagement through paying active and caring attention to intrinsic values. Good leadership and the intrinsic values of care, contribution, challenge and growth go hand in hand, which implicitly hints to moral aspects of good leadership. Leadership concepts, such as transformational leadership (Bass, 1985), authentic leadership (Avolio \& Gardner, 2005), and ethical leadership (Kalshoven et al., 2011) all stress the need for high moral and ethical behavior of leaders in organizations (cf. Gardner et al., 2005). Various researchers have identified specific leadership characteristics contributing to positive outcomes, e.g., authenticity and self- 
awareness in authentic leadership (Walumbwa et al., 2008), or integrity and genuine care in ethical leadership (Brown \& Treviño, 2006). However, despite the positive impact of such attributes on the motivation and performance of employees (Gardner \& Schermerhorn, 2004), and despite all the good great leaders accomplish, leadership theory remains leader-centered and performance orientated; It is about the attributes and nobility of the leader and the positive outcomes leadership may produce.

In contrast, the current study reveals how employees perceive the organization's values and, without aiming to be complete, which value orientations (intrinsic rather than extrinsic) leaders should heed to foster work engagement. In the present study, engaging leadership was found to positively associate with the perceived intrinsic value orientations of the organization. Our results suggest that leaders should be concerned with how their leadership is perceived, which points to a potential values gap between a leader-centered- versus a more employee-centered approach, such as engaging leadership.

The potential values gap can be elucidated as follows. Employees bring their values to the workplace and through interacting with colleagues, peers and managers in the organization, they will both express their values, and take in and adjust to the social norms and practices of the organization (cf. Burns, 1978, p. 428; Fukuyama, 2018, p. 56; Taylor, 1991, p. 29). We speculate that organizational culture is too much the playground of boards of management (leader-centered) and too little the birthplace of generative dialogue between employees and leaders in the organization (employeecentered); dialogues on what values they share, what futures they envision, how they may organize best, and what aspirations they hold (Denning \& Dunham, 2010; Vogt, 2009). Instead, boards generally emphasize and communicate the values of the organization to demarcate and justify boundaries, to direct employees to comply with these boundaries, to attract new hires who fit the profile, and to sustain a certain public image (Mackey \& Sisodia, 2014; Sagiv \& Schwartz, 2007). Employees will inadvertently reproduce the culture of the organization in their behavior through systemic pressure (Kofman, 2006), despite the different value preferences they may privately hold. Previous studies (Meglino et al., 1989; Sagiv \& Schwartz, 2000) showed that individuals experience an increased well-being when they can bring their own value orientations in line with how they perceive their environment. Meglino et al. and Sagiv and Schwartz both describe this phenomenon as value congruence and also found positive effects on job satisfaction and organizational commitment. When leaders in the organization are capable of positively influencing and aligning organizational values with how these values are perceived by employees, positive effects on work engagement can be expected. 


\section{Limitations}

The present study has some limitations. The first limitation is the cross-sectional design of study 1 . However, in developing this study, we followed the suggestions and instructions laid out by Spector (2019) about optimizing the use of cross-sectional designs (e.g., first exploring this relation) and further examined the directionality of the relations in the second longitudinal study.

A second limitation was that participants in the first study were selected from one organization specializing in research, design, production, delivery, and maintenance of health systems. The organization has its specific organizational culture, as all organizations do, and we could not control for corporate culture. Other types of organizations have different value systems which may impact the outcomes. To counterbalance this we conducted the second, longitudinal study among respondents from another organization, in another business with another organizational culture. The respondents of study 2 were engineers overseeing complex mass-production processes, whereas the respondents in study 1 were business information analysts and order-managers.

Despite its firm roots in a well-established theory of human motivation, the measure of engaging leadership is relatively new and cannot draw on a wealth of studies. Nevertheless, a growing body of research has been conducted, under which: a diary study investigating the impact of engaging leadership on daily team job-crafting (Mäkikanga et al., 2017); A crossed and lagged panel study into the relationships with autonomy, social support, learning opportunities and engagement (Nikolova et al., 2019); Mediational analyses on the role of basic psychological needs satisfaction (Rahmadani et al., 2019) and needs frustration (Van Tuin et al., 2020); an intervention study on the impact on business results and well-being (Van Tuin et al., 2020). Another aspect is the more general issue of construct proliferation in leadership research (Shaffer et al., 2016). Several authors point to item overlap and redundancy issues (e.g., Hoch et al., 2016). For this paper, we followed the suggestions of Bormann \& Rowold. The authors suggest that leadership constructs can be described more parsimoniously with self-determination theory as the underlying mechanism. We selected engaging leadership because it draws on this theory and, hence, is based on social psychological theory.

Given that the second study only included a limited number of respondents, it would be interesting, to expand our results to other organizations and to test their generalizability to organizations holding values diverging from mainstream corporate culture. Recent studies have documented organizations where intrinsic values, such as making a contribution to make the world a better place, are an integral part of the culture. For an overview of such companies see, for example, Laloux (2014) and Sisodia and Gelb (2019). 


\section{Implications for Practitioners}

Despite the limitations mentioned above, the current study holds valuable suggestions for practice. In day-to-day leadership practice we suggest to regularly enter into dialogue on values with employees, collectively and individually. It is important to know how employees perceive the organization's values. Through this dialogue on values need satisfaction and work engagement may increase. Well known results from higher work engagement are increased well-being, motivation, performance, and even better business performance (Schaufeli, 2012; Schneider et al., 2018). For the dialogue to be productive a process of deep listening, curiosity, and open questions in an atmosphere of psychological safety is a necessary precondition (Edmondson \& Lei, 2014). It goes without saying that support from the top of the organization adds credibility to the generative exchange of thoughts and values. Nevertheless, midlevel managers represent the organization and it is on that hierarchical level most employees interact with the organization's leadership (Gartenberg et al., 2016). It is a good habit in building strong teams to check-in with each other regularly on subjects beyond the scope of operational tasks and requirements. Meaningful exchanges between colleagues known to build the strongest bonds are about matters of the heart (Fredrickson, 2013). Leaders who dare to open and facilitate such conversations are generally found to lead high performance teams (Duhigg, 2016). Topics in needs and values employees care about deeply which were examined in the current study concern (a) their level of autonomy, self-direction and involvement; (b) The quality, depth and care in interpersonal relationships; (c) Making a meaningful contribution to something of value; (d) To be challenged in interesting ways; (e) To be offered opportunities for growth and self-development.

\section{Conclusion}

The present study tested the association of engaging leadership with employees' values perceptions, subsequent need satisfaction and work engagement. Engaging leadership related positively with the intrinsic values orientations of care, contribution, challenge and growth over extrinsic orientations of status, power and financial success. Leaders that pay close attention to their employees' intrinsic value preferences are likely to satisfy basic psychological needs and foster higher work engagement. 



\section{CHAPTER 5 \\ Business Results and Well-Being: An Engaging Leadership Intervention Study}

Appeared as: Van Tuin, L., Schaufeli, W. B., Van Rhenen, W., \& Kuiper, R. M. (2020). Business Results and Well-Being: An Engaging Leadership Intervention Study. International Journal of Environmental Research and Public Health, 17(12), 4515. http:// doi.org/10.3390/ijerph17124515 

Leadership effectiveness is of primary concern to organizations-hence the popularity of leadership development programs and the considerable investment organizations make in such programs (Day et al., 2014). Organizations are confronted with rapid change, growing interdependencies, and complexity in what is generally characterized as a world of volatility, uncertainty, complexity, and ambiguity ( $A$. Rodriguez \& Rodriguez, 2015). In response, organizations are experimenting with emerging approaches to leadership development (Ardichvili et al., 2016). One recent trend is the aim of synthesizing the growing popularity of self-management (Lee \& Edmondson, 2017; Mayfield et al. 2017) with the development needs of individuals (Kegan, 1982) and the pursuit of agility (Deloitte, 2016). As a result, participatory and more individualized approaches to leadership development gain ground (Kegan \& Lahey, 2016). A participatory approach involves the target group of leaders-the leaders who will participate in a development program-in the development and goal setting of the program together with their senior management. Conceiving a leadership development program together with its participants in a co-creation process helps to align hierarchical levels. It supports embedding leadership in the day-to-day business of the organization (Chen et al., 2006; Tafvelin et al., 2018). The principal ambition is to create a work environment where both employees and leaders may flourish, self-develop, and meaningfully contribute (Ryan \& Deci, 2017). New and emerging practices aim to contribute to both organizational performance and employee wellbeing (Ardichvili et al., 2016). However, studies on the effects on business performance are lacking (Mueller, 2019). The current study aims to fill this gap. The present study's leadership development program was shaped in a co-creation process and sought to improve actual business performance, decrease sick-leave absenteeism, and elevate motivation.

\section{Self-Determination Theory: A Psychological Theory Underpinning Leadership Development}

We chose self-determination theory (SDT) as the theoretical point of departure for the current study because of its integrative approach. SDT links a theory of human development and motivation with a view on organizational effectiveness and leadership. Through basic psychological needs theory (BPNT, Deci \& Ryan, 2000), and organismic integration theory (OIT) (Vansteenkiste et al., 2010), SDT explains how employees take in extrinsic regulations (regulations external to the individual), such as purpose, mission, vision, goals, targets, procedures and controls, and integrate these regulations with their sense of self (Ryan, 1995). The integration process is an essential aspect of the dialectic view on human development in SDT (Deci \& Ryan, 2000). Consequently, leadership and organizational experiences are experiences that are integrated into a person's sense of self (Gagné \& Deci, 2005). When, in a work 
context, extrinsic regulations are positively integrated into the sense of self, SDT speaks of autonomous motivation: individuals may identify with extrinsic regulations because they, for example, identify with the purpose of the department or organization and find personal meaning and value in the given purpose. Identifying with a purpose may add to a person's sense of meaningfully contributing and opens the possibility of self-directing one's motivational energy towards that purpose and supports well-being (Ryan \& Deci, 2017). In answer to the question "why do you do this work", a person may answer "because it is important to me" or "it aligns with my personal values" (Gagné et al., 2014). The more a person identifies with the organizational goals, values, purpose, or tasks at hand, the more a person is inclined to take on responsibilities and self-manage or self-lead (Ryan, 1995; Spence \& Deci, 2013).

In short, SDT posits that people flourish, are optimally motivated, perform well, and contribute positively to the organization's performance by positively identifying with and positively integrating leadership experiences (Ryan \& Deci, 2017). Hence, the current study's leadership development program was designed to support leaders in learning how to create work contexts where the integration process of extrinsic regulation is positively facilitated.

\section{Autonomy Satisfaction}

Autonomous and intrinsic motivation associate with the satisfaction of the basic psychological needs of autonomy, competence, and relatedness (Gagné \& Deci, 2005); The fulfilment of these needs induces optimal human functioning, autonomous motivation, and well-being. BPNT defines autonomy as the need to be the author of one's own fate and to be involved and heard in matters of personal interest (Deci \& Ryan, 2000). Relatedness refers to the need to be loved, held, and cared for, and to have meaningful relationships with others (Baumeister \& Leary, 1995), and competence relates to the need to feel effective relative to one's environment (White, 1959) and to be good at something. Ryan and Deci (2017) claim a specific role for autonomy satisfaction in the system of needs. In many instances, the capacity to self-organize precedes the fulfilment of the need for competence and relatedness. Autonomy-in the sense of agency-is a necessary ingredient for individuals to initiate behaviors through which these other two needs may be realized (Ryan \& Deci, 2017). Since the individual experience of autonomy is also a socio-contextual phenomenon (Vansteenkiste et al., 2010), it very much coheres with the active, positive role of the leader and whether team members experience an elevated sense of autonomy, which may induce a better realization of the needs for competence and relatedness (Van den Broeck et al., 2016). Leaders that fulfil the basic need of autonomy create a positive precondition for elevated work engagement (Gillet et al., 2015), well-being (Chen et al., 2014) and performance (Solansky, 2014). 


\section{Engaging Leadership and Positive Outcomes}

The engaging leadership concept was selected because it draws on BPNT and aims explicitly to identify leadership behaviors that may induce work engagement through the satisfaction of basic psychological needs (Schaufeli, 2015). Through BPNT, engaging leadership grounds itself in human motivation theory (Deci \& Ryan, 2000). It is a humancentered leadership approach, as opposed to more traditional leader-centered methods, such as transformational leadership (Bass, 1985), or authentic leadership (Avolio \& Gardner, 2005). Moreover, engaging leadership aspires to create the conditions that nurture performance (Shuck \& Herd, 2012) through the aspects of empowering, strengthening, and connecting (Schaufeli, 2015). Empowering corresponds to the need for autonomy and emphasizes that employees should be engaged in matters that concern them and should be made part of and have a say in the larger whole (Gagné \& Deci, 2005). An engaging leader allows employees to craft their work and self-direct within a clear and structured context (Spence \& Deci, 2013). Strengthening fosters the need for competence through plentiful feedback-mostly positive feedback-and creating space for employees to personally and professionally grow and self-develop (Deci \& Ryan, 2000). Connecting addresses the need for relatedness, through nurturing personal and meaningful relationships across hierarchical levels and setting a context of care and support (Schaufeli, 2015). Defining leadership behaviors to align with need satisfaction is a promising approach. A recent study found basic needs to mediate the relationship between engaging leadership and work engagement (Rahmadani, 2019) and identified need fulfilment as a potential explanatory mechanism. Previous studies also found to basic needs to mediate between leadership and work engagement (Kovjanic et al., 2012). Because of its explanatory value need satisfaction is sometimes referred to as the unifying principle (Vansteenkiste \& Ryan, 2013) .

Prior studies on the effectiveness of leadership development within SDT refer to "autonomy-supportive leadership" and found that leadership behaviors promoting the satisfaction of basic needs and autonomous motivation can be learned (Su \& Reeve, 2010). Still, it seems that leaders participating in leadership development programs benefit more than team members (Deci et al., 1989; Hardré \& Reeve, 2009) Researchers found autonomy-supportive leadership to be effective in fostering better performance in domains such as sports coaching (Gillet et al., 2009), educational and academic settings (Vansteenkiste et al., 2012), and healthcare ( $\mathrm{Ng}$ et al., 2012). In the realm of organizational psychology, however, most studies measure subjective performance based on self-reports in terms of in-role or extra-role performance (Breevaart et al., 2014) or based on performance appraisals by supervising leaders (Baard et al., 2004). We have found no studies within the domain of SDT reporting on actual business performance as an outcome measure. In the present study, we argue that co-creation 
by engaging team leaders (the participants) in the design and development of the intervention is an expression of autonomy support. We expect that this engagement will support the subsequent realization of business results and well-being.

\section{Documenting Business Performance}

Periodical progress in business performance is generally measured using the balanced scorecard methodology developed by Kaplan and Norton (Kaplan \& Norton, 2001), which aims to align performance indicators with strategic business objectives and definitions of business excellence (Bullinger et al., 2010). For supply chain management, an additional instrument, the supply chain operations reference (SCOR) model, has been developed. The model supports organizations to develop the ability to manage the full scope of the supply chain, from a functional level to inter-organizational integration (Estampe et al., 2013). In the current study, the aim was to test whether the leadership development initiative could positively contribute to actual business performance through carefully selecting a KPI (key performance indicator). A KPI is a metric indicating how a company or department is performing relative to a predefined key business objective. The selected KPI had to be a key indicator for the intervention group's performance, and it was considered essential that team leaders and their team members could influence the KPI. For this study, representatives of the team leaders, their supervising manager and the global department head of the intervention group selected one core business KPI in the process of co-creation-orders booked on time (ОВОT)-the percentage of the total number of new orders booked per month within the target parameter of 48 hours after receipt from the sales department. The target was to achieve 95\% OBOT, and team members logged progress in the company's CRM-software and reported monthly. These business metrics are specific for this department and will not be compared to the control group.

\section{Absenteeism}

Another widely used KPI is the level of sick-leave absenteeism, which is considered an objective, operationalized performance measure linked to organizational performance (Van Looy \& Shafagatova, 2016). Positive leadership styles, such as transformational leadership, contribute to lower levels of absenteeism (Elshout et al., 2013), whereas more controlling leadership styles (Gagné \& Deci, 2005) and passive-avoidant styles of leadership are associated with higher levels of absenteeism (Frooman et al., 2012). Additionally, increased autonomy satisfaction predicts lower levels of absenteeism (Baard et al., 2004; Landeweerd \& Boumans, 2011). Organizations with lower levels of absenteeism report higher engagement and productivity (Gallup, 2017), while higher frequencies of sick-leave absenteeism are associated with poor performance (Bycio, 1992). Lower levels of sick-leave absenteeism lead to lower costs and, just 
like productivity gains and increased performance, can be used as valuable input for business metrics, such as a return-on-investment (ROI) calculus, which is one of the most widely used performance evaluation metrics in the management literature (Heerkens, 2010; Mueller, 2019). We argue that engaging leadership, with its base in self-determination theory and need satisfaction, will also contribute to lower absenteeism rates. However, there are no prior empirical studies that we can draw on that have specifically explored this relationship for engaging leadership.

For the present study we used individual sick leave reports documented by the HR department and the occupational health and safety provider. Two separate periods were analyzed to measure sick-leave absenteeism: a pre-intervention period covering the 12 months preceding the intervention and a post-intervention period covering the 12 months after the program (Van Rhenen et al., 2007).The measures applied were sickness frequency, the absence rate, and the net number of lost workdays. Individual sickness frequency was expressed as the number of current and new sick-leave spells divided by the number of full-time equivalents (FTEs). The absence rate was defined as the number of lost workdays per employee reported sick, divided by the total number of available workdays times one hundred. The net number of lost workdays consisted of the reported workdays per month lost as a result of absenteeism.

\section{The Current Study}

The primary aim of the current study was to improve objective business performance and decrease absenteeism through a leadership development program of which cocreation formed an integral part to support autonomy of participating midlevel team leaders. The secondary aim was to test whether the content and the design of the leadership program would benefit participating team leaders and whether the positive effects would spill over to the team members. Three hypotheses were formulated:

Hypothesis 1: As a result of the leadership program, (a) the business performance of the department of the intervention group will increase to or exceed the agreed target level, and (b) absenteeism within the department will decrease compared to the control group. The business metrics measuring the intervention group's performance are specific for this department and will not be compared to the control group.

Hypothesis 2: (a) The team leaders participating in the leadership development program will report higher levels of engaging leadership compared to the control group, and (b) they will experience an increase in their levels of autonomy satisfaction and (c) intrinsic motivation. 
Hypothesis 3: The effects of the leadership program will positively spill over to the team members, who are expected to indirectly benefit from the program. As a result, team members will perceive more engaging leadership and higher levels of autonomy and intrinsic motivation than those in the control group whose leaders did not participate.

\section{METHOD}

\section{Participants and Procedure}

The present study used a quasi-experimental, pre-test-post-test control group design. The intervention and control groups were selected from the same multinational organization, which develops, produces, and services health systems. The intervention and the control group were responsible for back-office processes and delivered their information and services to other departments of the organization. The intervention group consisted of team leaders and team members of the customer fulfilment center, whose main task is to manage the back-office processing of new orders from sales to production, shipping, delivery, and invoicing. The control group members were information analysts from the information management department, whose jobs are to gather, analyze, control, and distribute information across the organization. The control group was selected on comparable qualities to the intervention group, such as department size in full-time equivalents, business process (back-office, administrative, Lean management, service role to other departments), and locality. The intervention group consisted of 14 team leaders ( $N=14$, female 29\%) and 148 team members, and team size averaged 10-12 members per team. At pre-test (To), 13 team leaders, 93\% response rate, female $=29 \%$, age $=38.57(S D=8.58)$, tenure $3.88(S D=2.35)$ and 106 team members, $71 \%$ response rate, female $=51 \%$, age $=39.32(S D=9.55)$, tenure 2.5 $(S D=2.23)$ completed the survey. At follow up ( $T 1$ ) eight months later, 14 team leaders completed the questionnaire, 12 of whom had also responded at To; This difference in follow up was due to a staff change in the team, as one of the team leaders left the department. Regarding the team members, 109 responses were received at $\mathrm{T}_{1}$ ( $74 \%$ response rate), 81 respondents had also completed the survey at To.

Unfortunately, the survey protocol of the organization forbade to link team members with their leaders in teams with fewer than 15 members for reasons of anonymity, implying that the team leaders and team members had to remain separate groups and could not be nested. As a consequence, within both the intervention and control group, two separate groups were included (a group of team leaders one of team members) instead of one leader per team with his or her direct reports. The control group consisted of 52 team leaders and 218 team members. At To, 39 team leaders, 
$74 \%$ response rate, female $=30 \%$, age $=42.42(S D=8.38)$, tenure $2.06(S D=1.10)$ and 119 team members, $55 \%$ response rate, female $=43 \%$, age $=44.36(S D=11.70)$, tenure 1.95 $(S D=1.31)$, completed the survey. At T1 eight months later, 23 team leaders responded, 21 of whom had also participated at To. A total of 104 responses were received from the team members, of whom 62 had also completed the survey at To.

\section{The Leadership Intervention}

The leadership development program consisted of three phases: (a) co-creation; (b), intervention or execution; and (c) evaluation and sustainment (Riddle et al. 2015; Tafvelin et al., 2018). Figure 1 schematically displays the structure and content of the program. The initiation and co-creation phase of the program took two months. The structure, operational details, and parameters for success were discussed with the team leaders and their supervising manager, the senior leadership team, and the global department head, who also initiated the program. Actively involving the team leaders in the design phase of the project mirrored the preferred leadership style that the department sought, which was reflected in the department's slogan for the project: "Co-creating a great place to work." Consequently, co-creation continued during the months of the intervention. The trainers remained in close contact with the global department head, his team, the supervising manager, and the participating team leaders. The team members were not involved in co-creation nor would they participate in the leadership development program's training sessions. Team members were asked to complete an online survey, to which their team leaders personally invited them. The program was launched with the pre-test survey to establish a baseline and unfolded eight months, after which the T1 follow-up survey was administered.

With the control group, the design and purpose of the program were discussed with representatives of the control group's senior leadership team, who then informed the team leaders, who invited direct reporting team members to participate in the survey on a voluntary basis through email. Team members were, however, not informed about the intervention group's leadership program.

The second phase of the intervention consisted of three building blocks (Figure 1): six training days with a 6-8-week interval, three peer-consultation sessions between the training sessions, and two one-on-one coaching sessions. The design was modelled on the professional experience of the trainers, on previous intervention studies within SDT (e.g., Deci et al.,1989), and studies conducted by the Center for Creative Leadership (Riddle et al., 2015). 


\section{Figure 1}

Program Structure

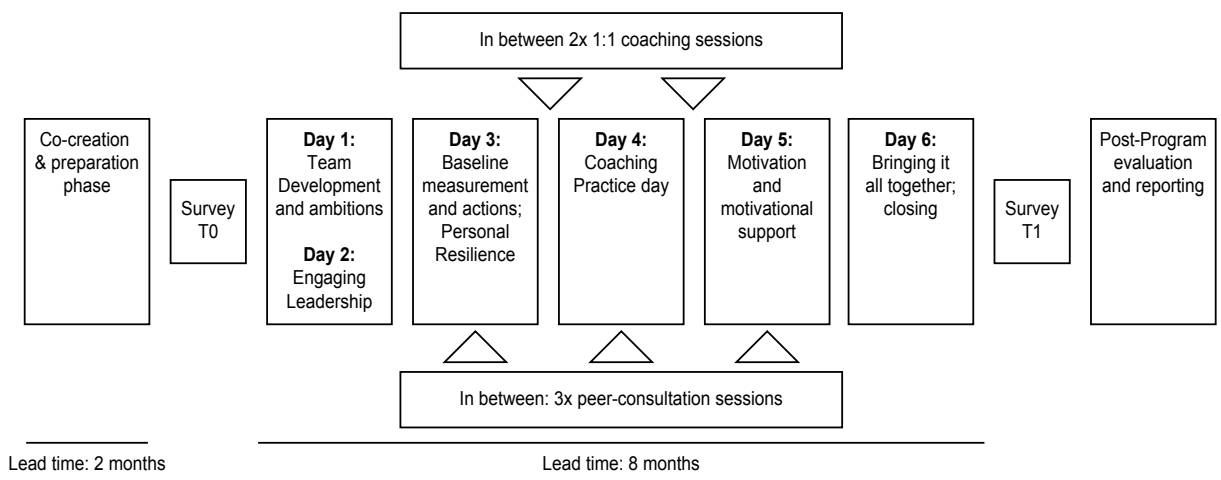

Note. This Figure displays the program's structure and content, starting with a two-month preparation and co-creation phase in which the goals and parameters for success were defined between the global leadership team of the department and the local leadership team that would participate in the program. Then, the pre-test survey was sent out to establish baseline (To). The training intervention consisted of 6 training days with a 6-8-week interval. The first training session lasted two consecutive days. In between, three peer consultation sessions and two one-on-one coaching sessions were offered. The total duration was eight months, after which the post-test measurement ( $\mathrm{T}_{1}$ ) was conducted. After the program had ended, business measures continued to measure progress.

The training program (Figure 1) commenced with a two-day off-site session for the team leaders and their supervising manager. Day one opened with a restatement of the purpose of the development program and a welcome speech by the department's global head and focused on improving team relations and trust through feedback and exercises. Day two explained the engaging leadership concept and participants formulated shared goals for the program. The third training day (six weeks later) focused on the progress made in generating positive outcomes relative to the goals and ambitions from the first training session. Furthermore, the findings of the baseline measurement were presented, and exercises and practice in personal resilience were offered. Coaching leadership and coaching conversation exercises formed the core of day four. Day five explained the SDT theory of motivation (motivation continuum and basic psychological needs, Deci \& Ryan, 2000; Gagné \& Deci 2005) and offered exercises in motivational coaching and handling push back and negative emotions. On day six the results realized were evaluated, and the progress made was celebrated.

Three guided peer-consultation sessions were offered between the training days. Peerconsultation provides a structured method of facilitated conversation for improving personal functioning and professional performance, addressing leadership challenges, 
and engaging in group problem solving based on mutual support and consultation with peers. The team leaders also had two personal coaching sessions to address their leadership challenges confidentially. The peer consultation sessions and coaching sessions were facilitated by two coaches, who worked according to the International Coach Federation (ICF) guidelines.

\section{Instruments}

Business performance was measured with the metric OBOT as defined earlier. The business metric was selected because it was considered the essential business metric for the department. Absenteeism was measured following the procedure described previously. The company's overall target for absenteeism was to remain below a $3 \%$ threshold. At the time of the initiation phase of the project, absenteeism in the department had risen to $7.7 \%$, which raised a red flag to senior management and accelerated the development of the leadership development program.

Engaging leadership (EL) was measured with the 9-item Engaging Leadership scale developed by Schaufeli (2015), which was distributed in two versions: a self-assessment for team leaders and an instrument for team members to assess their team leader. The aspects of Strengthening, Connecting, and Empowering were each represented by three items. The following is an example item for team leaders (Strengthening): "At work, I encourage team members to develop their talents as much as possible."; For team members this is: "At work, my supervisor encourages team members to develop their talents as much as possible."; An example of Connecting is: "I encourage collaboration among team members."; For team members this was: "my supervisor encourages collaboration among team members."; Empowering was represented through "I encourage team members to give their own opinion"; For team leaders, and for team members this item was introduced with "my supervisor encourages (...).". Responses were measured on a 5-point Likert scale ranging from 1 (completely disagree) to 5 (completely agree). The values of the Cronbach's alpha indicator for reliability are shown as follows: $\alpha=.92$ (To) and $\alpha=.93$ (T1) for team members and $\alpha=.82$ (To) and $\alpha=.78$ (T1) for team leaders.

Autonomy satisfaction (AS) was measured with the three items from the Balanced Measure of Psychological Needs (BMPN) Scale developed and validated by Sheldon and Hilpert (2012). The items were measured on a 5-point Likert scale (1, completely disagree; 5, completely agree). For example: "I am really doing what interests me." The reliability values were: $\alpha=.70$ (To) and $\alpha=.66\left(\mathrm{~T}_{1}\right)$. 
Intrinsic motivation (IM) was measured with the three items for intrinsic regulation from the Multidimensional Work Motivation Scale (Gagné et al., 2014). The items were scored on a 5-point Likert scale (1, completely disagree; 5, completely agree). For example: "Because I have fun doing my job." The reliability values were: $\alpha=.83$ (To) and $a=.86\left(T_{1}\right)$. See Appendix A for the survey items.

The business outcome measures were reported every month to the global department head and continued after the intervention had ended. In contrast, the survey was administered at two time-points, at pre-test and post-test after the intervention program had completed. The business measures were followed for another six months beyond the intervention program to evaluate whether the intervention results were sustained into the next year.

\section{RESULTS}

\section{Preliminary Analyses}

First, we screened the data for multivariate outliers using the Mahalanobis distance procedure, which identified one outlier in the intervention group at pretest: the respondent had dropped out and was thus not considered in the analyses. Skewness and kurtosis were verified to be within an acceptable range. The MCAR procedure was run to establish if data were missing completely at random (Asendorpf et al., 2014: Little \& Rubin, 2002). The test returned that data were MCAR, $X^{2}(103)=119.01, p=.134$. Nevertheless, it was checked whether one of the variables could be predictive of subsequent dropout of respondents through examining systematic attrition (Asendorpf et al., 2014) for the separate groups (Table 1). One team leader in the intervention group with a very low score on engaging leadership (presumably the outlier mentioned above) dropped out, which probably was related to the staff change mentioned earlier-it was assumed this was the team leader that had left the department. For team members in the intervention group, low scores on engaging leadership seemed predictive of medium risk of later dropout, $t(104)=3.29 ; p<.01 ; 95 \% \mathrm{Cl}[-0.91,-0.23]$; $d=0.69$. The other two variables (autonomy satisfaction and intrinsic motivation) did not and presumably counterbalanced the dropout risk. By the same token, low scores on autonomy satisfaction may have contributed to a medium-low risk of team members dropping out in the control group, $t(117)=2.23 ; p<.05 ; 95 \% \mathrm{Cl}[-0.53,-0.31] ; d=0.41$. No further steps were taken since the missing data were MCAR. 
The descriptive statistics were calculated for both the intervention and control group at baseline (Table 2). At pre-test the team leaders in the intervention group rated themselves higher on engaging leadership than their direct reporting employees assessed them $t(117)=1.92, p=.06,95 \% \mathrm{Cl}[-0.01,-0.81], d=0.63$. In the control group the difference between the leaders self-assessment and their team members was similar in strength: $t(156)=3.00, p=.003,95 \% \mathrm{Cl}[0.12,0.56], d=0.62$.

\section{Business Outcomes for KPI Performance and Absenteeism (Hypothesis 1)}

Hypothesis 1a predicted that business performance would increase to or exceed the target level set. To assess the department's business performance, as measured by OBOT, the "N-1" chi-square test (Campbell, 2007) was performed. The number of orders booked per month differed over the year. Peak moments were found at the end of each quarter and the two months at year-end. To compare the results, we have looked at business outcomes in March (quarter-end and pre-test), November (year-end and comparable with March and post-test), and in June the following year (quarter-end). December is by far the busiest month and not comparable with any other month, hence November was assessed. OBOT at To (March) was $87 \%$ of 22,368 orders, compared to $92 \%$ of 22,165 orders at $\mathrm{T}_{1}$ (November), which is a significant increase, $X^{2}(1, N=22,165)=295.88, p<.001,95 \% \mathrm{Cl}[4.43,5.57]$. The percentage increased another $3 \%$ in the six-month period after the intervention (June) to $95 \%, X^{2}(1, N=22,929)=167.50$, $p<.001,95 \% \mathrm{Cl}[2.55,3.46]$. Additionally, the average number of orders booked on time per fulltime equivalent developed positively: At pre-test, this was 304 OBOT/FTE, at post-test, this was 324, and 6 months after post-test this was 357.

Hypothesis $1 b$ predicted that absenteeism decreases as a result of the leadership program. The sick-leave absenteeism data obtained from the service provider were analyzed using nonparametric statistics due to the skewed nature of the sickness absence data. We applied the Wilcoxon signed ranks procedure for related samples to test the within-group differences between the pre- and post-test measurements. As depicted in Table 4, the intervention group's sick-leave absence decreased significantly over the twelve months after the intervention by $3.4 \%(p<.001)$. The total net number of lost workdays per month declined by almost 60\%, from an average of 113 per month in the twelve months preceding the leadership program to 66 after the program $(p=.02)$. Overall, the outcomes confirmed the hypothesis that sick-leave absenteeism would drop as a result of the leadership intervention program. 


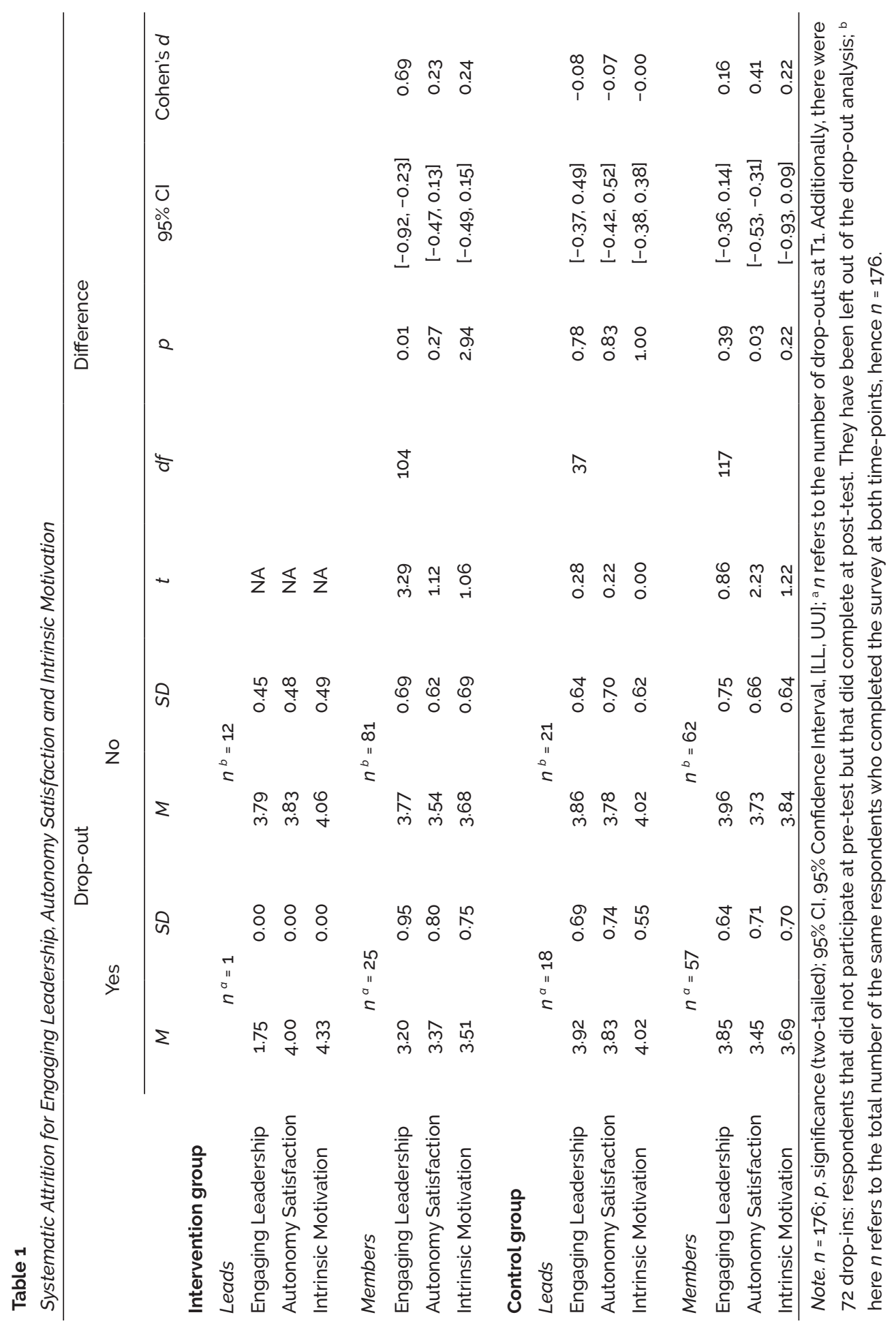




\section{Table 2}

Means (M) and Standard Deviations (SD) at Baseline

\begin{tabular}{|c|c|c|c|c|}
\hline & \multicolumn{4}{|c|}{ Intervention Group } \\
\hline & \multicolumn{2}{|c|}{ Leads $(n=13)$} & \multicolumn{2}{|c|}{ Members $(n=106)$} \\
\hline & M & $S D$ & M & $S D$ \\
\hline Team Leads Self-assessment & 4.06 & 0.51 & & \\
\hline Engaging Leadership & 3.40 & 0.81 & 3.66 & 0.73 \\
\hline Autonomy Satisfaction & 3.59 & 0.70 & 3.53 & 0.65 \\
\hline \multirow[t]{4}{*}{ Intrinsic Motivation } & 3.74 & 0.90 & 3.66 & 0.69 \\
\hline & \multicolumn{4}{|c|}{ Control Group } \\
\hline & \multicolumn{2}{|c|}{ Leads $(n=39)$} & \multicolumn{2}{|c|}{ Members $(n=119)$} \\
\hline & M & $S D$ & M & $S D$ \\
\hline Team Leads Self-assessment & 4.33 & 0.39 & & \\
\hline Engaging Leadership & 4.03 & 0.61 & 3.99 & 0.67 \\
\hline Autonomy Satisfaction & 3.75 & 0.72 & 3.58 & 0.68 \\
\hline Intrinsic Motivation & 3.97 & 0.58 & 3.74 & 0.70 \\
\hline
\end{tabular}

The means, standard deviations, and intercorrelations between variables were examined at the two time-points for the team leaders and the team members (Table 3).

\section{Table 3}

Means (M), Standard Deviations (SD), Intercorrelations ( $r$ )

\begin{tabular}{|c|c|c|c|c|c|c|c|c|c|c|}
\hline & \multicolumn{2}{|c|}{$\begin{array}{c}\text { Team } \\
\text { Leaders }\end{array}$} & \multirow[b]{2}{*}{ EL (To) } & \multirow[b]{2}{*}{ EL (T1) } & \multirow[b]{2}{*}{ AS (To) } & \multirow[b]{2}{*}{ AS (T1) } & \multirow[b]{2}{*}{ IM (To) } & \multirow[b]{2}{*}{ IM (T1) } & \multicolumn{2}{|c|}{$\begin{array}{c}\text { Team } \\
\text { Members }\end{array}$} \\
\hline & $M$ & $S D$ & & & & & & & $M$ & $S D$ \\
\hline $\mathrm{EL}(\mathrm{TO})^{\mathrm{a}}$ & 3.87 & 0.71 & 1 & $0.70^{* * *}$ & $0.50^{* * *}$ & $0.46^{* * *}$ & $0.38^{* * *}$ & $0.37^{* * *}$ & 3.83 & 0.73 \\
\hline$E L\left(T_{1}\right)^{b}$ & 3.86 & 0.55 & 0.50 ** & 1 & 0.38 * & $0.41^{* \star *}$ & 0.21 * & $0.34^{* * *}$ & 3.89 & 0.77 \\
\hline $\mathrm{AS}(\mathrm{TO})^{a}$ & 3.71 & 0.71 & $0.27^{*}$ & 0.23 & 1 & $0.61^{* * *}$ & $0.60^{* * *}$ & $0.57^{* * *}$ & 3.56 & 0.67 \\
\hline $\mathrm{AS}\left(\mathrm{T}_{1}\right)^{\mathrm{b}}$ & 3.83 & 0.62 & 0.27 & $0.48^{* *}$ & $0.50^{* *}$ & 1 & $0.51^{* * *}$ & $0.66^{* \star *}$ & 3.62 & 0.68 \\
\hline IM (To) a & 3.92 & 0.67 & 0.22 & 0.12 & $0.77^{* * *}$ & 0.06 & 1 & $0.64^{* \star *}$ & 3.70 & 0.70 \\
\hline $\mathrm{IM}\left(\mathrm{T}_{1}\right)^{\mathrm{b}}$ & 4.05 & 0.56 & 0.24 & $0.43^{* *}$ & $0.51^{* *}$ & $0.67^{\star \star \star}$ & $0.43^{*}$ & 1 & 3.73 & 0.72 \\
\hline
\end{tabular}

Note, ${ }^{\mathrm{a}} n=52$ (leads), 225 (members); ${ }^{\mathrm{b}} n=37$ (leads), 212 (members); ${ }^{*} p<.05 ;{ }^{* *} p<.01 ;{ }^{* * *} p<.001 ;$ Below the diagonal: team leaders; above the diagonal: team members. Separate correlation matrices for the intervention and control groups are available upon request by the first author. EL, Engaging Leadership; AS, Autonomy Satisfaction; IM, Intrinsic Motivation; (To), pretest; (T1), Posttest. 
Table 4

Absenteeism in the Intervention and Control Group

\begin{tabular}{lccccccc}
\hline & \multicolumn{2}{c}{ Pretest } & \multicolumn{2}{c}{ Posttest } & \multicolumn{2}{c}{ Wilcoxon ${ }^{\text {a }}$} & Mann-Whitney U \\
\cline { 2 - 8 } & $M$ & $S D$ & $M$ & $S D$ & $Z$ & $p$ & $p$ \\
\hline Frequency & & & & & & & \\
Intervention & 1.59 & 0.84 & 1.29 & 0.51 & -0.86 & .39 & .01 \\
Control & 0.62 & 0.47 & 0.78 & 0.40 & -0.71 & .48 & \\
Absence rate & & & & & & & \\
Intervention & 5.40 & 2.49 & 2.03 & 0.74 & -3.07 & .00 & .64 \\
Control & 1.03 & 0.20 & 1.96 & 0.72 & -2.67 & .01 & \\
& & & & & & & \\
Net number of lost workdays & 112.58 & 54.40 & 66.46 & 29.62 & -2.43 & .02 & .38 \\
Intervention & 5.44 & 7.47 & 52.72 & 29.97 & -2.98 & .00 & \\
Control & & & & & & & \\
\hline
\end{tabular}

Note. ${ }^{a}$ Wilcoxon signed-rank test

The "between"-group differences between the intervention and control groups were tested with the Mann-Whitney $U$ test for independent samples. The pre-test outcomes comparing the intervention and control groups indicated significant differences $(p<.001)$ between the two groups for all absenteeism tests performed, except for frequency $(Z=-2.72, p=.007)$. However, the differences between the two groups were non-significant in the post-test analysis, except for frequency $(Z=-2.60, p=.009)$, presumably due to the decreases in the intervention group and the parallel increases in the control group regressing to the mean.

\section{Effects on Team Leaders and Team Members (Hypotheses 2 and 3)}

Hypothesis za predicted that team leaders would (a) report higher levels of engaging leadership (EL) and (b) display an increase in autonomy satisfaction (AS) and (c) intrinsic motivation (IM). A multivariate test of variance was used to test the differences between the two groups over the two time-points, with EL, AS, and IM at T1 as dependent variables. The same variables were used as covariates at pre-test, to adjust the means between the intervention and control groups at the pre-intervention level. Additional checks on the underlying assumptions for a successful two-way multivariate analysis were conducted. The regression slopes were linear, and homogeneity checks were performed. Levene's test to assess the equality of the variances confirmed there were no significant differences in variance between the two groups or the leads and members. Box's $M$ test was conducted to assess the equality of co-variance and supported the assumption that the co-variance 
matrices between the groups could be assumed to be equal. As far as demographics variables are concerned, age had a positive and tenure had a negative effect on engaging leadership and motivation for team leads. Conversely, tenure had a positive effect on engaging leadership, autonomy, and motivation for team members. Therefore, we decided to control for age and tenure for team leads and tenure for team members.

Two separate analyses, one for team leaders and one for team members, were conducted. The intervention effects were non-significant for the team leaders and team members (Table 5). Considering the effects of small sample size on potential significance, we continued to test whether the effect sizes were relevant in magnitude. The partial epsilon squared is said to be the least biased effect measure for small samples (Okada, 2013). It is interpreted using Cohen's (1988) rules of thumb: 0.01, 0.06, 0.14 for small, medium, and large effect sizes respectively. We calculated the partial epsilon squared values with the formula by Albers and Lakens (2018) and found no effects for engaging leadership. In contrast, we found a very large effect $\left(\varepsilon_{p}{ }^{2}=0.25\right)$ for autonomy satisfaction and a large affect for intrinsic motivation $\left(\varepsilon_{p}^{2}=0.12\right)$. Hence Hypotheses $2 b$ and $2 c$ were supported by the data, whereas Hypothesis za was not.

Table 5

Difference of Intervention Effects Between Intervention and Control Group

\begin{tabular}{lccccc}
\hline & & $F$ & $p$ & $\eta_{p}{ }^{2}$ & $\varepsilon_{p}{ }^{2}$ \\
\hline Leads & Engaging Leadership & 0.02 & .91 & 0.00 & -0.12 \\
& Autonomy Satisfaction & 3.94 & .08 & 0.33 & 0.25 \\
& Intrinsic Motivation & 2.23 & .17 & 0.22 & 0.12 \\
& & & & & \\
Members & Engaging Leadership & 0.11 & .74 & 0.00 & -0.01 \\
& Autonomy Satisfaction & 0.97 & .33 & 0.01 & 0.00 \\
& Intrinsic Motivation & 0.89 & .35 & 0.01 & 0.00 \\
\hline
\end{tabular}

Note. The test controlled for age and tenure for team leads and tenure for team members.

Hypothesis 3 predicted that the effects of the leadership program would positively spill over to team members. However, no relevant changes were found in the team members' levels of perceived EL, AS, or IM (Table 5). Next, the effects within the intervention group were assessed. The analysis indicated a significant increase in $\operatorname{AS} F(1,88)=4.23, p=.04$, $\varepsilon_{\mathrm{p}}{ }^{2}=0.04$ for team leaders $(M=3.83, S D=0.48)$ compared with team members $(M=3.54$, $S D=0.62)$. Also, the IM scores for team leaders $(M=4.06, S D=0.49)$ were significantly higher, $F(1,88)=5.88, p=.02, \varepsilon_{\mathrm{p}}{ }^{2}=0.05$ than those of team members $(M=3.68, S D=0.69$ ). The corresponding effect sizes indicated a medium-small (AS) to medium (IM) strength. 


\section{DISCUSSION}

The present intervention study aimed to generate positive business outcomes in terms of KPI performance, reduced absenteeism, and elevated motivation and well-being through an engaging leadership development program. The program consisted of an initial co-creation phase. It targeted midlevel team leaders who were subsequently trained in engaging leadership and the satisfaction of basic psychological needs through six one-day training sessions. Peer consultation and personal coaching were offered to support the integration of the program contents in small groups and one-on-one coaching sessions. The program resulted in a significant increase in KPI performance (ОВОT), which continued after the program had ended and was in support of Hypothesis $1 \mathrm{a}$. The total rise in OBOT had a beneficial monetary impact $(8 \%$ more orders booked on time per month with the same number of FTEs and resources). The department was also able to invoice earlier, which led to a substantial positive effect on cash, as the department head reported.

Sick-leave absenteeism among the department's team leaders and team members decreased considerably during and after the program, which outcome was as expected (Hypothesis 1b). The longer-term sick-leave absenteeism analysis, averaging the 12 months before and the 12 months after the intervention, resulted in a considerable drop in absenteeism to $2 \%$ in the intervention group. Additionally, the net number of lost workdays dropped by almost $60 \%$. As with the KPI performance, the sick-leave absence rate continued to improve post-program, underscoring the sustainability of the intervention effects over time and beyond the program. With these two outcomes, KPI performance and absenteeism, the department's leadership considered the intervention to be a success.

Parallel to the organization's metrics, the team leaders and team members' psychological effects were measured and referenced with a control group. As expected, and in support of Hypotheses $2 \mathrm{~b}-\mathrm{c}$, the team leaders displayed higher levels (very large effect size) of autonomy (2b), and motivation (2c, large effect size) relative to the control group. The effect sizes match the general conclusions from a meta-analysis of leadership development programs in the private sector (between 1952 and 2002) based on similar study designs (Powell \& Yalcin, 2010), see also (Burke \& Day, 1986). For engaging leadership, however (Hypothesis 2a), no effect was registered.

The current leadership development program was titled "Co-creating a great place to work" and consisted of three phases: co-creation, intervention, and evaluation and sustainment. Co-creation was considered an expression of autonomy-supportive and 
engaging leadership. It aimed to facilitate productive dialogue between the leadership levels and helped align the global leadership team and the local team leaders. The selected business KPI, the ambition to lower sick-leave absence, and the aim to increase the levels of motivation via engaging leadership and autonomy satisfaction all stemmed from this first phase. Presumably, the co-creation process, as an integral part of the development program, facilitated achieving the observed changes in the autonomy and motivation of the team leaders relative to the control group.

Despite the positive effects of autonomy and motivation, the team members reported no relevant changes, which was unexpected (Hypothesis 3 ). The ambition to indirectly improve employee well-being by training their team leaders may prove problematic (Kelloway \& Barling, 2010). Other leadership intervention studies also found the intervention effects to be more substantial for the participating leaders than the indirect, spill-over effects for employees (see also Deci et al., 1989; Hardré \& Reeve, 2009)

\section{A Lesson Learned and a Suggestion for Future Programs}

Team members were not involved in co-creation and did not participate in the program, which may explain the absence of effects of the program for this group. A recent longitudinal study, however, illustrated the beneficial impact of perceived line management support and active employee participation on job outcomes (Tafvelin et al., 2018). Involving employees in the design and execution of leadership development might have contributed to the program's overall effectiveness. Additionally, actively engaging team members in co-creation corresponds with the growing popularity of participative and self-management approaches, replacing traditional commandand-control hierarchies (e.g., Laloux, 2014; Lee \& Edmondson, 2017). Additionally, it aligns with the conceptualization of SDT (Deci \& Ryan, 2000) on shaping autonomysupportive work environments where employees may flourish.

A practical proposal to involve employees as active participants may consist of including approaches such as action learning, where team leaders and team members collectively work on joint assignments (Volz-Peacock et al., 2016). Including team members, or employees more broadly speaking, may induce further positive changes in engagement and performance beyond the current study. Since it is broadly endorsed that employee engagement links to positive business outcomes, including financial performance (Schneider et al., 2018) improved effectiveness of a comparable future leadership intervention should be expected. 


\section{Contribution to Knowledge Development}

The present study is the first in the domain of SDT to report the impact of a leadership development intervention on actual business performance, as measured with business key performance indicators (i.e., productivity and absenteeism). Previous studies published on leadership impact within SDT reported on, for example, performance evaluations by supervising managers (Baard et al., 2004), or self-reported in-role versus extra-role behaviors (Breevaart et al., 2014). Another study measured the impact of autonomy-supportive leadership on employee perceptions (Hardré \& Reeve, 2009), and Deci et al. (1989)\} reported on the positive effects of a leadership intervention on supervising managers' orientations. Similar to the present study also in Deci et al.'s research, the impact on employees was less conclusive. The present study's contribution to leadership and SDT is relevant because it adds to the range of beneficial results that may be obtained through engaging leadership behaviors (Connecting, Empowering, Strengthening; Schaufeli, 2015) aiming to satisfy basic psychological needs (Deci \& Ryan, 2000). It also substantiates the claim that basic need satisfaction through autonomy-supportive leadership behaviors, such as described in engaging leadership, positively associates with enhanced performance (Ryan \& Deci, 2017; Niemiec \& Spence, 2016; Slemp et al., 2018).

Moreover, the present study also contributes to leadership development. The design of the leadership intervention facilitated the collective leadership experience through the participatory process of co-creation of senior leaders and the participating team leaders, and hence followed the call of Petri (2014) for more collective, networked approaches to leadership development. Engaging the participating team leaders supported the inclusion of the selected business KPI, absenteeism, and motivation as pillars of the program. Furthermore, engaging leadership behaviors that were taught in the training sessions followed the principles of coaching for leadership development, as described by Ting (2006). Examples are: creating a safe and challenging environment (Connecting), choosing facilitative leadership over directive action planning (Empowering), and promoting learning through collectively evaluating experiences and applying these to improve the business outcomes further (Strengthening).

We believe that designing a leadership development program in a real-time work environment with a real business challenge (Yost \& Plunkett, 2010) answers to the need for more contextually embedded leadership initiatives (Kellerman, 2012) and measurable outcomes(Gurdjian et al., 2014). We suggest that future leadership development practice can benefit from the incorporation of leadership development programs-like the one in the current study-in the day-to-day processes of departments and organizations (Ardichvili et al., 2016). 


\section{Implications for Practitioners}

There are a few important implications of the current leadership development program for practitioners. First, involving the target group of participants in a co-creation process is beneficial. It helps create direction, alignment, and commitment (DAC, Drath et al., 2008) across two or more hierarchical levels. Additionally, it answers to the need to work more peer-like and collaboratively in an autonomy-supportive manner. The second implication is to define program objectives that enthuse and inspire the targeted leaders and senior management. Improving business results should be one of the purposes and be positioned within the organization's broader goals to provide relevance for both participants and the organization. Thirdly, it is essential to use the program as a lever to embed autonomy-supportive engaging leadership in everyday practice. The leadership development program is more likely to become an actual practice when it is situated in a real-time context with real consequences. The fourth implication is to extend the program to, at least to a certain extent, other employees, not just team leaders or managers. Lastly, it is recommended to blend classroom training, with additional instruments such as peer-consultation in small groups, oneon-one coaching, and action learning.

\section{Limitations}

A major strength of the current study is that it was carried out in a real-world and, thus, dynamic organizational context. Despite its high ecological validity, it has a few limitations. The study is based on a single intervention within one organization. A second limitation is that the study relies on two measurement points, where three or more measurements over time could have added to the solidity of the findings, which is supported by the organizational outcomes displaying continued improvements six months after the second measurement. Third, the study incorporated small groups of team leaders, and the results could not be nested because of the survey protocol of the organization. Because of the small sample size, the power was too low to obtain significant parameter estimates and we relied on effect sizes only. We selected the partial epsilon squared because it is said to be the least biased in small samples (Albers \& Lakens, 2018). A future intervention study would benefit from larger groups of team leaders, which makes significance and robustness of relevant differences more feasible. Fourth, the quasi-experimental design plus the co-creation phase of the program, in which the senior leadership and team leaders participated, may have dripfed information on the proposed leadership intervention to team members previous to the initial survey. Hence, it cannot be assumed that the intervention group's team members were completely unaware of the experiment when filling out the survey. This limitation did, however, not extend to the control group because only its head of department knew about the experiment in the intervention group. 
Consequently, we could not distinguish the leadership impact of the various team leaders on their teams. Most likely, some team leaders had a positive impact on their team members' AS and IM, which was learned from the peer group consultation sessions and the individual coaching sessions with the team leaders during the program. However, for reasons of confidentiality, these sessions were not recorded or transcribed. Additionally, the small sample size for team leaders and the resulting low statistical power brings the risk of Type Il errors for the interpretation of the psychometric results. A fifth limitation is the quasi-experimental study design itself, which makes it more challenging to conclude the causality effects of the experiment. To balance this limitation, some measures were taken, such as the selection of a comparable control group and the correction for mean differences to create equivalence at baseline (Lonati et al., 2018). Another limitation on causality is the potential impact of unobserved managerial and organizational effects on observed performance, which may explain additional the variance in the outcome variables (Coles \& Li, 2011). We could not control for such influences.

A seventh limitation is the substantial difference in sick-leave absenteeism between the intervention and control group at pre-test. During the intervention period, both absence rates seemed to regress towards the mean, which potentially implies that it may be a natural regression rather than a real effect (Barnett, 2004). Nevertheless, we stand by the claim that it was an intervention effect for two reasons. First, because after a subsequent reorganization, two years later, the absence levels in the intervention group were back at their high pre-intervention levels. Second, because the drop in the intervention group was significant compared to the absenteeism within the organization at large, and even dipped below the organization's 3\% threshold.

\section{Conclusion}

The present study showed that a leadership development program focusing on engaging leadership and psychological well-being led to significant positive business results and lower absenteeism. Additionally, the intervention had a moderate to large effect for the motivation of team leaders and a substantial impact on the experienced autonomy of team leaders compared to the control group. The business outcomes exceeded the leadership team's ambitions and continued to improve post-program. The predicted positive spill-over effects on team members were absent despite the positive psychological effects on autonomy and motivation among team leaders and their subsequent well-being. 
From a practical point of view, co-creating a leadership program by actively involving its participants helped create direction, alignment, and commitment. It also supported the realization of business outcomes in a spirit of collaboration and continuous improvement. Embedding leadership development in everyday business processes with concrete business objectives and extending co-creation throughout the program supports team leaders in developing engaging leadership in their day-to-day practice and contributes to tangible results. The next step is to find ways to extend the program and engage team members in co-creation and implementation. Considering the current trend of self-management and agility in business organizations, we argue that leadership development should not be limited to management or a select group of high-potential individuals.

Despite the positive results of the program, generalization across organizations is limited, because it comprised a single intervention in one organization and a relatively small group of team leaders. Additionally, co-creation may lead to different foci in different organizations and influence the outcomes. However, we believe that the described approach can be strengthened through replication in other organizations. The present study contributes to the practical knowledge of the relatively new concept of engaging leadership and its successful application in leadership development programs. 


\section{APPENDIX A}

Survey Items

Engaging Leadership

Select the comment that best describes your present agreement or disagreement with each statement below. At work my supervisor...

\section{Strengthening}

1 encourages team members to develop their talents as much as possible

2 delegates tasks and responsibilities to team members

3 encourages team members to use their own strengths

Connecting

4 encourages collaboration among team members

5 actively encourages team members to aim for the same goals

6 promotes team spirit

\section{Empowering}

7 gives team members enough freedom and responsibility to complete their tasks

8 encourages team members to give their own opinion

9 recognizes ownership of team member's contributions

\section{Autonomy satisfaction}

At work...

10 I am free to do things my own way

11 My choices express my "true self"

12 I am really doing what interests me.

\section{Intrinsic motivation}

Why do you or would you put efforts in your job?

13 Because I have fun doing my job

14 Because what I do in my work is exciting

15 Because the work I do is interesting 




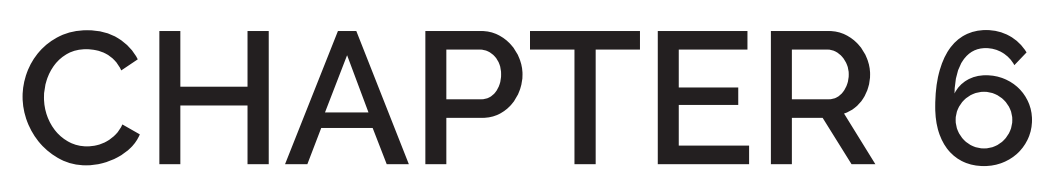

General Discussion 

The present thesis aimed to examine the potential beneficial effects of leadership, purpose, and values from the perspective of human motivation as defined in selfdetermination theory. As hypothesized, we found that engaging leadership, embracing and communicating a higher purpose, and paying careful attention to employee value perceptions enhance work engagement and motivation through the satisfaction of basic psychological needs. Need satisfaction, specifically autonomy satisfaction, explained over $55 \%$ of the variance in employee motivation and engagement. The studies in this thesis identified engaging leadership and purpose as antecedents to work engagement. Additionally, engaging leadership predicted employee's intrinsic value perceptions. Taken together, these outcomes underscore the fundamental role of need satisfaction as a linking pin between leadership-purpose-values and work engagement.

In Chapter 2, we examined the role of need satisfaction and frustration in engaging leadership. Interestingly, fulfillment of the basic psychological need of autonomy was positively associated with work engagement and autonomous motivation and helped decrease adverse forms of motivation. In contrast, lower relatedness frustration associated with decreased negative motivation, as predicted, but did not enhance autonomous motivation or engagement. Additionally, we found that autonomy satisfaction had a substantially higher predictive relevance over competence and relatedness satisfaction.

Chapter 3 examined the impact of a corporate objective on motivation and engagement. The objective fitted the definition of a higher or broader purpose and integrated various stakeholder perspectives (employees, customers, shareholders, society, and sustainability). The analyses showed a positive association with autonomous motivation and work engagement. Autonomous motivation explained $56.7 \%$ of the variance in engagement, whereas controlled motivation and amotivation played no role.

Subsequent longitudinal analyses confirmed the directionality from purpose to engagement and from autonomous motivation to engagement, but not from purpose to motivation. Nevertheless, employees who feel inspired by the purpose of their organization also display high work engagement. They sense that they contribute to its realization, strive to make the world a better place, and feel they bring value to customers and shareholders. A higher corporate purpose acts as an antecedent to work engagement. 
Chapter 4 tested the associations of engaging leadership with how employees perceive the organization's value orientations and the subsequent impact on work engagement via need satisfaction. We distinguished between intrinsic and extrinsic perceptions. Intrinsic perceptions assessed whether employees experienced the organization as valuing a caring work environment, adding a meaningful contribution to make the world a better place and whether they felt challenged and supported in their personal development and growth. In contrast, extrinsic perceptions refer to the values of power, status, and financial success. Our results show that engaging leadership positively associated with work engagement via perceived intrinsic organizational values and autonomy satisfaction, and negatively with extrinsic value perceptions. Contrary to what we expected, extrinsic value orientations were not negatively associated with the separate need satisfaction measures.

Cross-lagged panel modeling in the longitudinal study of Chapter 4 distinguished specific directionality from leadership to perceived intrinsic values and identified leadership as an antecedent to employees' value perceptions. Leaders who pay close attention to how employees assess the organization's value preferences facilitate positive outcomes regarding autonomy satisfaction and work engagement.

Lastly (Chapter 5), we conducted an intervention study into the effects of engaging leadership, need satisfaction, and motivation using a quasi-experimental pretestposttest control group design. The intervention aimed to increase business results and well-being and decrease sick-leave absenteeism through an eight-month leadership development program targeting mid-level team leaders. The program was conceived in co-creation between senior management and the participating team leaders. It consisted of six separate one-day training sessions with a 6-8-week interval. Additionally, participants intermediately received two one-on-one coaching sessions and peer-consultation sessions in small groups.

We hypothesized that as a result of the program, the business performance on a pre-selected key-performance indicator (KPI) would increase, absenteeism would decrease, and team leaders would display increased autonomy satisfaction and motivation relative to the control group. We also expected the program's effects to spillover to team-members, who were not involved in the program's co-creation nor participated in the training sessions. The posttest results showed significant increases in the business KPI, which still continued to increase six months after the intervention; Productivity and financial returns improved. Absenteeism decreased substantially throughout the intervention and also kept falling post-program. The team leaders who participated in the program displayed a substantial increase in autonomy satisfaction 
and a considerable rise in motivation relative to the control group. For team members, however, the expected spillover effect of autonomy satisfaction and motivation was not observed. Despite the decrease in employee absenteeism and increased productivity, team members did not benefit from their leaders' increased autonomy and motivation.

\section{Contributions to Knowledge and Theory}

The studies in this thesis contribute to knowledge and theory in four ways. First, in leadership research, it is suggested to pay more attention to the underlying process connecting leadership and job outcomes (cf. Judge et al., 2006; Inceoglu et al., 2018). In answering this call, we studied the role of satisfaction and frustration of basic psychological needs in explaining the relationship between (engaging) leadership behaviors and work engagement. Our research confirmed that need satisfaction contributes positively to work engagement, whereas need frustration has an adverse impact (Chapter 2). A recent study of Rahmadani et al. (2019) also confirmed that needs fulfillment connects engaging leadership and work engagement, just as prior studies into transformational leadership and positive job outcomes (Hetland et al., 2015) and employee engagement (Kovjanic et al., 2012). Positive leadership influences how employees experience their work context relative to their sense of self (van Knippenberg, 2018) and may therefore increase self-efficacy (Walumbwa et al., 2008), or eudaimonic well-being (Ilies et al., 2005).

More specifically, we found that autonomy satisfaction plays a specific role in the system of needs (Ryan \& Deci, 2017). Need satisfaction and frustration in engaging leadership were modeled both as a common factor and separately. Out-of-sample analysis (based on the Stone-Geiser Q2 analysis, see Hair et al., 2017) showed that autonomy satisfaction had the highest predictive relevance in explaining the outcomes compared to both other needs. Moreover, autonomy associated with positive outcomes and decreased negative motivational results. In contrast, relatedness frustration was related to adverse motivational consequences but had no impact on positive outcomes. These results confirm findings presented by Van den Broeck et al. (2016) in their meta-study on the role of basic psychological needs at work. The authors argued that one should consider measuring the basic needs separately because of their distinct predictive validity.

The specific role of autonomy satisfaction was also confirmed in the study on value orientations (Chapter 4). Here too, autonomy satisfaction mediated between leadership and work engagement, while neither competence nor relatedness satisfaction played a significant role. The study's structural model (assuming a link between engaging leadership and work engagement via intrinsic value perceptions and autonomy 
satisfaction) explained $55 \%$ of the variance in engagement-with all three basic needs $57 \%$. This result supports the theoretical consideration brought forward by Ryan and Deci (2017) that "In many circumstances, needs for relatedness and competence are dependent for their fulfillment on the person's capacity and freedom to self-organize actions" (p. 250). Moreover, "(...) autonomy (...) is essential to the initiation and regulation of behavior through which other needs are better realized" (p. 250). In summary, we found that the process underlying leadership explains positive outcomes through basic psychological needs theory, with a more prominent role for autonomy satisfaction. This implies that the basic psychological needs of autonomy, competence, and relatedness should be measured separately and not as one higher-order construct, because of their distinct roles and varying predictive relevance (Van den Broeck et al., 2016).

Second, the purpose study in Chapter 3 contributed to knowledge development by examining a real, existing corporate purpose that matched the definition of a higher purpose in alignment with shareholder value theory (Freeman, 2004). Our study confirmed that a broader purpose fuels work engagement and may inspire motivated employees. It is the first study to empirically research the psychological dynamic between purpose, motivation, and engagement. An earlier study by Parmar et al. (2017) supports our results indirectly. In that study the authors formulated and tested various hypothetical corporate objectives and found that that a broader corporate objective associated positively with higher need satisfaction.

Third, the study in Chapter 4 revealed that engaging leadership influences how employees experience the organization; Engaging leaders support employees to perceive the intrinsic qualities of the organization rather than the extrinsic qualities. We found that values such as care, contributing to make the world a better place, and self-development associated positively with enhanced need satisfaction and engagement. The study in Chapter 4 builds on a small number of studies that connect leadership with beneficial outcomes through intrinsic values. A recent study in the sports domain (Castillo et al., 2018) revealed that coaches' self-transcendent values, such as universalism and benevolence (Schwartz, 2012), enhanced feelings of autonomy-support among players. In a similar vein, Castillo et al. (2018) point to the importance of a strong intrinsic value base for effective, autonomy-supportive leadership. Parallel to the opposition between intrinsic and extrinsic orientations, Schwartz (1992) contrasted self-enhancement and self-transcendent orientations. Like the extrinsic values of power, status, and financial success (Kasser \& Ryan, 1996), selfenhancement is related to self-interest through controlling resources and people, and is demonstrated in ambition and competence (Schwartz, 2012). Self-transcendence aligns with intrinsic orientations and emphasizes serving others' interests, displaying 
genuine care for whom is close (benevolence), and acceptance and tolerance of all (universalism, Sagiv \& Schwartz, 2007). As Yukl (2012) pointed out, values and intrinsic orientations have received limited attention in leadership studies. However, many leadership theories (e.g., servant leadership, Greenleaf, 1998, or authentic leadership, Gardner et al., 2011; George, 2003) do contend that leaders who exhibit values such as compassion, fairness, and humility are more effective. As such, the present study adds to a small niche of leadership research into the positive effects of personal values on performance and well-being.

Fourth, the intervention study (Chapter 5) confirmed that engaging leadership, taught through leadership development training sessions, may lead to real-world business results, as measured through key performance indicators. Additionally, we found a positive impact on autonomy satisfaction and intrinsic motivation for the team leaders who participated in the intervention compared to a control group. Previous studies in leadership interventions or development programs that were based on selfdetermination theory also found that (autonomy-supportive) leadership behaviors can be learned (Hardré \& Reeve, 2009), and lead to improved performance (Deci et al., 1989) and positive performance evaluations (Baard et al., 2004). However, in the present study, we found no impact on employees beyond improved KPI performance and lower absenteeism. Deci et al. (1989) also found no conclusive spill-over effects on team members in their intervention study. In contrast, Hardré and Reeve (2009) reported positive differences for employees in autonomous motivation and work engagement from their training intervention.

The absence of indirect effects of leadership development programs from team leaders to employees is, however, not unique (Kelloway \& Barling, 2010). We assume that the lack of indirect beneficial psychological effects in our study is due to the fact that team members were not involved in the co-creation phase (Tafvelin et al., 2018). Hence, they had no influence on the goal-setting process, potentially explaining why their levels of autonomy satisfaction and intrinsic motivation remained unchanged. Nor did team members participate in the training sessions. Presumably, extending the training sessions to include team members in some way may have had an additional beneficial effect.

\section{Limitations}

The present thesis and the four studies presented have some limitations. The first limitation is that the data were gathered from three different groups of respondents employed in two European multinational organizations located in The Netherlands, limiting generalizability across geographic regions and cultures. Studies show that 
culture may moderate leadership outcomes and perceptions (Campion \& Wang, 2019). For example, a recent analysis among Australian managers using Hofstede's five dimensions of culture model showed that authentic leadership appealed more to followers with Western cultural values and that cultural values moderated leadership perceptions and trust in the leader (Lux \& Mao, 2019). For engaging leadership, the moderating role of culture has not been analyzed so far, but, considering previous research, should be assumed.

Another limitation is formed by the cross-sectional design that is used in some of the studies. We followed suggestions for the optimization of cross-sectional designs as put forward by Spector (2019). However, strictly speaking, the author also states that cross-sectional studies cannot serve the purpose of mediational analyses. The two longitudinal studies aimed to counterbalance this issue. They expanded the findings of cross-sectional studies in a two-step approach to explicitly test whether the results of the cross-sectional studies would hold over time and whether we could establish directionality.

Due to practical constraints, time intervals in the longitudinal studies' measurements were not identical and varied from eight months to one year, which poses a third limitation. It is considered good practice to have equal intervals between measurements (McArdle \& Nesselroade, 2014). Also, considering the intervals' length, all kinds of (intraand extra-) organizational phenomena may have occurred and influenced fluctuations in the variable's means (cf. Ancona et al., 2001). It would have been better to have had identical and shorter intervals between measurements, but unfortunately that was not possible for practical reasons.

A fourth limitation is that, despite its rooting in a well-established theory of human motivation, engaging leadership is a relatively new concept and cannot draw on a wealth of studies. However, more and more research on engaging leadership is being published. For instance, a diary study investigated the impact of engaging leadership on daily team job-crafting (Mäkikangas et al., 2017) and confirmed a positive effect on employee's job crafting behaviors. Another research project analyzed the relationships with autonomy, social support, learning opportunities, and work engagement in a crossed and lagged panel study (Nikolova et al., 2019). That study found a significant cross-lagged relationship between engaging leadership and autonomy, which supports our study's outcomes in Chapter 2, where we identified a pivotal role for autonomy. However, the Nikolova et al. 's study found no direct effect from engaging leadership to work engagement, in contrast with the outcomes in Chapter 2 that suggest the opposite. The relationship between engaging leadership and work 
engagement in our study in Chapter 2 is explained by need satisfaction, which result builds on the mediational analyses on the role of basic needs satisfaction, as found in e.g., Rahmadani et al. (2019). Additionally, in the present thesis, we found needs frustration in engaging leadership (Chapter 2) also partially mediated the relationship with work engagement. We further add to the developing body of research on engaging leadership by examining the impact of engaging leadership on employees' intrinsic value perceptions (Chapter 4), and the intervention study into business results and well-being (Chapter 5).

A more general challenge in leadership research is construct proliferation (Shaffer et al., 2016). Several authors point to item overlap and redundancy issues, such as between servant, ethical, authentic, and transformational leadership. Hoch et al. (2016) found that authentic leadership, for example, did not explain additional variance in outcome measures compared to transformational leadership. In a discussion paper on construct proliferation and leadership style research, Bormann \& Rowold (2018) suggested that leadership constructs can be described more parsimoniously by referring to selfdetermination theory as the underlying mechanism. Engaging leadership is based on self-determination theory, which, from this view, can be interpreted as a plea for using this concept. Still, readers will find item-overlap with other leadership constructs such, for example, empowering leadership (Amundsen \& Martinsen, 2015) or psychological empowerment (Spreitzer, 1995).

In our view, emphasizing the issue of construct proliferation, however important, blurs the essential point of the underlying process explaining the impact of leadership on work engagement. The strength of the engaging leadership concept does not lie in the description of specific leadership behaviors. Although a particular leadership concept may be associated with positive outcomes, it is more interesting to look into the process of why that may be so. In keeping with the tenets of self-determination theory, we believe that employee engagement, for a considerable part, results from dynamic interplay between the social context of work, including leadership (leadership behaviors) and how employees perceive it. Specific leadership behaviors may stir something in the recipients and hence foster or thwart their motivational energy. Still, it is not the leadership behaviors per se, but rather the dialectical relationship between these behaviors, the social context, and how employees integrate these in their sense of self (Deci et al., 1994). The focus on specific leadership behaviors or leadership style, for that matter, traps one into searching for and identifying particular behaviors. As a result, one risks becoming more authoritative and detailed about what leaders should do without adding explanatory value to the outcomes (as shown by Hoch et al., 2016) or knowing why particular behaviors matter. 


\section{Suggestions for Future Research}

A few specific suggestions for future research sprang forward from evaluating the studies' results. A first suggestion builds on the dialectic dynamic, as posited by selfdetermination theory, which postulates that leaders create social realities through interacting with social contexts. Employees respond to what leaders do or say, interact with them and each other, and thus co-create shared realities. Everyday reality is continuously recreated as a result of this dynamic and tends to influence and flow from the person's sense of self (Deci et al., 1994; Ryan \& Deci, 2017). It would be interesting to delve deeper into these exchanges and experiment with approaches that support healthy, sustainable motivation and foster engagement and well-being.

One aspect of the dynamic between managers and team members is the conversational exchanges they are engaged in at one-to-one and team-level. It would be interesting to follow leaders and their teams and qualitatively and quantitatively analyze their conversations (cf. Shotter, 1993; Tannen et al., 2015). This research might address questions such as: to what extent does their verbal exchange satisfy basic needs and contribute to motivation, engagement, and performance? What aspects of their interaction are detrimental to motivation and engagement? What conversations do leaders and colleagues have? What conversations do they think they should be having but are reluctant to have? The answers to these questions could be fed back and discussed in a group dialogue setting (cf. Bohm, 2004). The team can then decide to integrate the dialogue's outcomes in their everyday practices and evaluate progress regularly. External researchers and coaches can guide the process.

Secondly, we suggest to study the effects of different purposes of organizations on motivation and engagement through a typology of corporate objectives. In line with our findings and the literature we expect a broader, more comprehensive corporate purpose, as described in Chapter 3, will contribute to enhanced employee motivation, engagement, and performance. Conversely, a narrower objective emphasizing a traditional shareholder value perspective will, we expect, display lower positive or even negative associations. Future research into this issue is important because the study presented in this thesis comprised the analysis of one specific organization's purpose. It also was the first study to map the psychological effects of a corporate objective on motivation and engagement. The challenge for researchers is to gather and classify different corporate purposes from various organizations and geographical regions and test their association with employee's motivation and engagement. Additionally, the research could incorporate a meaning-in-life or purpose-in-life questionnaire (e.g. Schulenberg et al., 2010) or a short satisfaction with life scale (e.g., Kjell \& Diener, 2020). 
This would allow to investigate the centrality of work in employee's lives and their potential contribution to happiness, well-being, and becoming (Ciulla, 2000; Martela \& Pessi, 2018): In other words, does a corporate purpose contribute to a sense of meaning in life?

The third suggestion for further research is about values. Chapter 4 showed that engaging leaders influence how employees perceive their organization's values. Moreover, we found a significant positive association of intrinsic value perceptions with autonomy satisfaction and work engagement. However, we know little about how these value perceptions can be supported in practice through the interactions that leaders have with their teams and individual team members. Similar to the first suggestion for further study, we could zoom in on the exchange between team leaders and team members and focus specifically on value conversations and monitor the effects over time. Such a study may add to our knowledge about the role that values and value perceptions play in business life. It may deepen our understanding of how to lead in an autonomy-supportive and engaging manner and connect everyday leadership with well-being and performance more solidly.

\section{Practical Suggestions and Considerations for Leaders}

In this final section want to offer a few practical suggestions for leaders, based on the results of our studies. Not as a step-by-step 'how-to', but as suggestions worth considering. First, a short word of caution. Our studies uncovered statistical associations between variables, for example, that a broader purpose predicts work engagement. At first glance, the associations we found suggest that an organization with a broader corporate objective aiming to benefit all stakeholders is likely to have highly engaged employees and better business results. However, on second thought this would be too simplistic a representation. We believe it is necessary but far from sufficient for an organization to have a higher purpose or a well-defined set of values. Many organizations promote a higher purpose and concomitant values through their corporate communication, but that does not mean the organization lives and breathes them. It certainly does not automatically bring high levels of employee engagement; Otherwise, we would not have a crisis of work engagement (Mann \& Harter, 2016). Purpose and values should be actively propagated and discussed with employees and not remain empty vessels mainly to promote a companies' public image (cf. Urbany, 2005; Roth ,2013).

Motivation and engagement result from the dynamic interplay between organizational members in their various roles. Everyday reality is created by people who communicate with each other, either actively in dialogue or through any other means 
of communication, whether it be emails, social media, procedures, regulations, and the like (cf. Maturana \& Varela, 1992; Shotter, 1993; Taylor, 1991; Winch, 1988). These conversational exchanges, and the dynamic social realities they constitute, leave a psychological imprint on its participants, be it the manager or the employee. For example, when participants feel their basic needs are nurtured, we observed that these exchanges likely have been autonomy-supportive. Or contrarily, when participants feel their needs are being frustrated or even thwarted, their well-being may decrease at the cost of motivation, engagement, and performance. The psychological quality and the integrity of the interaction, we argue, is a determining factor in building a healthy and inspiring work environment for which the satisfaction of basic psychological needs is indispensable.

It follows that it is essential to live and enact your purpose and values and to focus on the quality of the exchange between organizational members and the psychological context you set as leaders to facilitate that exchange, whether initiated at midlevel or from the top. Practically speaking this means ensuring active participation of all employees, involving and engaging them in meaningful dialogue in a psychologically safe setting. And while so doing, paying close attention to the fulfillment of their basic psychological needs of autonomy, competence, and relatedness.

For leadership, purpose, or values, it is all the same. For example, as with an organizational goal and a life's purpose, values also carry a personal dimension, such as aspirations for a good life. And since we found that intrinsic preferences are associated with higher well-being and enhanced performance, it only seems logical to have a conversation about values. Before handing over the firm's values statement, one may ask employees about their personal values, how they see themselves, what they aspire, and what they wish to contribute to the company's goal. The dialogue about the employees' value preferences, the organization's values, and the broader organizational goal can help employees identify with the firm's aspirations. Through meaningful and fulfilling dialogue they may find ways to contribute to its realization.

Specific suggestions to satisfy basic psychological needs can be found in the Table below (Table 1), in the introduction section (Chapter 1), and at the end of Chapter 2. Specific considerations to explore and address the organization's purpose and raison d'être can be found in Chapter 3, which ends with a list of practical steps to evaluate its current purpose. Values and the impact of engaging leadership on value perceptions are discussed in Chapter 4, and specific lessons for leadership development programs and interventions are summarized in Chapter 5. 
Table 1

Some Practical Considerations for Engaging Leaders

\begin{tabular}{ll}
\hline $\begin{array}{l}\text { Engaging } \\
\text { leaders foster }\end{array}$ & \multicolumn{1}{c}{ Core suggestions } \\
\hline Autonomy & $\begin{array}{l}\text { Present a compelling vision, } \\
\text { employees identify with; Always } \\
\text { present a clear well-articulated } \\
\text { reason why; Involve employees in } \\
\text { decision making, allow for freedom of } \\
\text { choice and space to self-direct; Invite } \\
\text { to co-create. }\end{array}$ \\
Competence & $\begin{array}{l}\text { Frequent (positive) feedback; } \\
\text { Atmosphere of joy, playful exploration, } \\
\text { learning; Room and support for } \\
\text { personal and professional growth; } \\
\text { Provide interesting challenges }\end{array}$ \\
& $\begin{array}{l}\text { Make employees feel at home, listen } \\
\text { well, ask (open ended) questions; } \\
\text { Coach empathically, move with } \\
\text { resistance; Allow space to disagree } \\
\text { without repercussions; Be open and } \\
\text { clear about objectives } \\
\text { and show authentic care; Build } \\
\text { meaningful relationships }\end{array}$
\end{tabular}

Purpose Evaluate the firms' broader corporate purpose beyond its financial strategy and performance: to what cause does the firm contribute? Involve stakeholders including employees; Actively discuss the larger purpose with stakeholders. Measure and report the impact on stakeholders. Integrate ethics into governance and ways of working

Values
Enter into a meaningful dialogue on values with employees; Explore how employees perceive the organization's values and how this aligns with their personal aspirations. A caring interpersonal environment; Making a meaningful contribution to something of value; To be challenged in interesting ways; To be offered opportunities for growth and self-development.
Self-leadership, initiative, creativity, enthusiasm, perseverance, enhanced well-being and work engagement and autonomous motivation; Stimulates satisfaction of competence and relatedness as well

Positive atmosphere, sense of personal and professional growth, contribution, and significance

\section{A sense of belonging and} psychological safety, harmonious relationships, honesty and integrity

Increased work engagement and appeals to a sense of meaningfulness and significance. Stimulates autonomous motivation and satisfies basic psychological needs

Leads to higher need satisfaction, work engagement and performance 


\section{Conclusion}

The central premise of the current thesis was to assess whether engaging leadership, a broader corporate objective and attentive care for values and the basic psychological needs of employees contribute to eudaimonic well-being and enhanced performance. We considered this important because current leadership studies do not pay much attention to a broader purpose (e.g., Kempster et al., 2011), its psychological effects (Parmar et al., 2017), or intrinsic values (Yukl, 2012). On the other hand, business studies (e.g., Henderson \& Steen, 2015) and studies into corporate governance (e.g., Berger, 2019; Sjafjell \& Taylor, 2019) do emphasize the necessity of purpose and values for a sustainable future for businesses, people, society and the environment. However, they do not focus om the underlying psychological process.

Instead of looking into leadership and its direct relationships with positive outcomes, we investigated the underlying process in an attempt to offer a psychological explanation rooted in a theory on (employee) motivation. As expected, we found that engaging leadership, embracing and communicating a higher purpose, and attending to employee value perceptions enhance work engagement and motivation through the satisfaction of basic psychological needs. Moreover, we found that need satisfaction-specifically autonomy satisfaction-explained over half of the variance in motivation and engagement outcomes.

The importance of human motivation in explaining leadership outcomes underscores that leadership is about process and context rather than resulting from the leaders' personality, character, or behaviors. When the leadership context is positive, nourishing, and supportive, it stimulates personal growth and development, promotes self-direction and well-being, and increases performance. Following self-determination theory (Ryan \& Deci, 2017) and Ciulla (2018), we believe it is the task of leadership to create the social, psychological, and material conditions under which people flourish and can be productive.

Work may encourage and support people to self-actualize in their journey through life, as Maslow (1998) suggested. And why not? After all, work has become central to people's sense of meaning and significance. It is about time that organizations adjust to that reality. Engaging leaders can shape a work context where human beings flourish, grow, learn, and self-develop professionally and personally. Employees value contributing to meaningful outcomes beyond their immediate self-interest and make the world a better place. They find joy in exciting challenges and maintaining meaningful relationships in an environment of genuine care. They fare well when engaged and involved. And, finally, a wider awareness and enactment on a broader purpose adds to people's sense of agency and personal significance and may support human beings to fulfil their potential in dignity and equality. 


References 

Aguinis, H., Hill, N. S., \& Bailey, J. R. (2019). Best practices in data collection and preparation: Recommendations for reviewers, editors, and authors. Organizational Research Methods, 51 , 109442811983648. http://doi.org/10.1177/1094428119836485

Albers, C., \& Lakens, D. (2018). When power analyses based on pilot data are biased: Inaccurate effect size estimators and follow-up bias. Journal of Experimental Social Psychology, 74, 187195. http://doi.org/10.1016/j.jesp.2017.09.004

Alimo-Metcalfe, B. (2013). A critical review of leadership theory. In H. S. Leonard, R. Lewis, A. M. Freedman, \& J. Passmore (Eds.), The Wiley-Blackwell handbook of the psychology of leadership, change and organizational development. Chichester, West Sussex, UK: Wiley-Blackwell

Amabile, T. M. (1985). Motivation and creativity: Effects of motivational orientation on creative writers. Journal of Personality and Social Psychology, 48(2), 393-399. http://doi.org/10.1037/00223514.48.2.393

Amabile, T. M., \& Kramer, S. (2012). How leaders kill meaning at work. McKinsey Quarterly.

Amundsen, S., \& Martinsen, Ø. L. (2015). Linking empowering leadership to job satisfaction, work effort, and creativity. Journal of Leadership \& Organizational Studies, 22(3), 304-323. http:// doi.org/10.1177/1548051814565819

Ancona, D. G., Okhuysen, G. A., \& Perlow, L. A. (2001). Taking time to integrate temporal research. The Academy of Management Review, 26(4), 512. http://doi.org/10.2307/3560239

Anderson, S. E., \& Jamison, B. (2014). Do the top U.S. Corporations often use the same words in their Vision, Mission and Value Statements? (pp. 22-36). Presented at the 7Th Annual International Business, Health and Engineering Conference.

Ardichvili, A., Natt och Dag, K., \& Manderscheid, S. (2016). Leadership development. Advances in Developing Human Resources, 18(3), 275-285. http://doi.org/10.1177/1523422316645506

Argyris, C. (1964). Integrating the individual and the organization. New York, NY: John Wiley \& Sons.

Arntz, M., Gregory, T., \& Zierahn, U. (2020). Digitalization and the future of work: Macroeconomic consequences. In K. F. Zimmerman (Ed.), Handbook of Labor, Human Resources and Population Economics (pp. 1-29). Cham: Springer

Asendorpf, J. B., van de Schoot, R., Denissen, J. J. A., \& Hutteman, R. (2014). Reducing bias due to systematic attrition in longitudinal studies: The benefits of multiple imputation. International Journal of Behavioral Development, 38(5), 453-460. http://doi.org/10.1177/0165025414542713

Avolio, B. J., \& Gardner, W. L. (2005). Authentic leadership development: Getting to the root of positive forms of leadership. The Leadership Quarterly, 16(3), 315-338. http://doi.org/10.1016/j. leaqua.2005.03.001

Avolio, B. J., Zhu, W., Koh, W., \& Bhatia, P. (2004). Transformational leadership and organizational commitment: mediating role of psychological empowerment and moderating role of structural distance. Journal of Organizational Behavior, 25(8), 951-968. http://doi.org/10.1002/ job.283

Baard, P. P., Deci, E. L., \& Ryan, R. M. (2004). Intrinsic need satisfaction: A motivational basis of performance and well-being in two work settings. Journal of Applied Social Psychology, 34(10), 2045-2068. http://doi.org/10.1111/j.1559-1816.2004.tbo269o.x

Babcock-Roberson, M. E., \& Strickland, O. J. (2010). The relationship between charismatic leadership, work engagement, and organizational citizenship behaviors. The Journal of Psychology, 144(3), 313-326. http://doi.org/10.1080/00223981003648336

Bailey, C., Madden, A., Alfes, K., Shantz, A., \& Soane, E. (2017). The mismanaged soul: Existential labor and the erosion of meaningful work. Human Resource Management Review, 27(3), 416430. http://doi.org/10.1016/j.hrmr.2016.11.001 
Bajer, J. (2016). What's the point? The search for purpose at work. Strategic HR Review, 15(1), 25-28. http://doi.org/10.1108/SHR-12-2015-0094

Bakker, A. B. (2011). An evidence-based model of work engagement. Current Directions in Psychological Science, 20(4), 265-269. http://doi.org/10.1177/0963721411414534

Bakker, A. B., \& Demerouti, E. (2008). Towards a model of work engagement. Career Development International, 13(3), 209-223. http://doi.org/10.1108/13620430810870476

Bakker, A. B., \& Demerouti, E. (2013). The Job Demands-Resources model: state of the art. Journal of Managerial Psychology, 22(3), 309-328. http://doi.org/10.1108/02683940710733115

Bakker, A. B., \& Schaufeli, W. B. (2008). Positive organizational behavior: engaged employees in flourishing organizations. Journal of Organizational Behavior, 29(2), 147-154. http://doi. org/10.1002/job.515

Bakker, A. B., Hakanen, J. J., Demerouti, E., \& Xanthopoulou, D. (2007). Job resources boost work engagement, particularly when job demands are high. Journal of Educational Psychology. 99(2), 274-284. http://doi.org/10.1037/0022-0663.99.2.274

Bandura, A. (1977). Self-efficacy: Toward a unifying theory of behavioral change. Psychological Review, 84(2), 191-215.

Bandura, A. (2010). Self-Efficacy. In I.B. Weiner, \& W.E. Craighead. The Corsini Encyclopedia of Psychology, Vol. 1, pp. 69-3). Hoboken, NJ, USA: Wiley. http://doi.org/10.1002/9780470479216. corpsy0836

Barnett, A. G. (2004). Regression to the mean: what it is and how to deal with it. International Journal of Epidemiology, 34(1), 215-220. http://doi.org/10.1093/ije/dyh299

Bartholomew, K. J., Ntoumanis, N., Ryan, R. M., Bosch, J. A., \& Thøgersen-Ntoumani, C. (2011). Self-determination theory and diminished functioning: The role of interpersonal control and psychological need thwarting. Personality and Social Psychology Bulletin, 37(11), 1459-1473. http://doi.org/10.1177/0146167211413125

Barton, D., Horváth, D., \& Kipping, M. (Eds.). (2016). Re-imagining capitalism. Oxford, UK: Oxford University Press.

Bass, B. M. (1985). Leadership and performance beyond expectations. New York: The Free Press.

Baumeister, R. F., \& Leary, M. R. (1995). The need to belong: Desire for interpersonal attachments as a fundamental human motivation. Psychological Bulletin, 117(3), 497-529. http://doi. org/10.1037/0033-2909.117.3.497

Bekke, D. W. (2006). Joy at work: A revolutionary approach to fun on the job. Seattle, WA: Pear Press.

Bennett, N., \& Lemoine, J. (2014). What VUCA really means for you. Retrieved March 24 2019, from https://hbr.org/2014/01/what-vuca-really-means-for-you

Bentler, P. M. (1990). Comparative fit indexes in structural models. Psychological Bulletin, 107(2), 238-246. http://doi.org/10.1037/0033-2909.107.2.238

Berger, D. J. (2019). Reconsidering stockholder primacy in an era of corporate purpose. SSRN Electronic Journal. http://doi.org/10.2139/ssrn.3327647

Berger, J. B. (2014). Leadership: A Concise Conceptual Overview. Retrieved June 18, 2020, from https://scholarworks.umass.edu/cie_faculty_pubs/18

Bersin, J. (2015, January 27). Becoming irresistible: A new model for employee engagement. Retrieved May 26, 2020, from https://www2.deloitte.com/us/en/insights/deloitte-review/ issue-16/employee-engagement-strategies.html

Bockelbrink, B., Priest, J., \& David, L. (2019). Sociocracy 3.0, Effective collaboration at any scale. Retrieved June 15, 2019, from https://sociocracy30.org 
Bohm, D. (2004). On dialogue. Abingdon, Oxon, UK: Routledge Classics.

Bormann, K. C., \& Rowold, J. (2018). Construct proliferation in leadership style research. Organizational Psychology Review, 8(2-3), 149-173. http://doi.org/10.1177/2041386618794821 Bowles, S. (2016). The moral economy. New Haven: Yale University Press.

Braun, S., Peus, C., Weisweiler, S., \& Frey, D. (2013). Transformational leadership, job satisfaction, and team performance: A multilevel mediation model of trust. The Leadership Quarterly, 24(1), 270-283. http://doi.org/10.1016/j.leaqua.2012.11.006

Breevaart, K., Bakker, A. B., Demerouti, E., Sleebos, D. M., \& Maduro, V., (2014a). Uncovering the underlying relationship between transformational leaders and followers' task performance. Journal of Personnel Psychology, 13(4), 194-203. http://doi.org/10.1027/1866-5888/a000118

Brosseau, D., Ebrahim, S., Handscomb, C., \& Thaker, S. (2019, May). The journey into an agile organization. Retrieved May 12, 2019, from https://www.mckinsey.com/nl/our-insights/ the-journey-to-an-agile-organization

Brown, D. J. (2018). In the minds of followers: Follower-centric approaches to leadership. In D. V. Day \& J. Antonakis (Eds.), The Nature of Leadership (pp. 82-108). Thousand Oaks, CA: Sage.

Brown, M. A. (1976). Values - A necessary but neglected ingredient of motivation on the job. Academy of Management Review, 1(4), 15-23. http://doi.org/10.5465/amr.1976.4396236

Brown, M. E., \& Treviño, L. K. (2006). Ethical leadership: A review and future directions. The Leadership Quarterly, 17(6), 595-616. http://doi.org/10.1016/j.leaqua.2006.10.004

BRT, Business Roundtable (2019, August 19). Business Roundtable Redefines the Purpose of a Corporation to Promote "An Economy That Serves All Americans." www.businessroundtable. org. Retrieved from https://www.businessroundtable.org/business-roundtable-redefinesthe-purpose-of-a-corporation-to-promote-an-economy-that-serves-all-americans

Bullinger, H.-J., Kühner, M., \& Van Hoof, A. (2010). Analysing supply chain performance using a balanced measurement method. International Journal of Production Research, 40(15), 35333543. http://doi.org/10.1080/00207540210161669

Burke, M. J., \& Day, R. R. (1986). A cumulative study of the effectiveness of managerial training. Journal of Applied Psychology, 71(2), 232-245. http://doi.org/0021-90lO/86VS00.75

Burns, J. M. (1978). Leadership. New York: Harper \& Row, Publishers.

Bycio, P. (1992). Job performance and absenteeism: A review and meta-analysis. Human Relations, 45(2), 193-220. http://doi.org/10.1177/001872679204500206

Campbell, I. (2007). Chi-squared and Fisher-Irwin tests of two-by-two tables with small sample recommendations. Statistics in Medicine, 26(19), 3661-3675. http://doi.org/10.1002/sim.2832

Campion, L. L., \& Wang, C. X. (2019). Collectivism and individualism: the differentiation of leadership. TechTrends, 63(3), 353-356. http://doi.org/10.1007/s11528-019-00399-x

Carasco-Saul, M., Kim, W., \& Kim, T. (2015). Leadership and employee engagement. Human Resource Development Review, 14(1), 38-63. http://doi.org/10.1177/1534484314560406

Casillas, A., Kyllonen, P. C., \& Way, J. D. (2019). Preparing students for the future of work. In F. Oswald, T. S. Behrend, \& L. Foster (Eds.), Workforce Readiness and the Future of Work. London, UK: Routledge

Castillo, I., Adell, F. L., \& Alvarez, O. (2018). Relationships between personal values and leadership behaviors in basketball coaches. Frontiers in Psychology, 9, 189. http://doi.org/10.3389/ fpsyg.2018.01661

Chen, B., Vansteenkiste, M., Beyers, W., Boone, L., Deci, E. L., Van der Kaap-Deeder, J., et al. (2014). Basic psychological need satisfaction, need frustration, and need strength across four cultures. Motivation and Emotion, 39(2), 216-236. http://doi.org/10.1007/s11031-014-9450-1 
Chen, G., Tjosvold, D., \& Liu, C. (2006). Cooperative goals, leader people and productivity values: Their contribution to top management teams in China. Journal of Management Studies, 43(5), 1177-1200. http://doi.org/10.1111/j.1467-6486.2006.00633.x

Cho, E. (2016). Making reliability reliable: A systematic approach to reliability coefficients. Organizational Research Methods, 19(4), 651-682. http://doi.org/10.1177/1094428116656239

Ciulla, J. B. (2000). The working life: the promise and betrayal of modern work. New York, NY: Three Rivers Press.

Ciulla, J. B. (2018). Ethics and effectiveness: The nature of good leadership. In D. V. Day \& J. Antonakis (Eds.), The Nature of Leadership. Thousand Oaks, CA: Sage.

Cohen, J. (1988). Statistical power analysis for the behavioral sciences. New Jersey, NJ: L. Erlbaum Associates.

Coles, J. L., \& Li, Z. F. (2011). An empirical assessment of empirical corporate finance. SSRN Electronic Journal. http://doi.org/10.2139/ssrn.1787143

Conway, J. M., \& Lance, C. E. (2010). What reviewers should expect from authors regarding common method bias in organizational research. Journal of Business and Psychology, 25(3), 325-334. http://doi.org/10.1007/s10869-010-9181-6

Cordeiro, P., Paixão, P., Lens, W., Lacante, M., \& Luyckx, K. (2016). The Portuguese validation of the basic psychological need satisfaction and frustration scale: Concurrent and longitudinal relations to well-being and ill-being. Psychologica Belgica, 56(3), 193-209. http://doi. org/10.5334/pb.252

Day, D. V., Fleenor, J. W., Atwater, L. E., Sturm, R. E., \& McKee, R. A. (2014). Advances in leader and leadership development: A review of 25 years of research and theory. The Leadership Quarterly, 25(1), 63-82. http://doi.org/10.1016/j.leaqua.2013.11.004

de Charms, R. (1968). Personal Causation. New York: Academic Press.

De Muynck, G.-J., Vansteenkiste, M., Delrue, J., Aelterman, N., Haerens, L., \& Soenens, B. (2017). The effects of feedback valence and style on need satisfaction, self-talk, and perseverance among tennis players: An experimental study. Journal of Sport \& Exercise Psychology, 39(1), 67-80. http://doi.org/10.1123/jsep.2015-0326

Deci, E. L., \& Flaste, R. (1996). Why we do what we do. New York, NY: Penguin Books.

Deci, E. L., \& Ryan, R. M. (1985). Intrinsic motivation and self-determination in human behavior. New York, NY: Springer.

Deci, E. L., \& Ryan, R. M. (2000). The" what" and "why" of goal pursuits: Human needs and the self-determination of behavior. Psychological Inquiry, 11(4), 227-268. http://doi.org/10.1207/ S15327965PLI1104_01

Deci, E. L., \& Ryan, R. M. (2008). Facilitating optimal motivation and psychological well-being across life's domains. Canadian Psychology/Psychologie Canadienne, 49(1), 14-23. http://doi. org/10.1037/0708-5591.49.1.14

Deci, E. L., Connell, J. P., \& Ryan, R. M. (1989). Self-determination in a work organization. Journal of Applied Psychology, 74(4), 580-590. http://doi.org/10.1037/0021-9010.74.4.580

Deci, E. L., Eghrari, H., Patrick, B. C., \& Leone, D. R. (1994). Facilitating internalization: The selfdetermination theory perspective. Journal of Personality, 62(1), 119-142. http://doi. org/10.1111/j.1467-6494.1994.tbo0797.x

Deci, E. L., Olafsen, A. H., \& Ryan, R. M. (2017). Self-determination theory in work organizations: The state of a science. The Annual Review of Organizational Psychology and Organizational Behavior, 4, 19-43. http://doi.org/10.1146/annurev-orgpsych-032516-113108 
Delaney, M. L., \& Royal, M. A. (2017). Breaking engagement apart: The role of intrinsic and extrinsic motivation in engagement strategies. Industrial and Organizational Psychology, 10(1), 127-140. http://doi.org/10.1017/iop.2017.2

Deloitte. (2016). Global human capital trends 2016. Retrieved from https://www2.deloitte.com/ content/dam/Deloitte/global/Documents/HumanCapital/gx-dup-global-human-capitaltrends-2016.pdf

Denning, P. J., \& Dunham, R. (2010). The innovators way. Cambridge, MA: The MIT Press.

Derue, D. S., Nahrgang, J. D., Wellman, N., \& Humphrey, S. E. (2011). Trait and behavioral theories of leadership: an integration and meta-analytic test of their relative validity. Personnel Psychology, 64(1), 7-52. http://doi.org/10.1111/j.1744-6570.2010.01201.x

Di Fabio, A., \& Blustein, D. L. (2016). From meaning of working to meaningful lives: The challenges of expanding decent work. Frontiers Media SA.

Dittmar, H., Bond, R., Hurst, M., \& Kasser, T. (2014). The relationship between materialism and personal well-being: A meta-analysis. Journal of Personality and Social Psychology, 107(5), 879-924. http://doi.org/10.1037/a0037409

Doshi, N., \& McGregor, L. (2015). Primed to perform. New York: HarperCollins.

Douwes, M., \& Hooftman, W. (Eds.). (2020). Arbobalans 2018: Kwaliteit van de arbeid, effecten en maatregelen in Nederland. Leiden: TNO.

Drath, W. H., McCauley, C. D., Palus, C. J., Van Velsor, E., O'Connor, P. M. G., \& McGuire, J. B. (2008). Direction, alignment, commitment: Toward a more integrative ontology of leadership. The Leadership Quarterly, 19(6), 635-653. http://doi.org/10.1016/j.leaqua.2008.09.003

Duhigg, C. (2016). Smarter, better, faster. New York, NY: Random House.

Duriez, B., Soenens, B., \& Vansteenkiste, M. (2007). In search of the antecedents of adolescent authoritarianism: The relative contribution of parental goal promotion and parenting style dimensions. European Journal of Personality, 21(4), 507-527. http://doi.org/10.1002/per.623

Ebert, C., Hurth, V., \& Prabhu, J. (2018, July). The what, why and the how of purpose. Retrieved August 11, 2020, from https://www.managers.org.uk/ /media/Files/Reports/Guide-forLeaders-White-Paper.pdf

Edmondson, A. C., \& Lei, Z. (2014). Psychological safety: The history, renaissance, and future of an interpersonal construct. Annual Review of Organizational Psychology and Organizational Behavior, 1(1), 23-43. http://doi.org/10.1146/annurev-orgpsych-031413-091305

Ellsworth, R. R. (2002). Leading with purpose: The new corporate realities. Stanford, CA: Stanford University Press.

Elshout, R., Scherp, E., \& van der Feltz-Cornelis, C. M. (2013). Understanding the link between leadership style, employee satisfaction, and absenteeism: a mixed methods design study in a mental health care institution. Neuropsychiatric Disease and Treatment, 823. http://doi. org/10.2147/NDT.S43755

Estampe, D., Lamouri, S., Paris, J.-L., \& Brahim-Djelloul, S. (2013). A framework for analysing supply chain performance evaluation models. International Journal of Production Economics, 142(2), 247-258. http://doi.org/10.1016/j.ijpe.2010.11.024

Eversole, B. A. W., Venneberg, D. L., \& Crowder, C. L. (2012). Creating a flexible organizational culture to attract and retain talented workers across generations. Advances in Developing Human Resources, 14(4), 607-625. http://doi.org/10.1177/1523422312455612

Fink, L. (2019, January). Larry Fink's 2019 Letter to CEOs: Purpose and profit. Retrieved February 15, 2019, from https://www.blackrock.com/americas-offshore/2019-larry-fink-ceo-letter 
Fitzgerald, G. A., \& Desjardins, N. M. (2004). Organizational values and their relation to organizational performance outcomes. Atlantic Journal of Communication, 12(3), 121-145. http://doi. org/10.1207/s15456889ajc1203_1

Fotaki, M., Lioukas, S., \& Voudouris, I. (2019). Ethos is destiny: Organizational values and compliance in corporate governance. Journal of Business Ethics, 9(1), 483-19. http://doi.org/10.1007/ s10551-019-04126-7

Frankl, V. E. (2008). Man's Search for Meaning. London, UK: Ebury.

Fredrickson, B. L. (2013). Love 2.0: Creating happiness and health in moments of connection. New York, NY: Hudson Street Press.

Freeman, R. E. (1994). The politics of stakeholder theory: Some future directions. Business Ethics Quarterly, 4(4), 409-421. http://doi.org/10.2307/3857340

Freeman, R. E., Phillips, R., \& Sisodia, R. (2018). Tensions in stakeholder theory. Business and Society, 59(2), 213-231. http://doi.org/10.1177/0007650318773750

Freeman, R. E., Wicks, A. C., \& Parmar, B. (2004). Stakeholder theory and "The corporate objective revisited." Organization Science, 15(3), 364-369. http://doi.org/10.1287/orsc.1040.0066

Fremeaux, S., \& Pavageau, B. (2020). Meaningful leadership: How can leaders contribute to meaningful work? Journal of Management Inquiry, 57(4), 105649261989712-13. http://doi. org/10.1177/1056492619897126

Friedman, M. (2007). The social responsibility of business is to increase its profits. In W. C. Zimmerli, M. Holzinger, \& K. Richter (Eds.), Corporate ethics and corporate governance (pp. 173-178). Berlin, Heidelberg: Springer. http://doi.org/10.1007/978-3-540-70818-6_14

Frooman, J., Mendelson, M. B., \& Kevin Murphy, J. (2012). Transformational and passive avoidant leadership as determinants of absenteeism. Leadership \& Organization Development Journal, 33(5), 447-463. http://doi.org/10.1108/01437731211241247

Fukuyama, F. (2018). Identity: The demand for dignity and the politics of resentment. New York, NY: Farrar, Straus and Giroux.

Gagné, M., \& Deci, E. L. (2005). Self-determination theory and work motivation. Journal of Organizational Behavior, 26(4), 331-362. http://doi.org/10.1002/job.322

Gagné, M., Forest, J., Vansteenkiste, M., Crevier-Braud, L., Broeck, A. V. D., Aspeli, A. K., et al. (2014). The Multidimensional Work Motivation Scale: Validation evidence in seven languages and nine countries. European Journal of Work and Organizational Psychology, 24(2), 178-196. http://doi.org/10.1080/1359432X.2013.877892

Gallup (2017). State of the Global Workplace. New York: Gallup Press.

Gang Wang, Oh, I. S., Courtright, S. H., \& Colbert, A. E. (2011). Transformational leadership and performance across criteria and levels: A meta-analytic review of 25 years of research. Group \& Organization Management, 36(2), 223-270. http://doi.org/10.1177/1059601111401017

Gardner, W. L., \& Schermerhorn, J. R., Jr. (2004). Unleashing individual potential:. Organizational Dynamics, 33(3), 270-281. http://doi.org/10.1016/j.orgdyn.2004.06.004

Gardner, W. L., Avolio, B. J., Luthans, F., May, D. R., \& Walumbwa, F. (2005). "Can you see the real me?" A self-based model of authentic leader and follower development. The Leadership Quarterly, 16(3), 343-372. http://doi.org/10.1016/j.leaqua.2005.03.003

Gardner, W. L., Cogliser, C. C., Davis, K. M., \& Dickens, M. P. (2011). Authentic leadership: A review of the literature and research agenda. The Leadership Quarterly, 22(6), 1120-1145. http://doi. org/10.1016/j.leaqua.2011.09.007

Gartenberg, C., Prat, A., \& Serafeim, G. (2016, June 30). Corporate Purpose and Financial Performance. Retrieved November 18, 2019, from http://nrs.harvard.edu/urn-3:HUL.InstRepos:30903237 
Gelles, D., \& Yaffe-Bellany, D. (2019, August 19). Shareholder value is no longer everything, top C.E.O.s say. The New York Times. Retrieved November 18, 2019, from https://wwww.nytimes. com/2019/08/19/business/business-roundtable-ceos-corporations.html

George, B. (2003). Authentic leadership. San Francisco, CA: Jossey-Bass.

Gillet, N., Berjot, S., \& Gobancé, L. (2009). A motivational model of performance in the sport domain. European Journal of Sport Science, 9(3), 151-158. http://doi.org/10.1080/17461390902736793

Gillet, N., Fouquereau, E., Huyghebaert, T., \& Colombat, P. (2015). The effects of job demands and organizational resources through psychological need satisfaction and thwarting. The Spanish Journal of Psychology, 18, 1-19. http://doi.org/10.1017/sjp.2015.30

Grant, A. M. (2012). Leading with meaning: Beneficiary contact, prosocial impact, and the performance effects of transformational leadership. Academy of Management Review, 55(2), 458-476. http://doi.org/10.5465/amj.2010.0588

Grant, A. M., \& Berry, J. W. (2011). The necessity of others is the mother of invention: Intrinsic and prosocial motivations, perspective taking, and creativity. Academy of Management Review, 54(1), 73-96. http://doi.org/10.5465/amj.2011.59215085

Grant, A. M., Nurmohamed, S., Ashford, S. J., \& Dekas, K. (2011). The performance implications of ambivalent initiative: The interplay of autonomous and controlled motivations. Organizational Behavior and Human Decision Processes, 116(2), 241-251. http://doi.org/10.1016/j. obhdp.2011.03.004

Greenleaf, R. K. (1998). The power of servant-leadership. (L. C. Spears, Ed.). San Fransisco, CA: Berrett-Koehler Publishers.

GRI, \& UN Global Compact. (2019). Business reporting on the SDGs: An analysis of goals and targets. Retrieved March 20, 2020, from https://www.globalreporting.org/resourcelibrary/ GRI_UNGC_Business-Reporting-on-SDGs_Analysis-of-Goals-and-Targets.pdf

Gurdjian, P., Halbeisen, T., \& Lane, K. (2014). Why leadership development programs fail. McKinsey Quarterly, January.

Hair, J. F., Hult, G. T. M., Ringle, C. M., \& Sarstedt, M. (2017). A primer on Partial Least Squares Structural Equation Modeling (PLS-SEM). Thousand Oaks, CA, USA: Sage Publications.

Hair, J. F., Sarstedt, M., Ringle, C. M., \& Gudergan, S. P. (2018). Advanced issues in partial least squares structural equation modeling (PLS-SEM). Los Angeles: Sage Publications.

Hamaker, E. L., Kuiper, R. M., \& Grasman, R. P. (2015). A critique of the cross-lagged panel model. Psychological Methods, 20(1), 102-116. http://doi.org/10.1037/a0038889

Hardré, P. L., \& Reeve, J. (2009). Training corporate managers to adopt a more autonomysupportive motivating style toward employees: an intervention study. International Journal of Training and Development, 13(3), 165-184. http://doi.org/10.1111/j.1468-2419.2009.00325.x

Harrison, J. S., Phillips, R. A., \& Freeman, R. E. (2019). On the 2019 Business Roundtable "Statement on the purpose of a corporation." Journal of Management, 74. http://doi. org/10.1177/0149206319892669

Haski-Leventhal, D. (2020). On purpose, impact, vision and mission. In The purpose-driven university (Vol. 70, pp. 7-22). Emerald Publishing Limited. http://doi.org/10.1108/978-1-83867-283620201003

Heerkens, G. (2010). The mysteries of ROI revealed. PM Network, 24(8), 21.

Henderson, R., \& Steen, E. V. D. (2015). Why do firms have "purpose?" The firm's role as a carrier of identity and reputation. American Economic Review, 105(5), 326-330. http://doi.org/10.1257/ aer.p20151072 
Henseler, J., Ringle, C. M., \& Sarstedt, M. (2015). A new criterion for assessing discriminant validity in variance-based structural equation modeling. Journal of the Academy of Marketing Science. 43(1), 115-135. http://doi.org/10.1007/s11747-014-0403-8

Henseler, J., Ringle, C. M., \& Sarstedt, M. (2016). Testing measurement invariance of composites using partial least squares. International Marketing Review, 33(3), 405-431. http://doi. org/10.1108/IMR-09-2014-0304

Henseler, J., Ringle, C. M., \& Sinkovics, R. R. (Eds.). (2009). Advances in International Marketing (Vol. 20). Bingley: Emerald Group Publishing. http://doi.org/10.1108/S1474-7979(2009)0000020014 Hetland, J., Hetland, H., Bakker, A. B., Demerouti, E., Andreassen, C. S., \& Pallesen, S. (2015). Psychological need fulfillment as a mediator of the relationship between transformational leadership and positive job attitudes. Career Development International, 20(5), 464-481. http:// doi.org/10.1108/CDI-10-2014-0136

Hoch, J. E., Bommer, W. H., Dulebohn, J. H., \& Wu, D. (2016). Do ethical, authentic, and servant leadership explain variance above and beyond transformational leadership? A meta-analysis Journal of Management, 37, 1-29. http://doi.org/10.1177/0149206316665461

Hogan, R., \& Kaiser, R. B. (2005). What we know about Leadership. Review of General Psychology, 9(2), 169-180. http://doi.org/10.1037/1089-2680.9.2.169

Howard, J., Gagné, M., Morin, A. J. S., \& Van den Broeck, A. (2016). Motivation profiles at work: A self-determination theory approach. Journal of Vocational Behavior, 95-96, 74-89. http://doi. org/10.1016/j.jvb.2016.07.004

Hull, C. L. (1943). Principles of behavior, an introduction to behavior theory. New York, NY: AppletonCentury-Crofts.

Hurst, A., Pearce, A., Erickson, C., Parish, S., Vesty, L., Schnidman, A., et al. (2016). Purpose at work. Retrieved August 12, 2020, from https://cdn.imperative.com/media/public/Global_ Purpose_Index_2016.pdf

Husted, B. W. (2016). Being good and doing well: not as easy as you think. In D. Barton, D. Horváth, \& M. Kipping (Eds.), Re-imagining Capitalism. Oxford, UK: Oxford University Press.

Huyghebaert, T., Gillet, N., Fernet, C., Lahiani, F.-J., \& Fouquereau, E. (2018). Leveraging psychosocial safety climate to prevent ill-being: The mediating role of psychological need thwarting Journal of Vocational Behavior, 107, 111-125. http://doi.org/10.1016/j.jvb.2018.03.010

Ilies, R., Morgeson, F. P., \& Nahrgang, J. D. (2005). Authentic leadership and eudaemonic well-being: Understanding leader-follower outcomes. The Leadership Quarterly, 16(3), 373-394. http:// doi.org/10.1016/j.leaqua.2005.03.002

ILO, Global Commission on the Purpose of Work. (2019). Work for a brighter future. Geneva: International Labour Organization.

Inceoglu, I., Thomas, G., Chu, C., Plans, D., \& Gerbasi, A. (2018). Leadership behavior and employee well-being: An integrated review and a future research agenda. The Leadership Quarterly, 29(1), 179-202. http://doi.org/10.1016/j.leaqua.2017.12.006

Jaakson, K. (2010). Engagement of organizational stakeholders in the process of formulating values statements. Atlantic Journal of Communication, 18(3), 158-176. http://doi. org/10.1080/15456871003742138

Jacobs, M., \& Mazzucato, M. (2016). Rethinking capitalism: Economics and policy for sustainable and inclusive growth. (M. Jacobs \& M. Mazzucato, Eds.). Hoboken, NJ: Wiley-Blackwell.

Judge, T. A., \& Bono, J. E. (2000). Five-factor model of personality and transformational leadership. The Journal of Applied Psychology, 85(5), 751-765. http://doi.org/10.1037/0021-9010.85.5.751 
Judge, T. A., Fluegge Woolf, E., Hurst, C., \& Livingston, B. (2006). Charismatic and transformational leadership. Zeitschrift Für Arbeits- Und Organisationspsychologie a\&O, 50(4), 203-214. http:// doi.org/10.1026/0932-4089.50.4.203

Kalshoven, K., Hartog, Den, D. N., \& De Hoogh, A. H. B. (2011). Ethical leadership at work questionnaire (ELW): Development and validation of a multidimensional measure. The Leadership Quarterly, 22(1), 51-69. http://doi.org/10.1016/j.leaqua.2010.12.007

Kanze, D., Conley, M. A., \& Higgins, E. T. (2020, February 12). Research: organizations that move fast really do break things. Retrieved March 8, 2020, from https://hbr.org/2020/02/researchorganizations-that-move-fast-really-do-break-things

Kaplan, R. S., \& Norton, D. P. (2001). Transforming the balanced scorecard from performance measurement to strategic management: Part I. Accounting Horizons, 15(1), 87-104. http://doi. org/10.2308/acch.2001.15.1.87

Kasser, T. (2002). Sketches for a self-determination theory of values. In E. L. Deci \& R. M. Ryan (Eds.), Handbook of self-determination research (pp. 123-140). Rochester, NY.

Kasser, T. (2016). Materialistic values and goals. Annual Review of Psychology, 67(1), 489-514. http:// doi.org/10.1146/annurev-psych-122414-033344

Kasser, T., \& Ryan, R. M. (1993). A dark side of the American dream: correlates of financial success as a central life aspiration. Journal of Personality and Social Psychology, 65(2), 410-422. http:// doi.org/10.1037/0022-3514.65.2.410

Kasser, T., \& Ryan, R. M. (1996). Further Examining the American Dream: Differential Correlates of Intrinsic and Extrinsic Goals. Personality and Social Psychology Bulletin, 22(3), 280-287. http:// doi.org/10.1177/0146167296223006

Kaye, B., \& Giulinoni, J. W. (2012). Help them grow or watch them go: Career conversations employees want. Oakland, CA: Berrett-Koehler.

Kegan, R. (1982). The evolving self. Cambridge: Harvard University Press.

Kegan, R., \& Lahey, L. L. (2016). An everyone culture. Cambridge, MA: Harvard Business Review Press.

Keller, V. (2015). The business case for purpose. Harvard Business Review Analytic Services \& EY Beacon. Cambridge, MA: Harvard Business Review.

Kellerman, B. (2012, August). Cut off at the pass: The limits of leadership in the 21st century. Retrieved September 2, 2020, from https://www.brookings.edu/wp-content/uploads/2016/06/0810_ leadership_deficit_kellerman.pdf

Kelloway, E. K., \& Barling, J. (2010). Leadership development as an intervention in occupational health psychology. Work \& Stress, 24(3), 260-279. http://doi.org/10.1080/02678373.2010.5 18441

Kempster, S., Jackson, B., \& Conroy, M. (2011). Leadership as purpose: Exploring the role of purpose in leadership practice. Leadership, 7(3), 317-334. http://doi.org/10.1177/1742715011407384

Kjell, O. N. E., \& Diener, E. (2020). Abbreviated three-item versions of the satisfaction with life scale and the harmony in life scale yield as strong psychometric properties as the original scales. Journal of Personality Assessment, 1-12. http://doi.org/10.1080/00223891.2020.1737093

Kline, R. B. (2016). Principles and practice of structural equation modelling (Fourth Edition). New York: The Guilford Press.

Kofman, F. (2006). Conscious business. Boulder, CO: Sounds True.

Kossek, E. E., Valcour, M., \& Lirio, P. (2014). The sustainable workforce (2nd ed., Vol. 43, pp. 1-24). Chichester, UK: Wiley. http://doi.org/10.1002/9781118539415.wbwello30 
Kovjanic, S., Schuh, S. C., Jonas, K., Quaquebeke, N. V., \& van Dick, R. (2012). How do transformational leaders foster positive employee outcomes? A self-determination-based analysis of employees' needs as mediating links. Journal of Organizational Behavior, 33(8), 1031-1052. http://doi.org/10.1002/job.1771

Laloux, F. (2014). Reinventing organizations. Brussels: Nelson Parker.

Landeweerd, J. A., \& Boumans, N. P. G. (2011). The effect of work dimensions and need for autonomy on nurses' work satisfaction and health. Journal of Occupational and Organizational Psychology, 67(3), 207-217. http://doi.org/10.1111/j.2044-8325.1994.tbo0563.x

Lazonick, W. (2016). Innovative enterprise and the theory of the firm. In M. Jacobs \& M. Mazzucato (Eds.), Rethinking capitalism: Economics and policy for sustainable and inclusive growth. Hoboken, NJ: Wiley-Blackwell.

Lee, M. Y., \& Edmondson, A. C. (2017). Self-managing organizations: Exploring the limits of less-hierarchical organizing. Research in Organizational Behavior, 37, 35-58. http://doi. org/10.1016/j.riob.2017.10.002

Likert, R. (1967). The human organization. New York, NY: McGraw-Hill.

Ling, Y., He, Y., Wei, Y., Cen, W., Zhou, Q., \& Zhong, M. (2016). Intrinsic and extrinsic goals as moderators of stress and depressive symptoms in Chinese undergraduate students: $A$ multi-wave longitudinal study. BMC Psychiatry, 16(1), 120-8. http://doi.org/10.1186/s12888016-0842-5

Little, R. J. A., \& Rubin, D. B. (2002). Statistical analysis with missing data (Second Edition). Hoboken, $\mathrm{NJ}$ : Wiley.

Lonati, S., Quiroga, B. F., Zehnder, C., \& Antonakis, J. (2018). On doing relevant and rigorous experiments: Review and recommendations. Journal of Operations Management, 64(1), 19-40. http://doi.org/10.1016/j.jom.2018.10.003

Lux, A. A., \& Mao, I. (2019). Authentic leadership: A Western notion? Presented at the 33rd Annual Australian \& New Zealand Academy of Management Conference: Wicked Soluctions to Wicked Problems, CQUniversity, Cairns, Australia.

Lysova, E. I., Allan, B. A., Dik, B. J., Duffy, R. D., \& Steger, M. F. (2019). Fostering meaningful work in organizations: A multi-level review and integration. Journal of Vocational Behavior, 110 , 374-389. http://doi.org/10.1016/j.jvb.2018.07.004

Macey, W. H., \& Schneider, B. (2008). The meaning of employee engagement. Industrial and Organizational Psychology, 1(1), 3-30. http://doi.org/10.1111/j.1754-9434.2007.0002.x

Mackey, J., \& Sisodia, R. (2014). Conscious capitalism: Liberating the heroic spirit of business. (With a new preface by the authors). Cambridge, MA: Harvard Business Review Press. (Orginal work published 2007).

Malnight, T. W. (2019, August). Put purpose at the core of strategy. Retrieved May 25, 2020, from https://www-imd-org.proxy.library.uu.nl/research-knowledge/articles/Put-purpose-atthe-core-of-strategy/

Mankoff, A. W. (1974). Values-not attitudes-are the real key to motivation. Management Review.

Mann, A., \& Harter, J. (2016). The worldwide employee engagement crisis. Gallup. Retrieved August 11, 2020, from https://www.gallup.com/workplace/236495/worldwide-employeeengagement-crisis.aspx

Marsh, H. W., \& Balla, J. (1994). Goodness of fit in confirmatory factor analysis: The effects of sample size and model parsimony. Quality \& Quantity, 28(2), 185-217. http://doi.org/10.1007/ BF01102761 
Martela, F. (2017). Meaningfulness as contribution. The Southern Journal of Philosophy, 55(2), 232256. http://doi.org/10.1111/sjp. 12217

Martela, F., \& Pessi, A. B. (2018). Significant work is about self-realization and broader purpose: Defining the key dimensions of meaningful work. Frontiers in Psychology, 9, 543-15. http:// doi.org/10.3389/fpsyg.2018.00363

Maslow, A. H. (1965). Eupsychian management, a journal. Homewood, Ill: R. D. Irwin and The Dorsey Press.

Maslow, A. H. (1998). Maslow on management. New York, NY: Wiley.

Maturana, H. R., \& Varela, F. J. (1992). The tree of knowledge (Revised Edition). Boston, MA: Shambala Publications.

May, D. R., Gilson, R. L., \& Harter, L. M. (2010). The psychological conditions of meaningfulness, safety and availability and the engagement of the human spirit at work. Journal of Occupational and Organizational Psychology, 77(1), 11-37. http://doi.org/10.1348/096317904322915892

Maydeu-Olivares, A. (2017). Maximum likelihood estimation of structural equation models for continuous data: Standard errors and goodness of fit. Structural Equation Modeling: A Multidisciplinary Journal, 24(3), 383-394. http://doi.org/10.1080/10705511.2016.1269606

Mayfield, J., Mayfield, M., \& Neck, C. P. (2017). Speaking to the self: How motivating language links with self-leadership. International Journal of Business Communication, 7(2), 1-24. http://doi. org/10.1177/2329488417731861

Mazzucato, M. (2018). The value of everything: Making and taking in the global economy. London, UK: Allen Lane.

Mäkikangas, A., Bakker, A. B., \& Schaufeli, W. B. (2017). Antecedents of daily team job crafting. European Journal of Work and Organizational Psychology, 26(3), 421-433. http://doi.org/10.1 080/1359432X.2017.1289920

McArdle, J. J., \& Nesselroade, J. R. (2014). Longitudinal data analysis using structural equation models. Washington, DC: American Psychological Association.

Meglino, B. M., Ravlin, E. C., \& Adkins, C. L. (1989). A work values approach to corporate culture: A field test of the value congruence process and its relationship to individual outcomes. Journal of Applied Psychology, 74(3), 424-432.

Meindl, J. R. (1995). The romance of leadership as a follower-centric theory: A social constructionist approach. The Leadership Quarterly, 6(3), 329-341. http://doi.org/10.1016/10489843(95)90012-8

Metcalf, L., \& Benn, S. (2012). The Corporation is ailing social technology: Creating a "fit for purpose" design for sustainability. Journal of Business Ethics, 111(2), 195-210. http://doi.org/10.1007/ s10551-012-1201-1

Meyer, J. P., \& Gagne, M. (2008). Employee engagement from a self-determination theory perspective. Industrial and Organizational Psychology, 1, 60-62. http://doi.org/1754-9426/08

Mueller, M. (2019). Show me the money. International Journal of Organization Theory \& Behavior, 22(1), 43-64. http://doi.org/10.1108/IJOTB-05-2018-0056

Ng, J. Y. Y., Ntoumanis, N., Thøgersen-Ntoumani, C., Deci, E. L., Ryan, R. M., Duda, J. L., \& Williams, G. C. (2012). Self-determination theory applied to health contexts: A meta-analysis. Perspectives on Psychological Science, 7(4), 325-340. http://doi.org/10.1177/1745691612447309

Niemiec, C. P., \& Spence, G. B. (2016). Optimal motivation at work. In L. G. Oades, M. F. Steger, A. D. Fave, \& J. Passmore (Eds.), The Wiley Blackwell Handbook of the Psychology of Positivity and Strengths-Based Approaches at Work (pp. 82-98). Hoboken, NJ: Wiley-Blackwell. 
Nikolova, I., Schaufeli, W., \& Notelaers, G. (2019). Engaging leader - Engaged employees? A crosslagged study on employee engagement. European Management Journal, 37(6), 772-783. http://doi.org/10.1016/j.emj.2019.02.004

Okada, K. (2013). Is omega squared less biased? A comparison of three major effect size indices in one-way ANOVA. Behaviormetrika, 4O(2), 129-147. http://doi.org/10.2333/bhmk.40.129

Olafsen, A. H., Niemiec, C. P., Halvari, H., Deci, E. L., \& Williams, G. C. (2016). On the dark side of work: a longitudinal analysis using self-determination theory. European Journal of Work and Organizational Psychology, 26(2), 275-285. http://doi.org/10.1080/1359432X.2016.1257611

Ordonez, L. D., Schweitzer, M. E., Galinsky, A. D., \& Bazerman, M. H. (2009). Goals gone wild: The systematic side effects of over-prescribing goal setting. Retrieved November 12, 2020, from https://www.hbs.edu/faculty/Publication\%20Files/09-083.pdf

Padaki, V. (2000). Coming to grips with organisational values. Development in Practice, 10(3-4), 420-435. http://doi.org/10.1080/09614520050116578

Parmar, B. L., Keevil, A., \& Wicks, A. C. (2017). People and profits: The impact of corporate objectives on employees' need satisfaction at work. Journal of Business Ethics, 154(1), 13-33. http://doi. org/10.1007/s10551-017-3487-5

Payne, R. L. (2000). Eupsychian management and the millennium. Journal of Managerial Psychology, 15(3), 219-226. http://doi.org/10.1108/02683940010320570

Peters, D., Calvo, R. A., \& Ryan, R. M. (2018). Designing for motivation, engagement and well-being in digital experience. Frontiers in Psychology, 9, 179. http://doi.org/10.3389/fpsyg.2018.00797

Peterson, R. A., \& Kim, Y. (2013). On the relationship between coefficient alpha and composite reliability. Journal of Applied Psychology, 98(1), 194-198. http://doi.org/10.1037/a0030767

Petri, N. (2014). Future trends in leadership development. (White Paper). Greensboro, NC: Center for Creative Leadership.

Piccolo, R. F., \& Colquitt, J. A. (2006). Transformational Leadership and Job Behaviors: The Mediating Role of Core Job Characteristics. Academy of Management Review, 49(2), 327-340. http://doi. org/10.5465/AMJ.2006.20786079

Pink, D. H. (2009). Drive: the surprising truth about what motivates us. New York, NY: Riverhead Books, Penguin.

Podolny, J. M., Khurana, R., \& Hill-Popper, M. (2004). Revisiting the meaning of leadership. Research in Organizational Behavior, 26, 1-36. http://doi.org/10.1016/S0191-3085(04)26001-4

Polman, P. (2016). Re-establishing trust: Making business with purpose the purpose of business. In D. Barton, D. Horváth, \& M. Kipping (Eds.), Re-imagining Capitalism. Oxford, UK: Oxford University Press.

Powell, K. S., \& Yalcin, S. (2010). Managerial training effectiveness: A meta-analysis 1952-2002. Personnel Review, 39(2), 227-241. http://doi.org/10.1108/00483481011017435

Quinn, J. (2019). The sustainable corporate objective: Rethinking directors' duties. Sustainability, 11(23), 6734. http://doi.org/10.3390/su11236734

Rahmadani, V. G., Schaufeli, W. B., Ivanova, T. Y., \& Osin, E. N. (2019). Basic psychological need satisfaction mediates the relationship between engaging leadership and work engagement: A cross-national study. Human Resource Development Quarterly, 30(4), 453-471. http://doi. org/10.1002/hrdq.21366

Rahmadani, V. G., Schaufeli, W. B., Stouten, J., Zhang, Z., \& Zulkarnain, Z. (2020). Engaging leadership and its implication for work engagement and job outcomes at the individual and team level: A multi-level longitudinal study. International Journal of Environmental Research and Public Health, 17(3), 21. http://doi.org/10.3390/ijerph17030776 
Rath, T., \& Conchie, B. (2008). Strengths based leadership. New York, NY: Gallup.

Reeve, J. (1998). Autonomy support as an interpersonal motivating style: Is it teachable? Contemporary Educational Psychology, 23(3), 312-330. http://doi.org/10.1006/ceps.1997.0975 Renee Baptiste, N. (2008). Tightening the link between employee wellbeing at work and performance. Management Decision, 46(2), 284-309. http://doi.org/10.1108/00251740810854168

Riddle, D., Hoole, E. R., \& Gullette, E. C. D. (2015). The CCL Handbook of Coaching in Organizations. Hoboken, NJ: Wiley.

Rigby, C. S., \& Ryan, R. M. (2018). Self-determination theory in human resource development: New directions and practical considerations. Advances in Developing Human Resources, 20(2), 133-147. http://doi.org/10.1177/1523422318756954

Robertson, B. J. (2015). Holacracy: The revolutionary management system that abolishes hierarchy. New York, NY: Henry Holt.

Rodriguez, A., \& Rodriguez, Y. (2015). Metaphors for today's leadership: VUCA world, millennial and "Cloud Leaders." Journal of Management Development, 34(7), 854-866. http://doi. org/10.1108/JMD-09-2013-0110

Roth, S. (2013). Common values? Fifty-two cases of value semantics copying on corporate websites. Human Systems Management, 32(4), 249-265. http://doi.org/10.3233/HSM-130801

Ryan, R. M. (1995). Psychological needs and the facilitation of integrative processes. Journal of Personality, 63(3), 397-427. http://doi.org/10.1111/j.1467-6494.1995.tbo0501.x

Ryan, R. M., \& Deci, E. L. (2017). Self-determination theory. New York: Guilford Publications.

Ryan, R. M., Huta, V., \& Deci, E. L. (2008). Living well: a self-determination theory perspective on eudaimonia. Journal of Happiness Studies, 9(1), 139-170. http://doi.org/10.1007/s10902-0069023-4

Ryan, R. M., Sheldon, K. M., Kasser, T., \& Deci, E. L. (1996). All goals are not created equal: An organismic perspective on the nature of goals and their regulation. In P. M. Gollwitzer \& J. A. Bargh (Eds.), The psychology of action linking cognition and motivation to behavior (pp. 7-26). New York, NY: Guilford.

Ryan, R. M., Vansteenkiste, M., \& Deci, E. L. (2006). Self-determination theory and the explanatory role of psychological needs in human well-being. Status: Published.

Sagiv, L., \& Schwartz, S. H. (2000). Value priorities and subjective well-being: direct relations and congruity effects. European Journal of Social Psychology, 30(2), 177-198. http://doi. org/10.1002/(SICl)1099-0992(200003/04)30:2<177::AID-EJSP982>3.0.CO;2-Z

Sagiv, L., \& Schwartz, S. H. (2007). Cultural values in organisations: insights for Europe. European J. of International Management, 1(3), 176-15. http://doi.org/10.1504/EJIM.2007.014692

Saks, A. M. (2006). Antecedents and consequences of employee engagement. Journal of Managerial Psychology, 21(7), 600-619. http://doi.org/10.1108/02683940610690169

Salanova, M., Lorente, L., Chambel, M. J., \& Martinez, I. M. (2011). Linking transformational leadership to nurses' extra-role performance: the mediating role of self-efficacy and work engagement. Journal of Advanced Nursing, 67(10), 2256-2266. http://doi.org/10.1111/j.13652648.2011.05652.x

Salter, M. S. (2019). Rehabilitating corporate purpose. http://doi.org/10.2139/ssrn.3386356

Schaufeli, W. B. (2012). Work engagement: What do we know and where do we go? Romanian Journal of Applied Psychology, 14(1), 3-10.

Schaufeli, W. B. (2015). Engaging leadership in the job demands-resources model. Career Development International, 20(5), 446-463. http://doi.org/10.1108/CDI-02-2015-0025 
Schaufeli, W. B., \& Bakker, A. B. (2004). Job demands, job resources, and their relationship with burnout and engagement: a multi-sample study. Journal of Organizational Behavior, 25(3), 293-315. http://doi.org/10.1002/job.248

Schaufeli, W. B., \& Salanova, M. (2009). Enhancing work engagement through the management of human resources. In K. Naswall, J. Hellgren, \& M. Sverke (Eds.), The Individual in the Changing Working Life (pp. 380-402). Cambridge: Cambridge University Press. http://doi.org/10.1017/ CBO9780511490064.018

Schaufeli, W. B., \& Taris, T. W. (2013). A critical review of the Job Demands-Resources Model: Implications for improving work and health. In Bridging Occupational, Organizational and Public Health (pp. 43-68). Dordrecht: Springer Netherlands. http://doi.org/10.1007/978-94007-5640-3_4

Schaufeli, W. B., Bakker, A. B., \& Salanova, M. (2006). The measurement of work engagement with a short questionnaire: A cross-national Study. Educational and Psychological Measurement, 66(4), 701-716. http://doi.org/10.1177/0013164405282471

Schaufeli, W. B., Bakker, A. B., \& Van Rhenen, W. (2009). How changes in job demands and resources predict burnout, work engagement, and sickness absenteeism. Journal of Organizational Behavior, 30(7), 893-917. http://doi.org/10.1002/job.595

Schaufeli, W. B., Salanova, M., González-romá, V., \& Bakker, A. B. (2002). The measurement of engagement and burnout: A two sample confirmatory factor analytic approach. Journal of Happiness Studies, 3(1), 71-92. http://doi.org/10.1023/A:1015630930326

Schaufeli, W. B., Shimazu, A., Hakanen, J., Salanova, M., \& De Witte, H. (2019). An ultra-short measure for work engagement. European Journal of Psychological Assessment, 35(4), 577-591. http:// doi.org/10.1027/1015-5759/a000430

Schneider, B., Yost, A. B., Kropp, A., Kind, C., \& Lam, H. (2018). Workforce engagement: What it is, what drives it, and why it matters for organizational performance. Journal of Organizational Behavior, 39(4), 462-480. http://doi.org/10.1002/job.2244

Schreurs, B., van Emmerik, I. H., Van den Broeck, A., \& Guenter, H. (2014). Work values and work engagement within teams: The mediating role of need satisfaction. Group Dynamics: Theory, Research, and Practice, 18(4), 267-281. http://doi.org/10.1037/gdnoo00009

Schulenberg, S. E., Schnetzer, L. W., \& Buchanan, E. M. (2010). The Purpose in Life Test-Short Form: Development and psychometric support. Journal of Happiness Studies, 12(5), 861-876. http:// doi.org/10.1007/s10902-010-9231-9

Schwartz, S. H. (1992). Universals in the content and structure of values: Theoretical advances and empirical tests in 20 countries. Advances in Experimental Social Psychology, 25, 1-65. http:// doi.org/10.1016/S0065-2601(08)60281-6

Schwartz, S. H. (2012). An overview of the Schwartz theory of basic values. Online Readings in Psychology and Culture, 2(1). http://doi.org/10.9707/2307-0919.1116

Serrat, O. (2017). A primer on corporate values. In Knowledge Solutions (pp. 701-709). Singapore: Springer Singapore. http://doi.org/10.1007/978-981-10-0983-9_76

Shaffer, J. A., DeGeest, D., \& Li, A. (2016). Tackling the problem of construct proliferation. Organizational Research Methods, 19(1), 80-110. http://doi.org/10.1177/1094428115598239

Sheldon, K. M., \& Hilpert, J. C. (2012). The balanced measure of psychological needs (BMPN) scale: An alternative domain general measure of need satisfaction. Motivation and Emotion, 36(4), 439-451. http://doi.org/10.1007/s11031-012-9279-4 
Sheldon, K. M., \& Krieger, L. S. (2014). Walking the talk: Value importance, value enactment, and well-being. Motivation and Emotion, 38(5), 609-619. http://doi.org/10.1007/s11031-014-94243

Sheldon, K. M., \& Niemiec, C. P. (2006). It's not just the amount that counts: Balanced need satisfaction also affects well-being. Journal of Personality and Social Psychology, 91(2), 331341. http://doi.org/10.1037/0022-3514.91.2.331

Shotter, J. (1993). Conversational realities. London, UK: Sage.

Shuck, B., \& Herd, A. M. (2012). Employee engagement and leadership. Human Resource Development Review, 11(2), 156-181. http://doi.org/10.1177/1534484312438211

Shuck, B., \& Rose, K. (2013). Reframing employee engagement within the context of meaning and purpose: Implications for HRD. Advances in Developing Human Resources, 15(4), 341-355. http://doi.org/10.1177/1523422313503235

Sisodia, Raj, \& Gelb, M. J. (2019). The healing organization. New York, NY: Harper Collins.

Sjåfjell, B., \& Taylor, M. B. (2019). Clash of norms: Shareholder primacy vs. sustainable corporate purpose. SSRN Electronic Journal. http://doi.org/10.2139/ssrn.3444050

Slemp, G. R., Kern, M. L., Patrick, K. J., \& Ryan, R. M. (2018). Leader autonomy support in the workplace: A meta-analytic review. Motivation and Emotion, 42(5), 706-724. http://doi. org/10.1007/s11031-018-9698-y

Solansky, S. T. (2014). Self-determination and leader development. Management Learning, 46(5), 618-635. http://doi.org/10.1177/1350507614549118

Song, H.-D., \& Grabowski, B. L. (2006). Stimulating intrinsic motivation for problem solving using goal-oriented contexts and peer group composition. Educational Technology Research and Development, 54(5), 445-466. http://doi.org/10.1007/s11423-006-0128-6

Sparks, J. R., \& Schenk, J. A. (2001). Explaining the effects of transformational leadership: an investigation of the effects of higher-order motives in multilevel marketing organizations. Journal of Organizational Behavior, 22(8), 849-869. http://doi.org/10.1002/job.116

Spector, P. E. (2019). Do not cross me: Optimizing the use of cross-sectional designs. Journal of Business and Psychology, 34(2), 125-137. http://doi.org/https://doi.org/10.1007/s10869-01809613-8

Spence, G. B., \& Deci, E. L. (2013). Self-determination theory within coaching contexts: Supporting motives and goals that promote optimal functioning and well-being. In S. David, D. Clutterbuck, \& D. Megginson (Eds.), Beyond Goals (pp. 85-108). New York, NY: Routledge.

Spreitzer, G. M. (1995). Psychological, empowerment in the workplace: Dimensions, measurement and validation. Academy of Management Review, 38(5), 1442-1465. http://doi. org/10.2307/256865

Steger, M. F., Dik, B. J., \& Duffy, R. D. (2012). Measuring meaningful work. Journal of Career Assessment, 20(3), 322-337. http://doi.org/10.1177/1069072711436160

Stone, D. N., Deci, E. L., \& Ryan, R. M. (2009). Beyond talk: Creating autonomous motivation through self-determination theory. Journal of General Management, 34(3), 75-91. http://doi. org/10.1177/030630700903400305

Su, Y.-L., \& Reeve, J. (2010). A meta-analysis of the effectiveness of intervention programs designed to support autonomy. Educational Psychology Review, 23(1), 159-188. http://doi.org/10.1007/ s10648-010-9142-7 
Tafvelin, S., Thiele Schwarz, von, U., Nielsen, K., \& Hasson, H. (2018). Employees' and line managers' active involvement in participatory organizational interventions: Examining direct, reversed, and reciprocal effects on well-being. Stress and Health, 36(8), 1-12. http://doi.org/10.1002/ smi.2841

Tannen, D., Hamilton, H. E., \& Schiffrin, D. (2015). The handbook of discourse analysis. (D. Tannen, H. E. Hamilton, \& D. Schiffrin, Eds.) (2nd ed.). Hoboken, NJ: Wiley-Blackwell.

Taylor, C. (1991). The ethics of authenticity. Cambridge, MA: Harvard University Press.

Taylor, C. (2007). A secular age. Cambridge, MA: The Belknap Press of Harvard University Press.

Tessema, M., Dhumal, P., Sauers, D., Tewolde, S., \& Teckle, P. (2019). Analysis of corporate value statements: an empirical study. International Journal of Corporate Governance, 10(2), 149. http://doi.org/10.1504/IJCG.2019.10022950

Thakor, A. V., \& Quinn, R. E. (2013). The economics of higher purpose. SSRN Electronic Journal, Working Paper N:. 395/2013. http://doi.org/10.2139/ssrn.2362454

Ting, S. (2006). Our view of coaching for leadership development. In S. Ting \& P. Scisco (Eds.), The CCL handbook of coaching. San Francisco, CA: Jossey-Bass.

Tremblay, M. A., Blanchard, C. M., Taylor, S., Pelletier, L. G., \& Villeneuve, M. (2010). Work extrinsic and intrinsic motivation scale: Its value for organizational psychology research. Canadian Journal of Behavioural Science/Revue Canadienne Des Sciences Du Comportement, 42(1), 70. http://doi.org/10.1037/a0018176

UN, United Nations. (2015). Transforming our world: the 2030 agenda for sustainable development. Retrieved September 10, 2020, from https://sustainabledevelopment.un.org/post2015/ transformingourworld

UN, United Nations. (2019). The sustainable development goals report, 2019. Retrieved March 20, 2020, from https://unstats.un.org/sdgs/report/2019/The-Sustainable-DevelopmentGoals-Report-2019.pdf

Urbany, J. E. (2005). Inspiration and cynicism in values statements. Journal of Business Ethics, 62(2), 169-182. http://doi.org/10.1007/s10551-005-0188-2

Van de Schoot, R., Lugtig, P., \& Hox, J. (2012). A checklist for testing measurement invariance. European Journal of Developmental Psychology, 9(4), 486-492. http://doi.org/10.1080/174 05629.2012 .686740

Van den Broeck, A., Baillien, E., Vanbelle, E., De Cuyper, N., Vanhercke, D., \& De Witte, H. (2014). Perception of organization's value support and perceived employability: insights from selfdetermination theory. The International Journal of Human Resource Management, 25(13), 1904-1918. http://doi.org/10.1080/09585192.2013.860385

Van den Broeck, A., Ferris, D. L., Chang, C.-H., \& Rosen, C. C. (2016). A review of self-determination theory's basic psychological needs at work. Journal of Management, 42(5), 1195-1229. http:// doi.org/10.1177/0149206316632058

Van den Broeck, A., Lens, W., \& De Witte, H. (2013). Unraveling the importance of the quantity and the quality of workers' motivation for well-being: A person-centered perspective. Journal of Vocational Behavior, 82(1), 69-78. http://doi.org/10.1016/j.jvb.2012.11.005

Van den Broeck, A., Schreurs, B., Proost, K., Vanderstukken, A., \& Vansteenkiste, M. (2019). I want to be a billionaire: How do extrinsic and intrinsic values influence youngsters' well-being? The ANNALS of the American Academy of Political and Social Science, 682(1), 204-219. http:// doi.org/10.1177/0002716219831658 
Van den Broeck, A., Vansteenkiste, M., De Witte, H., \& Lens, W. (2008). Explaining the relationships between job characteristics, burnout, and engagement: The role of basic psychological need satisfaction. Work \& Stress, 22(3), 277-294. http://doi.org/10.1080/02678370802393672

Van der Kaap-Deeder, J., Vansteenkiste, M., Soenens, B., \& Mabbe, E. (2017). Children's daily wellbeing: The role of mothers', teachers', and siblings' autonomy support and psychological control. Developmental Psychology, 53(2), 237-251. http://doi.org/10.1037/devo000218

van der Mark, C. (2019). Emerging trends in leadership development in 2019 and beyond: Shaping Future Leaders for Success. Paris, Fr.: Stratx. Retrieved November 18, 2020 from https://cdn2.hubspot.net/hubfs/2701262/Emerging\%20Trends\%20in\%2OLeadership\%20 Development\%20White\%20Paper.pdf

van Knippenberg, D. (2018). Leadership and identity. In D. V. Day \& J. Antonakis (Eds.), The Nature of Leadership (pp. 300-326). Thousand Oaks, CA: Sage.

van Knippenberg, D., \& Sitkin, S. B. (2013). A critical assessment of charismatic-transformational leadership research: Back to the drawing board? Academy of Management Annals, 7(1), 1-60. http://doi.org/10.5465/19416520.2013.759433

Van Looy, A., \& Shafagatova, A. (2016). Business process performance measurement: a structured literature review of indicators, measures and metrics. SpringerPlus, 5(1), 1-24. http://doi. org/10.1186/s40064-016-3498-1

Van Rhenen, W., Blonk, R. W. B., Schaufeli, W. B., \& van Dijk, F. J. H. (2007). Can sickness absence be reduced by stress reduction programs: on the effectiveness of two approaches. International Archives of Occupational and Environmental Health, 80(6), 505-515. http://doi.org/10.1007/ s00420-006-0157-9

van Tuin, L., Schaufeli, W. B., \& Rhenen, W. (2020). The satisfaction and frustration of basic psychological needs in engaging leadership. Journal of Leadership Studies, 14(2), 6-23. http:// doi.org/10.1002/jls.21695

van Tuin, L., Schaufeli, W. B., Van Rhenen, W., \& Kuiper, R. M. (2020). Business results and wellbeing: An engaging leadership intervention study. International Journal of Environmental Research and Public Health, 17(12), 4515. http://doi.org/10.3390/ijerph17124515

Vansteenkiste, M., \& Ryan, R. M. (2013). On psychological growth and vulnerability: Basic psychological need satisfaction and need frustration as a unifying principle. Journal of Psychotherapy Integration, 23(3), 263-280. http://doi.org/10.1037/a0032359

Vansteenkiste, M., Neyrinck, B., Niemiec, C. P., Soenens, B., Witte, H., \& Van den Broeck, A. (2007). On the relations among work value orientations, psychological need satisfaction and job outcomes: A self-determination theory approach. Journal of Occupational and Organizational Psychology, 80(2), 251-277. http://doi.org/10.1348/096317906×111024

Vansteenkiste, M., Niemiec, C. P., \& Soenens, B. (2010). The development of the five minitheories of self-determination theory: an historical overview, emerging trends, and future directions. In The Decade ahead: theoretical perspectives on motivation and achievement (Vol. 16, pp. 105-165). Bingley: Emerald Group Publishing. http://doi.org/10.1108/So7497423(2010)000016A007

Vansteenkiste, M., Sierens, E., Goossens, L., Soenens, B., Dochy, F., Mouratidis, A., et al. (2012). Identifying configurations of perceived teacher autonomy support and structure: Associations with self-regulated learning, motivation and problem behavior. Learning and Instruction, 22(6), 431-439. http://doi.org/10.1016/j.learninstruc.2012.04.002 
Vansteenkiste, M., Sierens, E., Soenens, B., Luyckx, K., \& Lens, W. (2009). Motivational profiles from a self-determination perspective: The quality of motivation matters. Journal of Educational Psychology, 101(3), 671-688. http://doi.org/10.1037/a0015083

Vansteenkiste, M., Timmermans, T., Lens, W., Soenens, B., \& Van den Broeck, A. (2008). Does extrinsic goal framing enhance extrinsic goal-oriented individuals' learning and performance? An experimental test of the match perspective versus self-determination theory. Journal of Educational Psychology, 100(2), 387-397. http://doi.org/10.1037/0022-0663.100.2.387

Vogt, J. W. (2009). Recharge Your Team. Wesport, CT: Praeger.

Volz-Peacock, M., Carson, B., \& Marquardt, M. (2016). Action learning and leadership development. Advances in Developing Human Resources, 18(3), 318-333.

Vrieze, S. I. (2012). Model selection and psychological theory: A discussion of the differences between the Akaike Information Criterion (AIC) and the Bayesian Information Criterion (BIC). Psychological Methods, 17(2), 228-243.

Waldinger, R. J., \& Schulz, M. S. (2010). What's love got to do with it? Social functioning, perceived health, and daily happiness in married octogenarians. Psychology and Aging, 25(4), 422-431. http://doi.org/10.1037/a0019087

Walumbwa, F. O., Avolio, B. J., Gardner, W. L., Wernsing, T. S., \& Peterson, S. J. (2008). Authentic leadership: Development and validation of a theory-based measure. Journal of Management 34(1), 89-126. http://doi.org/10.1177/0149206307308913

White, R. W. (1959). Motivation reconsidered: The concept of competence. Psychological Review, 66(5), 297-333. http://doi.org/10.1037/ho040934

Winch, P. (1988). The idea of a social science and its relation to philosophy. London, UK: Routledge. Wittgenstein, W., (1980). Culture and value. (G.H. von Wright, Ed.). Chicago: The University of Chicago Press (Original work published, 1977).

Wong, P. T. P. (2012). Towards a dual-systems model of what makes life worth living. In P. T. P. Wong (Ed.), The human quest for meaning. Theories, Research and Applications. New York, NY: Routledge.

Yeoman, R., Bailey, C., Madden, A., \& Thompson, M. (2019). The Oxford handbook of meaningful work. Oxford, UK: Oxford University Press.

Yost, P. R., \& Plunkett, M. M. (2010). Leadership training programs. In Real time leadership development (pp. 165-176). Oxford, UK: Wiley-Blackwell. http://doi.org/10.1002/9781444315981

Yukl, G. (2012). Effective leadership behavior: What we know and what questions need more attention. Academy of Management Perspectives, 26(4), 66-85. http://doi.org/10.5465/ amp.2012.0088

Yukl, G., Gordon, A., \& Taber, T. (2016). A hierarchical taxonomy of leadership behavior: Integrating a half century of behaviour research. Journal of Leadership \& Organizational Studies, 9(1), 15-32. http://doi.org/10.1177/107179190200900102

Yukl, G., Mahsud, R., Hassan, S., \& Prussia, G. E. (2013). An improved measure of ethical leadership. Journal of Leadership \& Organizational Studies, 20(1), 38-48. http://doi. org/10.1177/1548051811429352 


Nederlandse samenvatting 

In dit proefschrift zoeken we een verklaring voor de positieve invloed van leiderschap, ondernemingsdoelstellingen en waarden op de bevlogenheid van werknemers. Bevlogen medewerkers ontlenen energie aan hun werk, gaan erin op en zijn eraan toegewijd. Daarbij vertonen ze een hoog psychologisch welzijn en dragen ze bij aan het succes van de onderneming. We hebben gevonden dat motivatie - een theorie over waarom we doen wat we doen - meer dan de helft van die verklaring voor bevlogenheid levert. Motivatie, zo bevestigt het onderzoek, is een onderliggend mechanisme dat leiderschap verbindt met positieve uitkomsten; Als het leiderschap binnen een organisatie zich ten dienste stelt van motivatie kun je bevlogenheid positief beïnvloeden. En een ondernemingsdoelstelling (purpose) die zich richt op alle belanghebbenden in plaats van alleen op de aandeelhouders, werkt positief uit op motivatie en bevlogenheid van werknemers. Ondernemingswaarden die zich daarbij ook richten op het bijdragen aan een betere wereld versterken dat nog verder. Evenals dat een werkomgeving waar ruimte is voor persoonlijke en professionele groei mensen helpt in hun ontwikkeling en gevoel van betekenisgeving.

Dit onderzoek naar motivatie als het onderliggende mechanisme en de relatie met leiderschap, ondernemingsdoelstellingen en waarden is belangrijk om een drietal redenen. In de eerste plaats omdat motivatie als onderliggend en verklarend mechanisme geen tot weinig aandacht krijgt in academische leiderschapsstudies, evenmin als duurzame ondernemingsdoelstellingen en intrinsieke waarden. Leiderschap in organisaties wordt veelal gelijkgesteld met economische prestaties; Er wordt een directe relatie verondersteld tussen leiderschap, prestaties en de bevlogenheid van medewerkers. Leiderschapsconcepten zoals transformationeel, authentiek, ethisch of spiritueel leiderschap worden dan ook tegen die achtergrond beoordeeld op hun effectiviteit. Er wordt veel minder gekeken naar wat het onderliggende psychologische mechanisme zou kunnen zijn dat het verband tussen leiderschap en positieve uitkomsten, zoals prestaties en bevlogenheid, zou kunnen verklaren.

In de tweede plaats omdat zelfrealisatie, oftewel het realiseren van je potentieel, via werk een steeds belangrijkere rol is gaan spelen in het leven van mensen. De behoefte aan zelfrealisatie is een uitdrukking van het fundamentele westerse ideaal van authenticiteit en zelfbeschikking dat de afgelopen decennia een uitgesproken onderdeel is geworden van onze cultuur van individualisme, erkenning van identiteit en de zoektocht naar betekenis. Deze sociaal-culturele ontwikkeling maakt het belangrijk om beter te begrijpen wat zich bij medewerkers afspeelt in de relatie tussen leiderschap en bevlogenheid. Meer dan de directe relatie tussen leiderschap en uitkomsten, kan bestudering van het onderliggende psychologische proces aanknopingspunten 
bieden om een betere aansluiting te vinden bij veranderende waardenpatronen en aspiraties. We denken dat het belangrijk is dat die inzichten zich vertalen naar het leiderschap binnen organisaties en dat organisaties veranderende behoeften herkennen en daarin voorzien. Zeker ook met het oog op jongere generaties die andere waarden en aspiraties meebrengen en voor wie zelfrealisatie en betekenisgeving, maar ook duurzaamheid van groot belang zijn.

In de derde plaats omdat er een intrinsieke spanning bestaat tussen enerzijds de behoefte aan zelfbeschikking van mensen en anderzijds het heersende besturingsmodel van ondernemingen. De meeste organisaties worden traditioneel en mechanisch geleid op basis van voorspelbaarheid en controle; Waarden die zich slecht verhouden met de toenemende behoefte aan zelfsturing, autonomie en betekenisgeving. Deze spanning wordt nog eens versterkt door de dominantie van aandeelhouderswaarde en de zogeheten financialisering van de economie. Het neoliberalisme heeft de afgelopen 40 jaar diepe sporen getrokken in termen van groeiende economisch ongelijkheid, kansenongelijkheid en de uitputting van menselijke en natuurlijke hulpbronnen. Ter illustratie: de inkomens van topmanagers zijn over de periode 1973-2014 zeer sterk gestegen, terwijl de inkomens van de gewone werknemers over diezelfde periode slechts marginaal omhooggingen, tegen een hoger gemiddeld aantal gewerkte uren en een hogere arbeidsproductiviteit $(72 \%)^{1}$. Daarenboven vertonen werkgerelateerde psychosociale stress en burn-out al jaren een stijgende lijn.

Meerdere onderzoeken wijzen naar een sociaalpsychologische theorie over motivatie, de zelfdeterminatietheorie, om het verband tussen leiderschap en motivatie te verklaren. Gebleken is dat verschillen in bevlogenheid van medewerkers voor een groter deel verklaard worden met behulp van deze motivatietheorie dan door de directe relatie van verschillende leiderschapsconcepten met bevlogenheid. En eigenlijk is dat ook wel logisch. Een leiderschapsconcept, stijl en gedrag van leidinggevenden, heeft een psychologisch effect op medewerkers en beïnvloedt de prestaties en de bevlogenheid van de medewerkers via die psychologische effecten. Dus als we een verklaring zoeken voor de effectiviteit van een leiderschapsconcept, ligt het voor de hand om naar de psychologische effecten van leiderschap op medewerkers te kijken in plaats van enkel naar de prestaties. Wat de onderhavige studie naar dit onderliggende proces kan opleveren is kennis en inzicht over waarom een bepaalde aanpak tot goede uitkomsten leidt. Dat zou goede handvatten kunnen bieden om een werkomgeving te scheppen waarin mensen kunnen groeien en zich ontplooien, waarin ze zingeving vinden door bij te dragen aan een ondernemingsdoel dat verder gaat dan winstmaximalisatie en aandeelhouderswaarde, en waarin het psychologisch welzijn hoog is en de psychosociale stress laag. 


\section{De kern van zelfdeterminatietheorie}

Centraal in zelfdeterminatietheorie staat het idee dat mensen actieve organismen zijn die van nature gericht zijn op groei en ontwikkeling in relatie met hun omgeving en die allerlei levenservaringen actief integreren in hun zelfbeeld. Dit perspectief op menselijke ontwikkeling stelt de dynamiek van de sociale context centraal: hoe gaan we met elkaar om, wat zijn die omgangsvormen en hoe beleven en integreren we die met het zelf. De sociale context van werk wordt gevormd door de organisatie, collega's, leidinggevenden, klanten, leveranciers; ledereen met wie je vanwege je werk contact hebt. Als de werkcontext positief en ondersteunend is aan het individu, dan stimuleert de werkomgeving persoonlijke groei en ontwikkeling en worden welzijn en prestaties bevorderd.

\section{Soorten motivatie}

Wat is motivatie en hoe werkt het? Wat drijft ons gedrag? Dit zijn vragen waarop zelfdeterminatietheorie een antwoord probeert te vinden. Een deel van ons gedrag wordt van binnenuit gestuurd, door onszelf. Dingen die we leuk, interessant of leerzaam vinden, doen we zonder dat iemand ons aan hoeft te sporen. De voldoening ligt in het doen van de activiteit zelf. Als sporten, schilderen of onderzoek doen je passie is, heb je niemand nodig die je aanmoedigt om lekker te gaan sporten, schilderen of onderzoek te doen. Dit verschijnsel wordt intrinsieke motivatie genoemd. Soms is het zelfs zo prettig dat we erin opgaan en de tijd vergeten-dan komen mensen in "flow". Tot zover weinig nieuws onder de zon.

Waar zelfdeterminatietheorie zich door onderscheidt is dat niet zozeer gekeken wordt naar de sterkte van de motivatie, maar naar de kwaliteit ervan, en wel met behulp van een typologie. Intrinsieke motivatie vormt daar een onderdeel van. Een groot deel van ons (werkende) leven wordt echter gevormd door extrinsieke prikkels die onze motivatie reguleren. Dat betekent dat deze regulatie van buitenaf wordt ingegeven. Bijvoorbeeld het werken in ruil voor een beloning, het voldoen aan taakvereisten, het volgen van regels en procedures en het werken binnen vastgestelde kaders. Maar ook ondernemingsdoelstellingen en waarden worden doorgaans van buitenaf ingegeven.

Met een deel van die extrinsieke regulatie kunnen werknemers zich goed vereenzelvigen of identificeren. Bijvoorbeeld een organisatiedoelstelling die zich richt op het bijdragen aan een groter goed ten behoeve van het welzijn van anderen of aan duurzaamheid. Een voorbeeld van het eerste is de organisatiedoelstelling van Philips. Dit bedrijf heeft zich ten doel gesteld om het leven van mensen te verbeteren door middel van medische innovatie en draagt dit consequent uit. Een voorbeeld van het tweede is het Amerikaanse kledingmerk Patagonia dat ernaar 
streeft om oplossingen te implementeren die het milieu en het klimaat duurzaam ontlasten. Het bedrijf wil nadrukkelijk een voortrekkersrol spelen en voegt ook echt de daad bij het woord. Dit trekt medewerkers aan die zich kunnen vereenzelvigen met die doelstelling en de bijbehorende waarden. Leiderschap speelt hierin een belangrijke rol. Als je medewerkers vraagt naar de reden waarom ze bij een dergelijk bedrijf werken zeggen ze bijvoorbeeld: "omdat ik het belangrijk vind om aan dit doel bij te dragen", of "omdat dit in lijn ligt met mijn persoonlijke waarden". Dus ondanks dat de organisatiedoelstelling 'van buiten' komt leidt het tot een kwalitatief hogere motivatie via vereenzelviging met dat doel; internalisatie. In zelfdeterminatietheorie wordt dit type positieve motivatie samen met intrinsieke motivatie samengevat onder de noemer autonome motivatie. Autonome motivatie ondersteunt gevoelens van betekenisgeving en leidt tot hoger welzijn en meer bevlogenheid. Maar ook tot meer creativiteit, volharding om het doel te realiseren, initiatief en zelfsturing. De kracht van autonome motivatie is dat medewerkers zich richten op het werk zelf; Het versterkt de motivationele energie voor het werk. Het werk is immers belangrijk en waardevol, maar ook leuk, interessant en leerzaam.

Andere vormen van extrinsieke regulatie worden minder goed, slecht of helemaal niet geïnternaliseerd. Voorbeelden daarvan zijn veel vormen van beloning en straf. Het gevolg van een dergelijke extrinsieke regulatie is dat het gedrag van de medewerker zich richt op de prikkel en minder op het werk zelf. Het wordt dan belangrijker om een negatieve consequentie te vermijden of om de positieve beloning te krijgen, zoals een goede beoordeling, een promotie of een salarisverhoging. Het is een type motivatie dat als dwingend en controlerend kan worden ervaren en wordt dan ook gecontroleerde motivatie genoemd. In een werkomgeving waar sprake is van gecontroleerde motivatie is het te verwachten dat medewerkers minder initiatiefrijk en creatief zijn en zich meer afwachtend opstellen. Deze vorm van motivatie hangt negatief samen met welzijn en bevlogenheid. Als de werkomgeving te dwingend is ontstaan gevoelens van machteloosheid en zinloosheid, hetgeen aanleiding vormt voor amotivatie.

\section{Drie psychologische basisbehoeften}

Zelfdeterminatietheorie staat het meest bekend om de formulering van drie psychologische basisbehoeften. Dit zijn autonomie, competentie en verbondenheid.

Het voldoen aan deze basisbehoeften leidt tot optimaal welzijn, creativiteit, betrokkenheid, motivatie, zelfredzaamheid en (dus) ook bevlogenheid. Het heten basisbehoeften omdat ze, net als de biologische behoeften aan lucht, water en voedsel, noodzaken zijn zonder welke mensen niet of minder goed functioneren. 
Autonomie is de behoefte van mensen om zelf invloed uit te kunnen oefenen op waar ze mee bezig zijn of bij betrokken zijn. Zelf sturing kunnen geven aan belangrijke aspecten in het werk draagt bij aan de bevrediging van deze behoefte. Competentie gaat over het gevoel ergens goed in te zijn en effectief te zijn binnen de omgeving waarin iemand functioneert. Deze behoefte wordt gevoed door een werkomgeving waar persoonlijke en professionele ontwikkeling gestimuleerd wordt, veelvuldig (positieve) feedback wordt gegeven en waarin groei, exploratie en plezier belangrijke aspecten zijn. Verbondenheid gaat over de behoefte om ergens deel van uit te maken en je verbonden te voelen met anderen die om je geven in een betekenisvolle persoonlijke relatie. In deze behoefte wordt voorzien door mensen zich thuis te laten voelen in een sfeer van zorg, saamhorigheid en psychologische veiligheid.

Sinds een aantal jaren wordt ook de keerzijde van de vervulling van basisbehoeften in kaart gebracht. Behoeften kunnen namelijk ook gefrustreerd worden, bijvoorbeeld door een sterk controlerende werkomgeving, micromanagement of zelfs door de behoeften aan autonomie, competentie en verbondenheid van medewerkers actief te dwarsbomen. Dit leidt tot negatieve uitkomsten, zoals psychosociale stress, ontevredenheid met het werk en personeelsverloop.

\section{De centrale vraag en de bevindingen uit de studies}

De centrale vraag van dit proefschrift is hoe en in welke mate de relatie tussen leiderschap, ondernemingsdoelstellingen en waarden met bevlogenheid verklaard wordt door motivatie. Daarvoor zijn vier empirische studies verricht. In Hoofdstuk 2 wordt de rol van satisfactie (bevrediging of voldoening) en frustratie van psychologische basisbehoeften bestudeerd in relatie tot bevlogen leiderschap (engaging leadership) en bevlogenheid voor het werk (work engagement). De rol van satisfactie van psychologische basisbehoeften door middel van bevlogen leiderschap is al eerder in kaart gebracht, maar de rol van frustratie van basisbehoeften nog niet. Het concept van bevlogen leiderschap is in 2015 geïntroduceerd en wordt in een groeiend aantal onderzoeken verkend en getoetst. Het is het eerste leiderschapsconcept dat zich specifiek richt op leiderschapsgedragingen die de psychologische basisbehoeften van medewerkers bevredigen. Daarmee is het een aantrekkelijk leiderschapsconcept, omdat niet zozeer de uitkomsten centraal staan, maar juist het belang van het onderliggende proces van behoeftensatisfactie wordt benadrukt in relatie tot de effecten op bevlogenheid. 
In de eerste studie in Hoofdstuk $2(N=304)$ werd verwacht dat bevlogen leiderschap een positieve relatie zou hebben met behoeftensatisfactie en bevlogenheid, en een negatieve relatie met de frustratie van die behoeften. Dit bleek inderdaad het geval. Daarbij kwam tevens naar voren dat het stimuleren van autonomie via bevlogen leiderschap het meeste effectief leek te zijn, omdat het niet alleen motivatie en bevlogenheid bevordert, maar ook negatieve vormen van motivatie, zoals gecontroleerde motivatie en amotivatie, vermindert. De frustratie van basisbehoeften hing weliswaar samen met negatieve uitkomsten, zoals verwacht, maar vertoonde geen significant verband met autonome motivatie.

Bevlogen leiderschap bleek in sterke mate indirect samen te hangen met bevlogenheid via het voorzien in de basisbehoefte aan autonomie. Aansluitend kwam naar voren dat de basisbehoeften het best apart van elkaar kunnen worden onderzocht omdat de relevantie van autonomie, competentie en verbondenheid voor bevlogenheid van elkaar bleken te verschillen. Satisfactie van de behoefte aan autonomie is een belangrijkere voorspeller van bevlogenheid dan competentie en verbondenheid. Dit lijkt in overeenstemming te zijn met de onderliggende theorie die stelt dat satisfactie van de behoefte aan autonomie vaak aan de vervulling van competentie en verbondenheid voorafgaat. Samenvattend concludeerden we uit de eerste studie dat bevlogen leiderschap effectiever is als het zich richt op het vervullen van psychologische basisbehoeften omdat het mes dan aan twee kanten snijdt. Het kan leiden tot zowel hogere autonome motivatie en bevlogenheid alsook tot lagere negatieve aspecten van motivatie, terwijl een lagere frustratie van basisbehoeften vooral samenhangt met verlaging van negatieve aspecten, maar niet zozeer met positieve motivatie en bevlogenheid.

In Hoofdstuk 3 wordt de rol van een ondernemingsdoelstelling (corporate purpose) in een tweede studie onderzocht. Hiervoor zijn de bestaande missie en visie van een multinationale onderneming als uitgangspunt genomen en is gekeken naar de impact op bevlogenheid via autonome motivatie. De onderhavige missie en visie voldeden aan de definitie van een hoger doel (higher purpose) zoals beschreven in de stakeholdertheorie. Dat wil zeggen dat de missie en visie een breder maatschappelijk doel dienen en specificeren hoe aan dat doel wordt bijgedragen. Belanghebbenden die benoemd worden zijn de klanten, de samenleving, de medewerkers, duurzaamheid en de aandeelhouders. Er is onderzocht in welke mate deze missie en visie als inspirerend werden ervaren door medewerkers en in welke mate medewerkers vonden dat zij daar actief aan bijdroegen door hun werk. 
De uitkomsten van de tweede studie $(N=270)$ laten zien dat een bredere ondernemingsdoelstelling een positief effect heeft op bevlogenheid, ook over meerdere momenten in de tijd. Concreet betekent dit dat werknemers die zich meer identificeren met dit hogere doel en ervaren dat zij eraan bijdragen, meer bevlogen zijn. Voor autonome motivatie waren de resultaten minder duidelijk, omdat bij de analyse over meerdere tijdsmomenten geen verklarende rol voor autonome motivatie kon worden vastgesteld, terwijl dit in het cross-sectionele deel van het onderzoek wel het geval was. Uit dat laatste onderdeel van de studie bleek dat autonome motivatie $56 \%$ van de variantie in bevlogenheid verklaarde, terwijl gecontroleerde motivatie en amotivatie geen rol van betekenis vervulden. De conclusie van de tweede studie luidt dat een hoger ondernemingsdoel positief samenhangt en zelfs voorspellend is voor bevlogenheid. De complexere rol van autonome motivatie zou erop kunnen duiden dat een hoger ondernemingsdoel voornamelijk aantrekkelijk is voor medewerkers die al over een hogere autonome motivatie beschikken en zich kunnen identificeren met de doelstelling van de onderneming. Deze interpretatie ondersteunt de veelgehoorde overtuiging dat een hoger ondernemingsdoel belangrijk kan zijn bij het aantrekken van talent en voor nieuwe generaties die andere waardenaspiraties meebrengen.

Hoofdstuk 4 behandelt hoe medewerkers de waarden van de onderneming ervaren en wat de invloed is van bevlogen leiderschap op deze waarden. Vervolgens is gekeken naar de impact op de bevlogenheid van medewerkers en de verklarende waarde daarbij van behoeftensatisfactie. Erwordt onderscheid gemaakt tussen verschillende soorten waarden. Aan de ene kant worden deze gevormd door meer universele, intrinsieke waarden zoals zorg hebben voor elkaar, een bijdrage leveren aan een betere wereld en persoonlijke groei en ontwikkeling. De andere kant van het spectrum wordt gevormd door meer extrinsieke waarden, zoals het verkrijgen van sociale status, het hebben van macht en invloed over anderen en financieel succes. We verwachtten dat bevlogen leiderschap positief samenhangt met intrinsieke waarden en negatief met extrinsieke waarden. Ook was de verwachting dat intrinsieke waarden een positief verband zouden vertonen met behoeftensatisfactie, dit in tegenstelling tot extrinsieke waarden. Tezamen genomen was de verwachting dat de combinatie van intrinsieke waarden en behoeftensatisfactie de relatie tussen leiderschap en bevlogenheid zou kunnen duiden.

De resultaten uit de derde studie $(N=436)$ laten een positieve associatie zien van leiderschap met de bevlogenheid van medewerkers via intrinsieke waardenpercepties en behoeftensatisfactie. Daarentegen was er een negatieve relatie met extrinsieke waardenpercepties. De analyse over meerdere tijdsmomenten bevestigde de 
volgorde van bevlogen leiderschap naar intrinsieke waardenpercepties. Bevlogen leiderschap beïnvloedt hoe medewerkers de organisatie ervaren. Als intrinsieke waarden prevaleren heeft dat een positief effect op de bevlogenheid. Samen met de vervulling van basisbehoeften verklaarde het meer dan $55 \%$ van de variantie in bevlogenheid.

Tot slot werd de uitwerking van een leiderschapsontwikkelingsprogramma getoetst in een interventiestudie (Hoofdstuk 5 ) in vergelijking met een controlegroep die geen interventie kreeg. Het programma werd ontwikkeld in co-creatie tussen de deelnemers aan het programma (middenkader teamleiders) en hun leidinggevenden. Co-creatie betekent dat verschillende belanghebbenden met elkaar in overleg een gezamenlijke koers bepalen of een probleem oplossen. In deze co-creatiefase werden de doelstellingen van het programma gedefinieerd: verbeterde ondernemingsresultaten (business performance) op een vooraf vastgestelde parameter, ofwel key performance indicator (KPI), lager ziekteverzuim en hogere satisfactie van de behoefte aan autonomie en intrinsieke motivatie. Het programma leerde de teamleiders $(N=14)$ de principes van bevlogen leiderschap en behoeftensatisfactie in een aantal trainingssessies van één dag, verspreid over acht maanden. Tussendoor kregen de deelnemers intervisie (een specifieke gespreksmethode voor groepen) en één-op-één coaching aangeboden. Verwacht werd dat het leiderschapsprogramma ook de autonomie en motivatie van de teamleden $(N=148)$ zou bevorderen doordat de positieve effecten van de teamleiders zouden doorsijpelen naar de teamleden. De controlegroep (52 teamleiders en 218 teamleden) ontving alleen een presentatie waarin bevlogen leiderschap en behoeftensatisfactie werden uitgelegd. Om de effecten van het programma te kunnen beoordelen werd voorafgaand aan en na afloop van het programma een vragenlijst afgenomen onder de teamleiders en de medewerkers van de interventie- en de controlegroep. De businessdoelen en het ziekteverzuim werden over een langere periode bijgehouden, zodat ook zes maanden na afloop bekeken kon worden of de resultaten beklijfden.

De meting na afloop van het programma liet een significante stijging zien in de productiviteit en de financiële prestaties van de interventiegroep. Deze stijging zette zich door in de daaropvolgende periode. Het ziekteverzuim binnen de interventiegroep ging significant omlaag en zette zich eveneens door na afloop van het programma. De teamleiders die deelnamen aan het programma vertoonden een substantiële stijging in satisfactie van de behoefte aan autonomie en in intrinsieke motivatie. Het verwachte doorsijpeleffect van autonomie en motivatie van teamleiders naar de medewerkers bleef echter uit, ondanks het lagere verzuim en de hogere productiviteit van de teams. 
Een van de leeraspecten uit de interventiestudie is dan ook dat het actief betrekken van teamleden in de co-creatiefase en de uitvoeringsfase de positieve effecten van het programma verder zou kunnen ondersteunen.

Samenvattend laat deze interventiestudie zien dat het mogelijk is om positieve bedrijfsresultaten te behalen in combinatie met een lager ziekteverzuim en hogere motivatie en satisfactie van autonomie door middel van een leiderschapsprogramma. De koppeling van het programma aan een concreet bedrijfsdoel maakte het programma relevant voor de deelnemers. Het gezamenlijk opstellen van dat specifieke doel zorgde voor draagvlak en betrokkenheid. Daarenboven zorgde de inbedding van deze doelen in het leiderschapsprogramma voor een heldere context waarbinnen de doelen behaald moesten worden en voorzag het de deelnemers van de kennis en instrumenten die nodig waren om de gestelde doelen te realiseren.

Over het geheel genomen laten de vier studies zien dat het vervullen van de psychologische basisbehoeften inderdaad een essentiële rol speelt in de relatie tussen leiderschap, ondernemingsdoelstellingen, waarden en bevlogenheid. De resultaten onderschrijven tevens het belang van het onderliggende proces van leiderschap. Bovendien bleek zowel uit de studie naar bevlogen leiderschap (Hoofdstuk 2), als uit de studie naar waardenpercepties (Hoofdstuk 4) dat satisfactie van de behoefte aan autonomie een centrale rol speelt in relatie tot bevlogenheid. Ook is duidelijk geworden dat leiderschap, ondernemingsdoelstellingen en waarden elkaar goed aanvullen en meer als één geheel zouden moeten worden gezien (Hoofdstuk 1). Er zou in leiderschapsstudies dan ook meer aandacht aan ondernemingsdoelstellingen en waarden moeten worden besteed. Studies van businessscholen toonden reeds aan dat een hogere en duurzame ondernemingsdoelstelling bijdraagt aan de financiële resultaten van ondernemingen, ook op langere termijn. Juridische, bestuurskundige en economische studies naar ondernemingsbestuur benadrukken dat verbreding van de ondernemingsdoelstelling ten bate komt van duurzaamheid, maatschappelijke verantwoordelijkheid, innovatie en winstgevendheid op langere termijn. In aanvulling daarop laten de studies in dit proefschrift zien dat ondernemingsdoelstellingen en waarden ook voor de motivatie en bevlogenheid van medewerkers essentieel zijn.

\section{Suggesties voor verder onderzoek}

Er zijn een aantal suggesties gedaan voor vervolgonderzoek. De dynamiek in de relatie tussen leidinggevenden en medewerkers, zoals verondersteld in zelfdeterminatietheorie zou meer aandacht dienen te krijgen. Dit kan bijvoorbeeld door de concrete uitwisseling tussen leidinggevenden en medewerkers te onderzoeken in de gesprekken die ze met elkaar hebben. Hiermee kan de kern van 
zelfdeterminatietheorie ook in praktische zin worden getoetst. Immers, motivatie is een resultaat van de uitwisseling tussen het individu en zijn of haar omgeving en het psychologische effect daarvan op het individu. Verwacht wordt dat bepaalde gesprekken een positieve uitwerking hebben op motivatie en bevlogenheid. Kennis over de specifieke kenmerken van die interactie zouden concrete handvatten kunnen bieden aan leidinggevenden over hoe autonomie, competentie en verbondenheid het best bevorderd kunnen worden. Specifiek zou ook gekeken kunnen worden naar de gesprekken over het ondernemingsdoel en de bijbehorende waarden van de onderneming en op welke manier deze dialoog het beste bijdraagt aan motivatie en bevlogenheid.

Een andere suggestie is om breder te kijken naar de effecten van ondernemingsdoelstellingen door een typologie van verschillende doelstellingen op te stellen en te onderzoeken in welke mate bepaalde doelstellingen wel bijdragen aan motivatie en bevlogenheid en andere juist niet. Bijvoorbeeld door de effecten van ondernemingen met een aandeelhoudersperspectief te vergelijken met de impact van ondernemingen met een meer duurzame ondernemingsdoelstelling. Aanvullend zou onderzocht kunnen worden wat de effecten van die verschillende doelstellingen zijn op persoonlijke zingeving, aangezien betekenisgeving en zelfrealisatie door werk een steeds centralere plaats innemen.

\section{Praktische implicaties}

Uit de studies in dit proefschrift komt naar voren dat motivatie veel verklaart over de relatie tussen leiderschap, ondernemingsdoelstellingen, waarden en bevlogenheid. De studies zeggen minder over hoe dat in de praktijk vorm kan krijgen. De organisatie, leidinggevenden en medewerkers zijn nauw met elkaar verweven. De kwaliteit en de dynamiek van die verbinding verklaart een belangrijk deel van de uitkomsten. Het is dus niet zozeer alleen het gedrag van leidinggevenden dat bepalend is voor motivatie en bevlogenheid, maar ook hoe leidinggevenden en medewerkers met elkaar omgaan.

Door medewerkers actief te betrekken in een betekenisvolle dialoog kunnen de basisbehoeften beter worden vervuld. Zo kan autonomie bevorderd worden door een heldere reden aan te geven waarom een bepaalde taak of actie van belang is, door goed te luisteren naar wat medewerkers vinden en ruimte te bieden om daar hun eigen mening over te vormen. Meer dan praten, vertellen en instrueren zou het gedrag gericht moeten zijn om het onderwerp in een duidelijke context te plaatsen, te luisteren, open vragen te stellen en niet al te zeer te sturen op een bepaalde uitkomst. Een van de meest effectieve manieren om competentie te bevorderen is het veelvuldig geven van (positieve) feedback. De behoefte aan verbondenheid kan vervuld worden 
door onder meer oprechte interesse te tonen en een gevoel van openheid en veiligheid te scheppen. Ook gesprekken over de ondernemingsdoelstelling en de waarden van de onderneming kunnen medewerkers helpen om zich meer verbonden te voelen met de onderneming en met elkaar en kunnen het gevoel van betekenisgeving en significantie versterken.

\section{Conclusie}

Dit proefschrift onderzocht de invloed van leiderschap, ondernemingsdoelstellingen en waarden op bevlogenheid en de rol van motivatie daarbij. Zoals verwacht vonden we dat bevlogen leiderschap, higher purpose en aandacht van de leidinggevende voor de waardenpercepties van medewerkers motivatie en bevlogenheid bevorderen door het vervullen van psychologische basisbehoeften. Behoeftensatisfactie - en specifiek het vervullen van de behoefte aan autonomie - verklaarde meer dan de helft van het verschil in bevlogenheid. Motivatie zoals beschreven in zelfdeterminatietheorie vormt een essentieel onderdeel voor het verkrijgen van positieve uitkomsten. Structurele aandacht voor het voldoen aan de behoefte aan autonomie, competentie en verbondenheid draagt bij aan het welzijn en de prestaties van medewerkers.

De essentie van motivatie als verbindende en verklarende factor voor de relatie tussen leiderschap en bevlogenheid laat ook zien dat leiderschap niet zozeer gaat over de leider als persoon of over zijn of haar karaktereigenschappen en gedrag in een directe relatie met de uitkomsten. Leiderschap gaat veel meer over het scheppen van de sociale, psychologische en materiele context waarbinnen mensen optimaal kunnen presteren. In de juiste context hoeven mensen niet gemotiveerd te worden, maar motiveren zij zichzelf en elkaar. Als mensen niet gemotiveerd zijn zou men, in plaats van het aan de medewerkers te wijten, goed moeten kijken naar de leiderschapscontext en de dynamiek waarbinnen mensen hun motivatie moeten vinden. Vaak zal blijken dat er spanning bestaat tussen het besturingsmodel en het effect daarvan op motivatie enerzijds en bevlogenheid via het vervullen of juist frustreren van psychologische basisbehoeften anderzijds. Het vermogen om die dynamiek te herkennen en daar goed op in te spelen zijn belangrijke aspecten van effectief leiderschap en kan leiden tot gezonde organisaties met beter welzijn voor medewerkers, meer creativiteit, betere prestaties en hogere niveaus van autonome motivatie en bevlogenheid.

Werk kan voldoen aan de behoefte aan zelfrealisatie van mensen. Maslow concludeerde dit al in 1962. Nu, bijna 60 jaar later, zijn zelfrealisatie en zingeving door werk alleen nog maar belangrijker geworden. Daarmee is voor organisaties het 
belang toegenomen om daarin te voorzien. En ondanks dat er veel experimenten lopen met andere manieren van governance, operationele besturing en inspirerende werkomgevingen is het traditionele hiërarchische model van voorspelbaarheid en controle nog steeds dominant. Ook het sturen op aandeelhouderswaarde staat nog steeds centraal. Wij hopen met de studies in dit proefschrift een bijdrage te hebben geleverd aan de ontwikkeling van inzichten en kennis over een werkomgeving waarin in de psychologische basisbehoeften van mensen wordt voorzien en waar mensen een basis kunnen vinden voor een betekenisvol en waardig bestaan.

${ }^{1}$ Stiglitz, J.E. (2016). Inequality and economic growth. In Jacobs M., \& Mazzucato, M. (Eds.). Rethinking Capitalism. (pp. 134 - 155). Chichester, UK: Wiley-Blackwell. 


Acknowledgments 

Ludwig Wittgestein (1980) once wrote, "If people did not sometimes do silly things, nothing intelligent would ever get done" (p. 50e). Embarking on the journey to write this dissertation was the silliest thing I have ever done. I hope something intelligent got done. Nothing would have happened without the support of the countless people who have allowed me to prepare for and conduct my dissertation research; colleagues, friends, clients, teachers, and family. You probably have no idea, but your trust and encouragement have considerably contributed to my personal development, growth, and perseverance to complete this project. If, at this moment, you are wondering if this acknowledgment includes you? Yes, it does, and I am deeply grateful.

I like to thank a few people personally. Willem van Rhenen stimulated me to enter this path and commit myself to do all the work a dissertation requires. He also introduced me to Paul Smilde, whose effort and commitment to this thesis' motive was essential for gathering the data. Precious friendship resulted. Wilmar Schaufeli accepted me as his student and invested relentless effort and patience to raise me to a decent doctoral student level and improve my writing and reporting. Willem and Wilmar were generous in their support and stimulated me to persist. Anja van den Broeck, through her rigorous feedback, taught me the disciplined structure of academic writing and supported me to express my thoughts more succinctly. Rebecca Kuiper, who I could always turn to for support with statistics. 

Biography 

Lars van Tuin (Amsterdam, 1963) is an executive coach and works with leaders to improve leadership effectiveness and build work cultures where excellence in performance meets personal growth and development needs.

Lars brings a background of experience and knowledge in business management, leadership, and entrepreneurial spirit. His last in-house position was business development manager with a listed (NYSE, AEX) telecommunications firm. His responsibilities included international internet-provider growth strategy and mergers and acquisitions on Internet and media.

As a coach and facilitator to senior management he has worked in various industries such as Automotive, Financial Services, Oil \& Gas, Telecommunications, Home Appliances, Pharma, and Retail. His activities range from one-on-one coaching to team retreats, training, and complete leadership development programs.

He was a mentor and program coach with the renowned coach training school Newfield Network and coached in their programs in Asia, Europe, South Africa, and the US. Also, he taught and coached in the Global Leadership Program at the International Christian University (ICU), Tokyo, Japan. Currently, he is an executive coach and leadership associate with the Center for Creative Leadership.

Lars holds an honors degree (Cum Laude) in Political Science from the University of Amsterdam (1992) and followed post-graduate programs at IMD Lausanne, $\mathrm{CH}$ (2001) and Ashridge College, UK (1998). He is a Professional Certified Coach (PCC, 2008) with the International Coach Federation (ICF) and a Newfield Certified Ontological Coach (NCOC, 2008). 

Motivation lies at the core of human behavior. It explains why we do what we do. With this thesis, we seek an explanation for the beneficial influence of leadership, corporate purpose, and values on employee engagement through motivation. Engaged employees derive energy from their work, are dedicated, and display higher psychological well-being and performance. Our research identifies motivation as an underlying mechanism linking leadership with positive outcomes. Leadership at the service of motivation boosts engagement and serves the need for self-determination and meaning. A corporate purpose embracing all stakeholders instead of just the shareholders positively affects motivation and engagement; Employees identify with an inspiring mission and vision. Corporate values aimed at contributing to a better world reinforce this even further, as does a work environment with room for personal and professional growth. We have empirically tested these principles in three studies. A fourth tested leadership and motivation in an intervention study. Navigating motivation at work supports employees to flourish, develop, and find significance. 